DANILO VIEIRA CASTEJON

\title{
MÉTODOS DE REDUÇÃO DO ARRASTO E SEUS IMPACTOS SOBRE A ESTABILIDADE VEICULAR
}

Dissertação apresentada à Escola de Engenharia de São Carlos da Universidade de São Paulo, como parte dos requisitos para obtenção do Título de Mestre em Engenharia Mecânica.

Orientador: Prof. Dr. Titular Fernando Martini Catalano

\begin{tabular}{|lrr|}
\hline ESTE & EXEMPLAR & TRATA-SE \\
DA VERSÃO & TORRIGIDA APÓS \\
A DEFESA. & A & VERSÃO \\
ORIGINAL & ENCONTRA-SE \\
DISPONÍVEL & JUNTO & AO \\
DEPARTAMENTO & DE \\
ENGENHARIA & MECÂNICA & DA \\
EESC-USP. & & \\
\hline
\end{tabular}

São Carlos

2011 



\section{DANILO VIEIRA CASTEJON}

\section{MÉTODOS DE REDUÇÃO DO ARRASTO E SEUS IMPACTOS SOBRE A ESTABILIDADE VEICULAR}

Dissertação apresentada à Escola de Engenharia de São Carlos da Universidade de São Paulo, como parte dos requisitos para obtenção do Título de Mestre em Engenharia Mecânica.

Área de Concentração: Aeronaves.

Orientador: Prof. Dr. Titular Fernando Martini Catalano 


\section{AUTORIZO A REPRODUÇÃO E DIVULGAÇÃO TOTAL OU PARCIAL DESTE TRABALHO, POR QUALQUER MEIO CONVENCIONAL OU ELETRÔNICO, PARA FINS DE ESTUDO E PESQUISA, DESDE QUE CITADA A FONTE.}

Ficha catalográfica preparada pela Seção de Tratamento da Informação do Serviço de Biblioteca - EESC/USP

Castejon, Danilo Vieira

$\mathrm{C} 347 \mathrm{~m}$

Métodos de redução do arrasto e seus impactos sobre a estabilidade veicular / Danilo Vieira Castejon ; orientador Fernando Martini Catalano. -- São Carlos, 2011.

Dissertação (Mestrado - Programa de Pós-Graduação em Engenharia Mecânica e Área de Concentração em Aeronaves) -- Escola de Engenharia de São Carlos da Universidade de São Paulo, 2011.

1. Aerodinâmica. 2. Arrasto veicular. 3. Arrasto de pressão. 4. Estabilidade veicular. 5. Modelo de turbulência. 6. Navier-Stokes. 7. Carros. 8. Veículos. I. Título. 
FOLHA DE JULGAMENTO

Candidato(a): Engenheiro DANILO VIEIRA CASTEJON.

Dissertação defendida e julgada em 02/06/2011 perante a Comissão Julgadora:

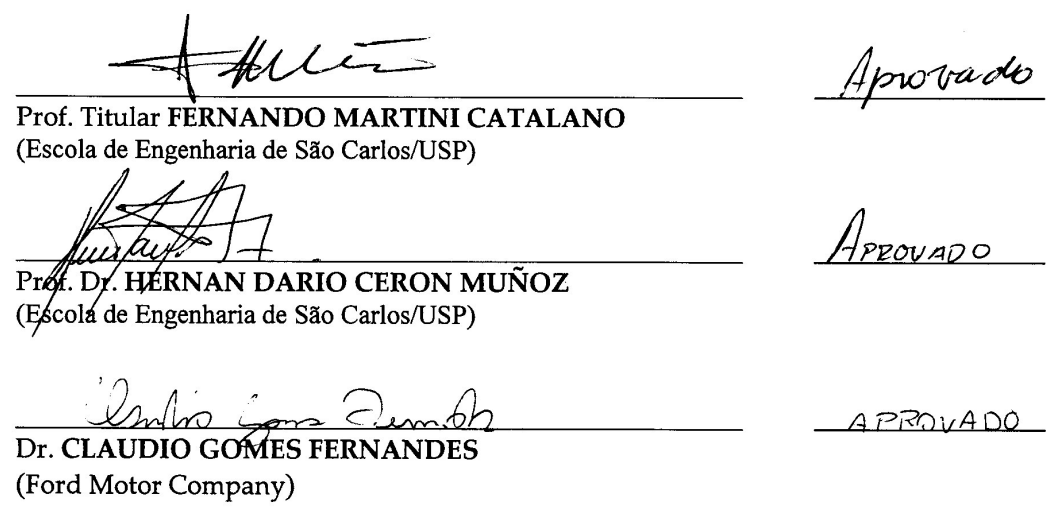

$\ln$ in.M

Prof. Associado MARCELO AREIAS TRINDADE

Coordenador do Programa de Pós-Graduação em

Engenheira Mecânica

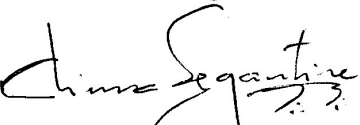

Prof. Associado PAULo CÉSAR LIMA SEGANTINE Presidente dạ Comissão da Pós-Graduação da EESC 

Dedico esse trabalho a todos que acreditaram que eu seria capaz de concluí-lo e que colaboram para que isso de fato viesse a acontecer. 


\section{Agradecimentos}

Sentimentos de gratidão que tenho a oferecer:

À Deus, como principal alicerce através da fé.

À USP (Universidade de São Paulo), instituição que me possibilitou o acesso ao programa de Pós-Graduação, bem como, ao departamento de Engenharia Mecânica.

Ao meu orientador, Professor Titular Doutor Fernando Martini Catalano, pela confiança e paciência.

Aos colegas, profissionais de áreas afins que me auxiliaram no desenvolvimento desse trabalho. Em especial, agradeço imensamente ao Geraldo Severi Júnior por sua amizade, ajuda e compreensão.

Aos meus familiares, em especial à minha mãe, Simone e às minhas irmãs, Letícia e Fernanda que sempre me estiveram ao meu lado. Ao meu pai por investir, e exigir, na formação de seus filhos.

À minha namorada, Nayara, pela compreensão e apoio.

À diretoria e gerência da empresa Delphi pela compreensão, apoio e estímulo em viabilizar esta oportunidade.

Aos colegas engenheiros da Delphi pela ajuda e suporte nos momentos em que foram necessárias minhas atenções ao programa de pós-graduação, de forma a não prejudicar o rendimento profissional da equipe.

E a todos aqueles que de alguma forma contribuíram para o êxito de meu trabalho. 
"Não importa quais sejam os obstáculos e dificuldades. Se estamos possuídos de uma inabalável determinação, conseguiremos superá-los".

Dalai-Lama 


\section{RESUMO}

CASTEJON, D. V. Métodos de redução do arrasto e seus impactos sobre a estabilidade veicular. 2011. 108 f. Dissertação (Mestrado). Departamento de Engenharia Mecânica, Escola de Engenharia de São Carlos, Universidade de São Paulo, São Paulo, 2011.

A crescente preocupação ambiental e a necessidade de se criar produtos mais eficientes têm impulsionado os pesquisadores a realizarem estudos acerca da aerodinâmica veicular. Estes dois fatores constituem os principais motivos, pelos quais existe uma grande procura por conhecimento nesta área. Esta ciência pode ser considerada relativamente nova e ainda carece de uma base de dados. Entender como a aerodinâmica se relaciona com o consumo de combustível nos automóveis, à medida que o arrasto impõe resistência ao deslocamento dos mesmos, é algo que tem estimulado as indústrias automotivas a investirem grandes esforços na obtenção de ferramentas, que possam representar as condições de tráfego normais e, assim conseguir prever o desempenho do produto em desenvolvimento. Os túneis de vento e a simulação computacional surgem neste ambiente como as principais ferramentas de análise e predição do escoamento ao redor do veículo. Por isso seu entendimento faz-se de extrema necessidade. Ter conhecimento sobre a concepção do seu projeto, como funcionam, seus pontos fortes e suas fraquezas, são requisitos necessários para a pessoa que deseja estudar esta ciência. O presente trabalho traz uma contextualização histórica da aerodinâmica veicular nas indústrias automotiva e automobilística, além de apresentar aspectos técnicos relacionados aos túneis de vento e simulação computacional. Abordando as vantagens e desvantagens de cada ferramenta, expõe-se o fato de que estas ferramentas são complementares no estudo aerodinâmico. Para exemplificar a utilização dessas ferramentas, foi realizado um estudo aerodinâmico sobre uma geometria básica, que representa com similaridade os veículos tipo hatchback, denominada Modelo SAE em ambiente computacional. Os conceitos acerca do arrasto veicular e estabilidade veicular foram expostos para embasar este estudo. Este modelo foi submetido a diferentes geometrias traseiras e condições de escoamento simétricas e assimétricas. Este estudo demonstrou que o arrasto e a estabilidade veicular compreendem conceitos distintos e, dessa forma, é possível diminuir o arrasto de um veículo sem haver perda de estabilidade. 


\section{AbSTRACT}

CASTEJON, D. V. Methods of drag reduction and the impacts on the vehicle aerodynamics stability. 2011. $108 \mathrm{f}$. Thesis (Master's degree). Departamento de Engenharia Mecânica, Escola de Engenharia de São Carlos, Universidade de São Paulo, São Paulo, 2011.

The growing environmental concern and the necessity to create more efficient products have motivated researchers to conduct studies about the aerodynamic vehicle. These two aspects are the main reasons which are promoting a great demand for knowledge in this theme. This science may be considered relatively new and still lacks more databases. Understand how aerodynamics is related to automobiles fuel consumption such as drag resistance imposed to their displacement, is something that has made the automotive industries invest considerable effort in obtaining tools which may represent the normal traffic conditions and thus, able to predict the performance of the product in development stage. The wind tunnels and computer simulations appear in this environment as the main tools for analysis and prediction of the flow around vehicle. The understanding about them is so of utmost necessity. Knowing how it was designed, how they work, their strengths and weaknesses are essential requirements for the person who wants to study this science. This material presents a historical development of vehicle aerodynamics in automotive and motor-racing industries, indeed technical aspects related to wind tunnels and computational fluid dynamics. Exposing the advantages and disadvantages of both tools, it is evidenced these tools complement each other during an aerodynamic study. To exemplify these tools utility an aerodynamic research was conducted using a basic form geometry known as SAE Model that represents with similarity the hatchback vehicles in the market. Drag and vehicle stability concepts were exposed to build a solid basis for this study. This model was submitted to different rear geometries, symmetric and asymmetric flow conditions. It could be demonstrated that drag and vehicle stability have distinct concepts and therefore it is possible diminish the first without damaging the later. 


\section{SUMÁRIO}

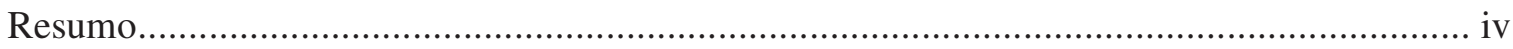

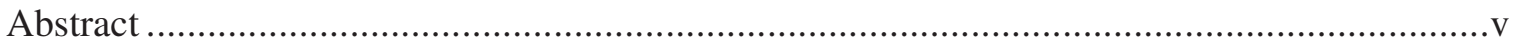

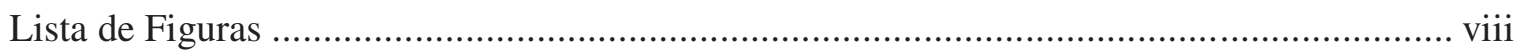

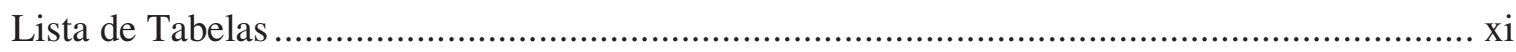

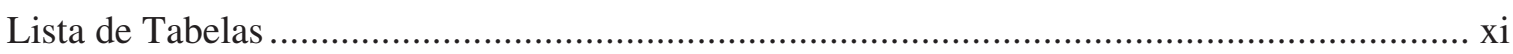

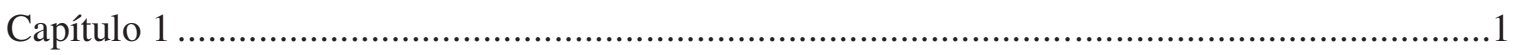

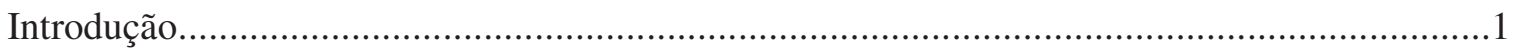

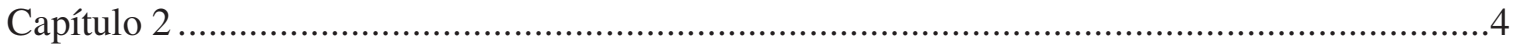

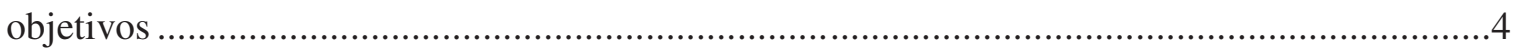

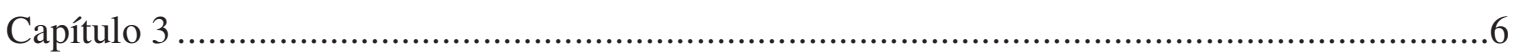

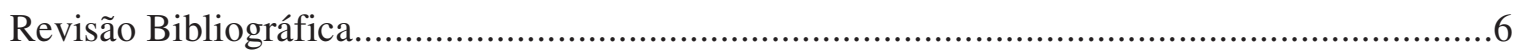

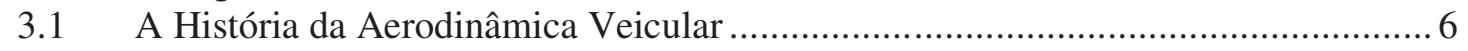

3.2 A aerodinâmica e a indústria automobilística ...................................................... 11

3.3 Dispositivos aerodinâmicos provedores de sustentação negativa (downforce) ........ 13

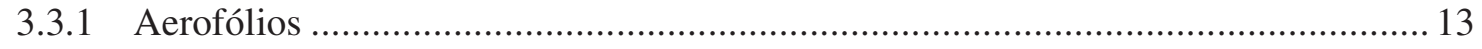

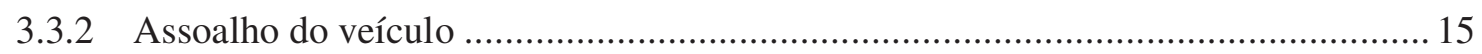

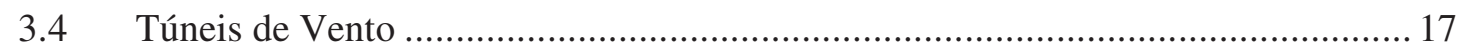

3.5 Simulação Fluidodinâmica Computacional (CFD) ............................................ 25

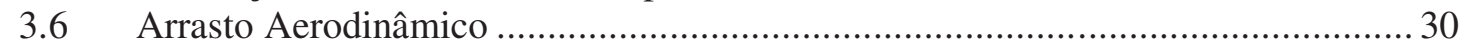

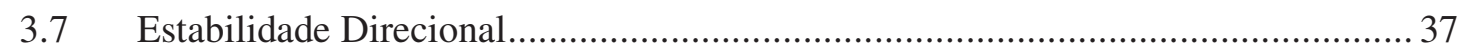

3.7.1 Equacionamento Aerodinâmico e Modelo Dinâmico Single-Track ......................... 38

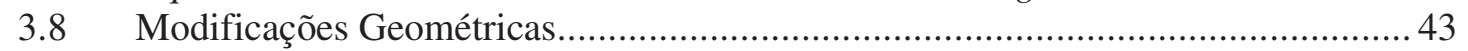

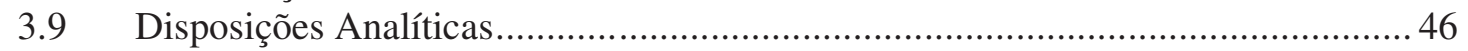

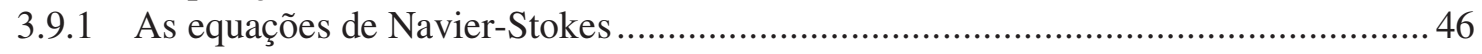

3.9.2 Método Numérico de Discretização das Equações de Navier-Stokes....................... 48

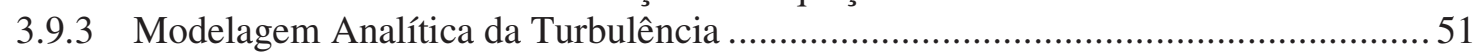

3.9.3.1 Modelo de turbulência SST K-

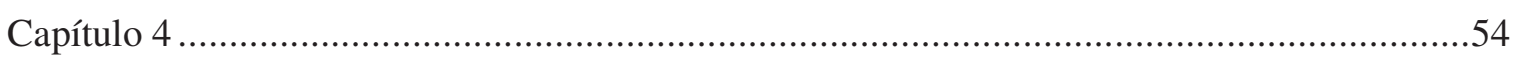

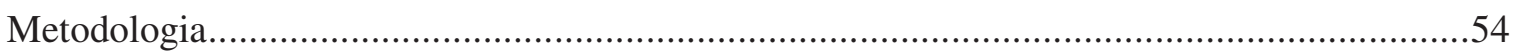

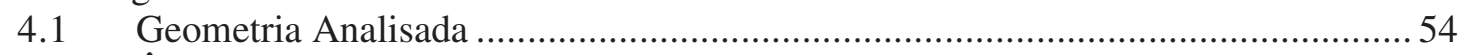

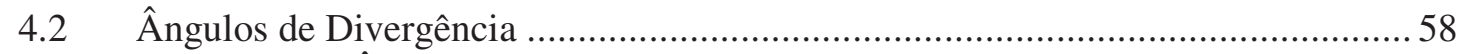

4.3 Influência de Ângulos de Guinada sobre o escoamento do modelo............................59

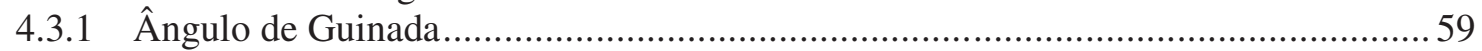

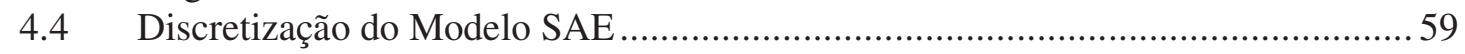

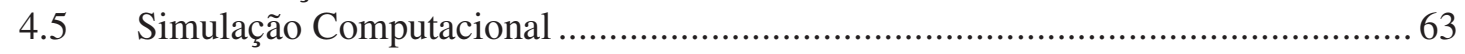

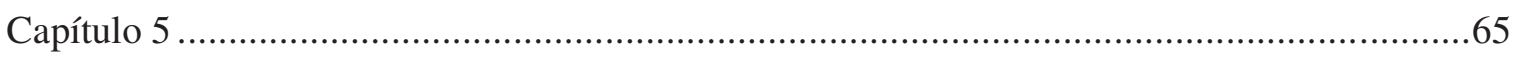

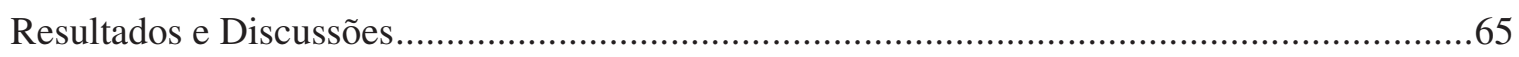

5.1 Métodos de Diminuição do Arrasto Veicular Aplicados ao Modelo SAE ...............65

5.2 Manutenção da Estabilidade Veicular .................................................................... 72

5.3 Influência do Ângulo de Guinada sobre o Carregamento aplicado no Modelo SAE 78

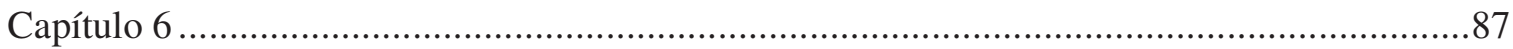

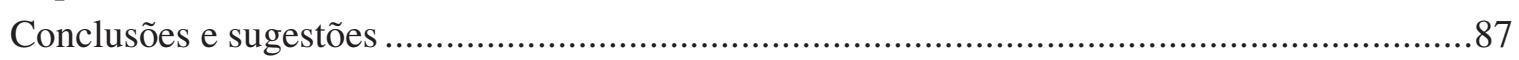


Referências Bibliográficas ${ }^{1}$ 89

Apêndice A

Apêndice B 


\section{LiSTA DE FigURAS}

FIGURA 1: Primeiro veículo rodoviário construído, por Camille Jenatzy, com formato aerodinâmico

FIGURA 2: Perfis aerofólios avaliados por Jaray e Klemperer próximos ao solo..................... 7

FIGURA 3: Veículo baseado na geometria proposta do Kamm. Observa-se um descolamento da camada limite gradativo na região traseira do veículo. ................................................. 8

FIGURA 4: Chaparral 2E, o primeiro protótipo de competição com asas geradoras de

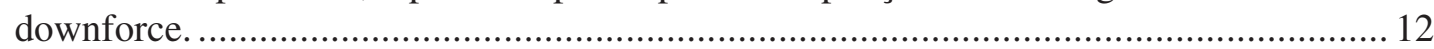

FIGURA 5: Túnel de vento dotado de esteira rolante e uma haste vertical conectada a uma balança com seis graus de liberdade. A direita um esquemático desta balança. ................ 13

FIGURA 6: Variação dos coeficientes de sustentação, $\mathrm{Cl}$, e arrasto, $\mathrm{Cd}$, em função da distância entre o protótipo e o solo,

FIGURA 7: Diferentes seções de testes em túneis de ventos utilizados na indústria automotiva,

FIGURA 8: Perfil de velocidade em um escoamento sob o veículo quando simulado em chão rígido, esteira rolante e vento tangencial..

FIGURA 9: Coeficiente de pressão ao longo da linha central na superfície da roda, $\theta$ medido no sentido anti-horário..

FIGURA 10: Geradores de vórtices propostos por Cogotti após analisar a intensidade e comprimento dos vórtices a alturas compatíveis aos automóveis.

FIGURA 11: Hierarquia dos modelos de turbulência

FIGURA 12: Regiões do veículo que geralmente são modificadas para obtenção de menor arrasto.

FIGURA 13: Analogia da proporcionalidade existente entre as forças de sustentação e de yaw em função dos ângulos de incidência. Características justificadas pelo aumento das zonas de baixa pressão.

FIGURA 14: Sistema de Coordenadas para estudos dos esforços aerodinâmicos................... 39

FIGURA 15: Modelo Single Track representando o sistema de suspensão e direção de um veículo.

FIGURA 16: Influência dos arredondamentos dos vértices de um protótipo de formado básico, sobre a força lateral, momento de yaw e a força de sustentação.

FIGURA 17: Altura do capô, ângulo do vidro frontal, inclinação lateral, altura e comprimento do bagageiro, outros parâmetros analisados.

FIGURA 18: Exemplo de volume de controle infinitesimal discretizado.

FIGURA 19: Especificações das medidas propostas para o Modelo SAE.

FIGURA 20: Réplica computacional do Modelo SAE em escala 1:4, considerando-se um ângulo de convergência de $15^{\circ}$. a) Modelo Tri-dimensional; b) Modelo Uni-dimensional.

FIGURA 21: Réplica computacional do Modelo SAE em escala 1:4. Visualização do ângulo de divergência adotado a fim de impor melhorias na estabilidade direcional.....

FIGURA 22: Réplica computacional do Modelo SAE em escala 1:4. Ilustração do Modelo SAE posicionado no interior do túnel de vento virtual.

IGURA 23: Malha bi-dimensional triangular aplicada na superfície do Modelo SAE.

FIGURA 24: Malha bi-dimensional triangular aplicada na superfície inferior do túnel de vento virtual. Detalhe do refinamento imposto na região localizada sob o Modelo. 
FIGURA 25: Coeficientes de arrasto gerados a partir dos dados obtidos para diferentes ângulos de convergência.

FIGURA 26: Coeficiente de Sustentação apresentado pelo Modelo SAE, para diferentes ângulos de convergência de sua superfície superior. O sinal positivo está direcionado para valores negativos do eixo $\mathrm{z}$

FIGURA 27: Momento de Arfagem apresentado pelo Modelo SAE, com diferentes ângulos de convergência para sua superfície superior.

FIGURA 28: Distribuição de pressão no plano longitudinal central do túnel de vento virtual. À esquerda se situa a geometria com $10^{\circ}$ de convergência e à direita àquela com $35^{\circ}$..... 69

FIGURA 29: Centro de Pressão apresentado pelo Modelo SAE, para diferentes ângulos de convergência de sua superfície superior, quando submetido a um escoamento simétrico. $\mathrm{O}$ sinal negativo é referente aos valores negativos no eixo $\mathrm{x}$.

FIGURA 30: Vetores velocidade do escoamento aferido no plano de simetria longitudinal, sobre o eixo $\mathrm{x}$, a fim de avaliar qualitativamente a quantidade de movimento na esteira do modelo.

FIGURA 31: Vetores velocidade do escoamento aferido no plano de simetria longitudinal, tomados em detalhe para a visualização do par de vórtices contra-rotativos na superfície vertical traseira do modelo.

FIGURA 32: Linhas de corrente aplicadas ao caso em que o ângulo de convergência da superfície superior do Modelo tem valor igual a $35^{\circ}$. É possível constatar a ocorrência do descolamento da camada limite na seção convergente.

FIGURA 33: Pressão ao longo de um eixo longitudinal localizado na superfície inferior do Modelo SAE. Observa-se a área afetada pelo uso dos difusores.

FIGURA 34: Coeficientes de Sustentação apresentados pelo Modelo SAE, para diferentes ângulos de convergência de sua superfície superior. E ainda os valores destes coeficientes na presença de um ângulo de difusão. A sustentação com sinal positivo possui sinal contrário ao convencionado para o eixo $\mathrm{z}$.

FIGURA 35: Momentos de Arfagem apresentados pelo Modelo SAE, para diferentes ângulos de convergência de sua superfície superior. $E$ ainda os valores destes coeficientes na presença de um ângulo de difusão. O sinal positivo está direcionado para movimentos no sentido de suspender a região dianteira do Modelo.

FIGURA 36: Coeficientes de Arrasto Total apresentados pelo Modelo SAE, para diferentes ângulos de convergência de sua superfície superior. E ainda os valores destes coeficientes na presença de um ângulo de difusão. O sinal negativo atribui-se ao sentido contrário da grandeza em relação àquele convencionado para $\mathrm{x}$.

FIGURA 37: Vetor velocidade do escoamento aferido no plano de simetria longitudinal, sobre o eixo $\mathrm{x}$, a fim de avaliar qualitativamente a quantidade de movimento na esteira do modelo. Note que os dois modelos na região inferior da figura apresentam o difusor...... 77

FIGURA 38: Detalhe dos vetores velocidade na esteira da geometria dotada de $6^{\circ}$ de divergência. É possível constatar uma maior simetria nos vórtices contra-rotativos. ........ 77

FIGURA 39: Distribuição de pressão sobre a superfície do Modelo SAE, perante a uma escoamento simétrico, a esquerda, e assimétrico a direita.

FIGURA 40: Distribuição de pressão sobre um plano horizontal localizado $50 \mathrm{~mm}$ acima da superfície inferior sendo paralelo a esta. É evidente o surgimento de uma zona de baixa pressão no lado oposto à incidência do escoamento.

FIGURA 41: A variação do coeficiente de Arrasto em função do ângulo de guinada. Cd D6 refere-se à divergência $6^{\circ}$ e Cd D10 a divergência $10^{\circ}$.

FIGURA 42: A variação do coeficiente de sustentação em função do ângulo de guinada. CL D6 refere-se à divergência $6^{\circ}$ e CL D10 a divergência $10^{\circ}$. 
FIGURA 43: Variação do coeficiente de Momento de Arfagem em função do ângulo de guinada. D6 refere-se à divergência $6^{\circ}$ e D10 a divergência $10^{\circ}$.

FIGURA 44: Variação do coeficiente de Momento de Rolagem em função do ângulo de guinada. D6 refere-se à divergência $6^{\circ} \mathrm{e}$ D10 a divergência $10^{\circ}$.

FIGURA 45: Momento de Yaw em função do ângulo de guinada. D6 refere-se à divergência $6^{\circ}$ e D10 a divergência $10^{\circ}$

FIGURA 46: Coeficientes de Força Lateral experimentados pelo Modelo SAE, dotado de geometrias divergentes de $6^{\circ}$ e $10^{\circ}$ (D6 e D10, respectivamente), em função do ângulo de guinada.

FIGURA 47: Variação dos coeficientes de Arrasto, Momento de Arfagem, Momento de Guinada e Força Lateral em função do ângulo de guinada. D10 refere-se à divergência $10^{\circ}$. 


\section{LiSTA DE TABELAS}

TABELA 1: Exemplos de carros presentes no mercado brasileiro, divididos em notchback, fastback e squareback, de acordo com sua geometria traseira.

TABELA 2: Modelo SAE aplicado ao estudo sobre os ângulos de convergência...................57

TABELA 3: Dimensionais da seção de testes virtual utilizada na simulação computacional. 60

TABELA 4: Configuração utilizada no Fluent v12.1 para a simulação do experimento. ....... 64

TABELA 5: Resultados obtidos na simulação decorrente de diferentes ângulos de convergência utilizados no Modelo SAE.

TABELA 6: Características Aerodinâmicas resultantes das simulações para o ângulo de convergência da superfície superior igual a $10^{\circ}$, conjugado com ângulos de divergência da superfície inferior nos valores de $0^{\circ}, 6^{\circ}$ e $10^{\circ}$.

TABELA 7: Características Aerodinâmicas resultantes de diferentes configurações geométricas. Legenda: $\mathrm{C} 10=$ Ângulo de convergência de $10^{\circ} ; \mathrm{D} 10=$ Ângulo de Divergência de $10^{\circ}$; D6 = Ângulo de Divergência de $6^{\circ} ; \mathrm{Yx}=$ Ângulo de Guinada (Yaw). 


\section{Capítulo 1}

\section{INTRODUÇÃO}

A aerodinâmica veicular é uma área de estudo que está intimamente ligada à recente história petrolífera. A partir década de 70 até os dias atuais, tem-se observado, cada vez mais, elevações no preço do barril de petróleo. Isso decorre de crises políticas entre os principais países produtores e de especulações de mercado. Todas as vezes que ocorrem estas altas, uma grande atenção é voltada para a concepção aerodinâmica dos veículos comercializados, de forma a fomentar o interesse e a demanda por veículos tecnicamente mais atraentes e eficientes.

Outro aspecto que tem contribuído para um crescente destaque da aerodinâmica veicular é a conscientização ambiental. As pessoas estão se conscientizando de que os recursos naturais estão cada vez mais escassos, para uma população mundial que cresce continuamente. Portanto é preciso criar meios para que se comprometa o mínimo possível o meio ambiente e, por isso, há a necessidade de se obter veículos cada vez mais eficientes em termos de aproveitamento energético.

Um dos pontos chaves para alcançar esta eficiência nos veículos é a aerodinâmica veicular, mais especificamente um de seus principais fundamentos, o Arrasto Aerodinâmico. Este pode ser definido como uma força resistiva imposta pelo ar ambiente a um objeto, que por ele se locomove. Em outras palavras, no caso dos veículos rodoviários, é a força que, aliada ao atrito existente entre os pneumáticos e o pavimento, devido a sua deformação, contrapõe a força propulsiva oriunda do motor.

A aerodinâmica, além do arrasto, possui diversos outros aspectos que devem ser estudados para conferir segurança, conforto e qualidade ao veículo. Entre estes, pode-se citar: a estabilidade direcional; a acústica do vento circundante; uso do escoamento de ar para conter superaquecimento do motor, freio e transmissão; retenção de umidade nos faróis e vidros; e circulação de ar no interior do veículo. Todos estes parâmetros juntos compõem o estudo aerodinâmico a ser feito durante o projeto do veículo.

Ao analisar o veículo rodoviário do ponto de vista da Fluidodinâmica, pode-se dizer que o mesmo constitui um corpo rombudo, provedor de arrasto, que se movimenta 
próximo ao solo. O escoamento de ar ao redor do mesmo apresenta características tridimensionais que, aliadas a uma geometria relativamente complexa, composta por chapas com diversas curvaturas, fendas entre as mesmas e estruturas como retrovisores e rodas, torna inviável, e até então impossível, uma quantificação analítica dos esforços aerodinâmicos ao qual o veículo está sujeito.

Apesar disso, existem ferramentas que permitem ao aerodinamicista estimar valores muito próximos aos reais para estes esforços. Estas ferramentas se dividem em dois grupos: as simulações numéricas computacionais, mais conhecidas como análises Fluidodinâmicas Computacionais, e as análises em túneis de vento. Quando utilizadas em conjunto, avaliando o corpo como um todo, permitem que se obtenham aproximações, com certa exatidão, dos esforços atuantes. Um bom exemplo é a utilização dessas ferramentas para previsão do arrasto.

Ao se estudar o arrasto de um veículo, deve-se notar que o mesmo é constituído por duas componentes: o arrasto viscoso, proveniente das forças de fricção entre as partículas do ar e as das superfícies do modelo; e o arrasto de pressão, que está associado à distribuição de pressão sobre estas mesmas superfícies e às perturbações causadas no escoamento pelo modelo.

A definição de corpos rombudos para os modelos de transporte rodoviários, em geral, se deve ao fato de ser o arrasto de pressão a forma de arrasto predominante nestes veículos. Estudos, como de Morelli (2000), apontam que arrasto de pressão configura algo em torno de noventa por cento do arrasto total de um veículo. Essa porcentagem por sua vez pode ser dividida em duas fontes de arrasto: a primeira, conhecida como arrasto induzido, provém do carregamento que o escoamento impõe ao veículo, conhecido pelos engenheiros aeronáuticos como sustentação; a segunda é o arrasto de forma, que pode ser entendido como uma força gerada por interações entre a viscosidade do fluido e a geometria do modelo.

Estas análises feitas para quantificação das componentes de arrasto em túnel de vento ou ambientes computacionais partem de alguns pré-supostos, como um escoamento de ar laminar incidente no modelo. Em outras palavras, um escoamento onde as linhas de corrente de ar não se interagem e possuem trajetória bem definida, em geral, coincidente com a trajetória do veículo. Porém, ao trafegar por estradas ou ruas, o mesmo está exposto a um escoamento não comportado, turbulento. Por esta razão, alguns carregamentos teóricos se diferem das cargas impostas por uma situação real. 
Árvores, construções, outros veículos e o vento lateral são fontes de turbulência encontradas no ambiente real, às quais os automóveis são submetidos. Uma consequiência direta dessas turbulências é a mudança da direção do escoamento incidente no veículo. Sendo o escoamento incidente não coincidente à trajetória do veículo, observa-se o surgimento de esforços laterais. A predição destes esforços é de extrema importância na fase de projeto, pois afeta a dirigibilidade e segurança do veículo. Esta é a parte da aerodinâmica conhecida como estudo da Estabilidade Direcional.

Todos esses aspectos que envolvem a aerodinâmica dos veículos necessitam ser minuciosamente estudados para o alcance de melhores resultados, visando o aprimoramento do: design, desempenho, segurança, aproveitamento energético, entre outros parâmetros indutores à demanda pelo veículo. 


\section{CApítulo 2}

\section{OBJETIVOS}

A aerodinâmica veicular é uma ciência que está em pleno desenvolvimento. Embora os primeiros passos em busca de automóveis mais eficientes, que oferecessem menor resistência ao escoamento de ar, se deram por volta de 1920, foi a partir da década de 80 que uma grande evolução foi observada com o advento de ferramentas como o túnel de vento e a simulação computacional. (HUCHO, 1998)

Para se compreender como esta ciência é tratada atualmente é preciso conhecer o seu desenvolvimento desde seus primórdios. Para isso, uma ampla revisão bibliográfica é apresentada neste trabalho, buscando a elucidação de aspectos históricos e do impulso às pesquisas proporcionado pelo automobilismo, que objetivava a geração de maior sustentação negativa, uma maior força aplicada sobre os pneumáticos. O presente trabalho apresenta ferramentas de análises utilizadas pela indústria automotiva e conceitos aerodinâmicos acerca do arrasto e da estabilidade veicular.

O objetivo maior desse trabalho foi o de demonstrar através de uma abordagem analítica e simulações computacionais, conceitos sobre o arrasto veicular e sobre a estabilidade direcional, além de apresentar métodos de redução de arrasto de forma a não comprometer a estabilidade dos mesmos.

Para tanto, um modelo proposto pela Sociedade dos Engenheiros Automotivos, denominado Modelo SAE, foi submetido ao ambiente de simulação computacional Fluent, versão 12.1, correspondente a um pacote comercial bastante utilizado por pesquisadores da área. Impondo-se diferentes ângulos de convergência e difusão para a geometria traseira desse modelo, pretendeu-se obter uma diminuição no arrasto longitudinal, de forma a não alterar significativamente a sustentação e momento de arfagem.

Em seguida foram eleitas duas geometrias para se verificar esses mesmos parâmetros aerodinâmicos, ao submeter o modelo a um escoamento incidente com certo ângulo de guinada (em inglês, chamado de yaw), sendo elas: aquela com o melhor ângulo de convergência e dois ângulos distintos de difusão. $\mathrm{O}$ intuito foi verificar os impactos de um 
escoamento assimétrico sobre os coeficientes aerodinâmicos apresentados em condições de simetria longitudinal.

Por fim, este trabalho visa difundir o pensamento de que o arrasto e a estabilidade veicular são dois parâmetros com definições distintas, sendo possível obter melhorias em ambos, através de modificações geométricas, contrapondo a idéia de que estes parâmetros possuem relação inversamente proporcional. 


\section{Capítulo 3 \\ REVISÃo BIBLIOGRÁFICA}

\subsection{A História da Aerodinâmica Veicular}

O início do século XX foi marcado pelo surgimento da indústria a automotiva. Os carros comercializados neste período em nada se pareciam com os veículos atuais. Eles se assemelhavam com as carruagens da época, porém movidos a motores de combustão, que devido à baixa eficiência, não lhes proporcionava grandes velocidades. Em virtude dos parâmetros da época, não se notava o baixo desempenho aerodinâmico característico dessas máquinas.

Neste mesmo período histórico, a indústria aeronáutica passava por uma grande ascensão e a cada dia surgiam novos estudos a cerca da aerodinâmica das aeronaves. Baseados nestes estudos surgiram os primeiros veículos terrestres com formato aerodinâmico. Dentre esses, acredita-se que Camille Jenatzy tenha construído o primeiro modelo, conforme apresenta a Figura 1, o qual foi o primeiro a ultrapassar a barreira dos 100 km/h, (HUCHO, 1998, Capítulo 1). Estes veículos se caracterizavam por formatos semelhantes a torpedos ou fuselagens de aviões sobre rodas. Apesar do formato aerodinâmico, não se sabia até então o efeito que o solo exercia sobre o desempenho do veículo, ocasionando um acréscimo no arrasto sobre os mesmos.

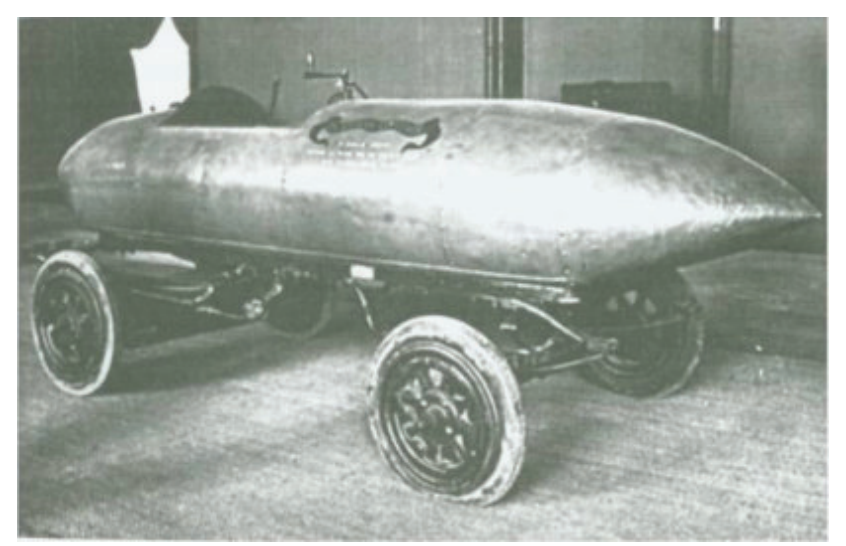

FIGURA 1: Primeiro veículo rodoviário construído, por Camille Jenatzy, com formato aerodinâmico.

FONTE: HUCHO (1998), Capítulo 1. 
A Primeira Guerra Mundial proporcionou o surgimento de um grande número de pesquisadores aeronáuticos direcionados a tecnologias militares e, com o fim da guerra em 1914, muitos destes cientistas voltaram seus esforços ao estudo da aerodinâmica veicular. Hucho, Jansen e Elmmelmann (1976) fazem referência a esse período, como sendo o início da Era of the Streamline, que em português significaria "a busca por Contornos Suaves", os quais se inspiravam no formato de uma gota de água em queda.

Paul Jaray obteve grande destaque na época por conduzir um estudo sobre corpos aerodinâmicos e propor geometrias que mais tarde serviriam de inspiração para alguns modelos comercializados. Em conjunto com Klemperer, realizaram estudos em um túnel de vento observando o efeito do solo sobre um perfil aerodinâmico. Os pesquisadores observaram que o perfil simétrico próximo ao solo perde sua simetria e, portanto, perfis assimétricos seriam mais indicados para veículos rodoviários. Além disso, constataram que um aerofólio, cujo coeficiente de arrasto $(\mathrm{Cd})$ é 0,05 , próximo ao solo, apresenta um $\mathrm{Cd}=$ 0,09 e, ao se posicionar as rodas no perfil, o mesmo apresenta um $\mathrm{Cd}$ de 0,15 . Um valor bem abaixo dos coeficientes de arrasto apresentados, em torno de 0,7 , levou Jaray a propor perfis geométricos compostos, como os apresentados na Figura 2 (HUCHO, 1998, Capítulo 1).

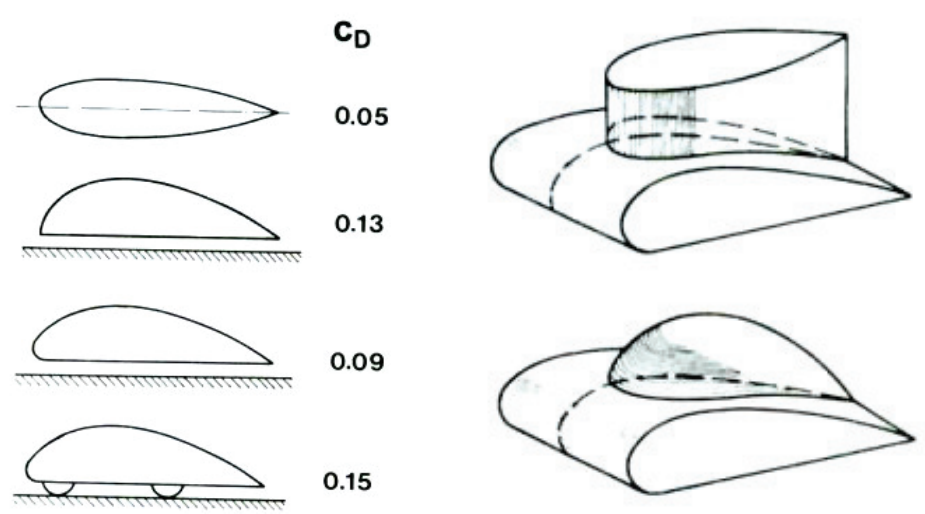

FIGURA 2: Perfis aerofólios avaliados por Jaray e Klemperer próximos ao solo. FONTE: HUCHO (1998), Capítulo 1.

Apesar dos baixos coeficientes de arrasto apresentados no estudo de Jaray, suas proposições não tiveram grande aceitação, pois para garantir que não haveria separação do escoamento ocasionando um aumento no arrasto, era preciso uma região traseira (calda) no veículo, demasiadamente alongada. 
Na década de 30, Wunibald Kamm propôs uma geometria traseira não tão alongada como a de Jaray, conforme Figura 3. Esta geometria deveria seguir o seguinte conceito: a partir de uma espessura máxima, o veículo deveria convergir suavemente de forma a manter um baixo gradiente de pressão e, próximo à região de separação do escoamento, haveria um truncamento abrupto. Os protótipos criados seguindo este conceito demonstravam que era possível se obter baixos coeficientes de arrasto, em torno de 0,3 , sem se perder a praticidade de projeto (HUCHO, 1998, Capítulo 1).

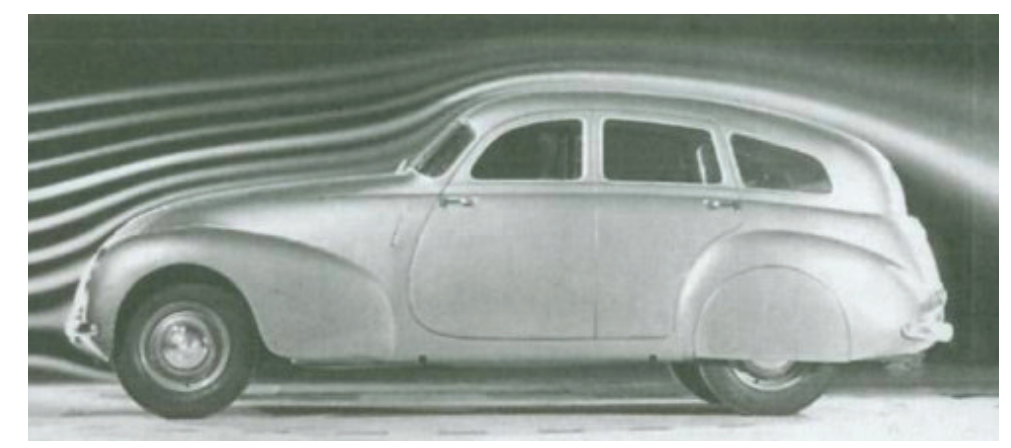

FIGURA 3: Veículo baseado na geometria proposta do Kamm. Observa-se um descolamento da camada limite gradativo na região traseira do veículo.

FONTE: HUCHO (1998), Capítulo 1.

Na Figura 3, observa-se um descolamento gradativo da camada limite na região traseira do veículo, motivo pelo o qual, Kamm atribuiu os baixos coeficientes de arrasto observados. (HUCHO, 1998, Capítulo 1).

Neste mesmo período, estudos relacionados à estabilidade direcional também foram feitos. Klemperer ao estudar o efeito solo sobre o aerofólio percebeu um aumento no arrasto quando o perfil estava posicionado de forma que o ângulo formado pelo escoamento e o eixo lateral do perfil não era reto $\left(90^{\circ}\right)$. Kamm mencionou em seus estudos que "um veículo perde sua estabilidade na medida em que sua geometria é adequada para um menor arrasto". Tal fato foi contraposto mais tarde por métodos que diminuíam o arrasto sem prejudicar a estabilidade do veículo.

Schlor, entre outros, concentrou seus estudos em proposições de geometrias para veículos como um volume único. Para isso utilizou-se de dois perfis de aerofólios desenvolvidos em Aerodynamic Test Establishment Gottingen (AVA) que apresentavam baixos coeficientes de arrasto, $\mathrm{Cd}=0,125$. Trabalhando estes perfis não se esquecendo dos aspectos ergonômicos, Schlor obteve através de uma geometria específica que utilizou 
durante ensaios de túnel de vento, Cd igual a 0,186, se aproximando do coeficiente obtido por Klemperer em sua análise de "semi-perfis" de aerofólios dotados de rodas (Figura 1). Neste estudo, analisou também a sensibilidade de seu protótipo a ventos laterais. Por um lado, seu veículo apresentou menor força lateral, por outro, o momento de giro em torno de seu eixo vertical central, conhecido como momento de yaw, foi maior do que nos carros convencionais (HUCHO, 1998, Capítulo 1).

Ao final da Segunda Guerra Mundial a América do Norte e a Europa começaram a apresentar tendências distintas com relação à aerodinâmica veicular. Concomitantemente, no continente europeu continuava-se a aprimorar geometrias propostas no período pré-guerra e cada vez mais, a aplicá-los no mercado. Já no continente americano, surgiu um novo conceito geométrico baseado na divisão do veículo em três volumes. A princípio, este conceito parecia retroceder nos avanços propostos nos anos 30, porém, detalhes como extremidades arredondadas, faróis e rodas embutidas na carroceria fizeram com que essa geometria apresentasse um coeficiente de arrasto em torno de 0,55, compatível com os modelos europeus (HUCHO, 1998, Capítulo 1).

Após esse período, a aerodinâmica passou por uma fase de estagnação durante a década de 50 e pouco avanço se deu em relação à redução de arrasto. Difundia-se o pensamento que não era possível obter coeficientes de arrasto menores que 0,5 através da adoção de contornos suaves. Os consumidores não se interessavam por veículos eficientes e sim pelo estilo apresentado pelo veículo. Os responsáveis por conferir este estilo ganharam cada vez mais poder de decisão sobre a geometria do veículo em detrimento das questões ligadas à aerodinâmica (HUCHO, 1998, Capítulo 1).

$\mathrm{Na}$ década seguinte, esta situação mudou com o surgimento de uma nova abordagem aerodinâmica, a qual ficou conhecida como "Otimização de Detalhes". Uma vez que o aerodinamicista não possuía autonomia para definir os contornos de um veículo, e pelo contrário, deveria impor melhorias aerodinâmicas sem comprometer seu estilo, lhe restava estudar pontos provedores de arrasto e assim propor melhorias com base em pequenas modificações (HUCHO, 1998, Capítulo 1).

O afilamento da traseira, inclinação do "capô" e do vidro, geometria dos vidrosretrovisores, tomada de ar para refrigeração do motor, são exemplos de alguns aspectos estudados e avaliados nas contribuições para a diminuição do arrasto total do veículo. Esta abordagem permitiu uma diminuição no coeficiente de arrasto de 0,50 para 0,4, em média. 
Uma abordagem mais detalhada pode ser vista no artigo de Hucho, Jansen e Elmmelmann (1976).

A Primeira Grande Crise do petróleo ocorrida em 1973 trouxe à tona novamente a necessidade de se construir veículos mais eficientes, com menor consumo de combustível. O estudo da "Otimização dos Detalhes" estava saturado e era preciso criar novas abordagens que permitissem a diminuição da resistência aerodinâmica dos veículos.

Tomando por base os estudos desenvolvidos nos anos 20 e utilizando-se a experiência adquirida com as técnicas de melhoria dos detalhes, deu-se início então à "Era da Otimização de Formas".

Este novo conceito tinha como ponto de partida protótipos, chamados de "corpos básicos", os quais possuíam coeficientes de arrasto muito próximos ao perfil de Klemperer e Jaray, porém, corpos não muito alongados. A partir desses, eram feitas consecutivas modificações e analisados os efeitos através de técnica semelhante à "Otimização de Detalhes". Após esta etapa, o protótipo de um veículo passaria a ter uma "forma básica" estabelecida, a qual seria estilizada conforme o segmento de mercado ao qual seria destinado.

Esta abordagem proporcionou uma maior aproximação dos times de design e aerodinamicistas durante as fases de projeto, e com isso, o surgimento de veículos com coeficientes de arrasto em torno de 0,3 . O bom resultado obtido com a iteração entre estes dois times de projeto, fez com esta metodologia perdurasse até os dias atuais na indústria automotiva.

Da década de 80 em diante, a busca por veículos eficientes se intensificou, impulsionada pelos altos preços do petróleo e pelo apelo ambientalista. Neste contexto, não mais se questionou a forma como a aerodinâmica do veículo era desenvolvida durante as fases de projeto. E, o que se busca atualmente, é melhorar as ferramentas utilizadas neste tipo estudo.

São três as ferramentas utilizadas no estudo aerodinâmico de um veículo: a análise fluidodinâmica computacional, que em inglês corresponde a Computational Fluid Dynamics (CFD); ensaios em Túneis de Vento; e Testes em Pista com o modelo de pré-produção. Esse último é utilizado basicamente para validação dos dois primeiros. O modo como se simula as condições reais no computador ou nos túneis de vento será detalhado posteriormente neste trabalho. 


\subsection{A aerodinâmica e a indústria automobilística}

Pode-se dizer que a indústria automobilística, como parte da indústria automotiva, teve seu desenvolvimento paralelo e em conjunto com esta última. Apesar de ser visto por muitos como um tipo de esporte, o automobilismo, na maioria das vezes, patrocinado por grandes montadoras é um laboratório onde novas tecnologias são constantemente testadas. Novos sistemas de frenagem, componentes pneumáticos, motores mais eficientes, assim como a aerodinâmica, são constantemente testados em pistas e expostos a condições severas de trabalho, durante as corridas, antes de se tornar componentes em um carro convencional.

A busca por carros cada vez mais velozes foi o primeiro motivo que impulsionou as pesquisas sobre a aerodinâmica veicular. Eram carros criados com objetivos de quebra de recordes de velocidade e para corridas que já aconteciam no início do século vinte. Sobre estes veículos eram adaptados os formatos aerodinâmicos baseados em geometrias de aviões (torpedos) e navegações buscando-se uma melhor penetração no ar.

Na da década de 20, o uso de contornos suaves visando a redução do arrasto difundido pelos resultados provenientes dos estudos de Jaray e Klemperer, foram incorporados às geometrias dos veículos de competição. $\mathrm{O}$ fato de apresentarem uma geometria alongada não era visto como uma desvantagem, uma vez que sua perda de ergonomia e estilo era compensada pelo ganho de desempenho.

Desde então, a aerodinâmica dos protótipos de competição era voltada inteiramente à redução do arrasto. Os veículos apresentavam cada vez mais curvas suaves a fim de se obter velocidades finais maiores. Porém, quanto menos regiões de separação, estes veículos apresentavam, maiores eram os esforços aerodinâmicos. O principal esforço observado era a sustentação. À medida que a velocidade desses protótipos era aumentada, o veículo exercia uma força menor sobre o sistema de suspensão e seus componentes pneumáticos tinham a aderência diminuída.

Além da sustentação, a existência de forças laterais características de um escoamento turbulento, tornou necessária a utilização de estruturas que compensassem esta força vertical e estabilizassem direcionalmente o veículo. Com isso, superfícies semelhantes ao leme aeronáutico e aerofólios provedores de sustentação negativa passaram a equipar estes protótipos. O Chaparral 2E, conforme Figura 4, foi o primeiro a apresentar asas com sustentação negativa, ou seja, asas geradoras de downforce, em 1966. 


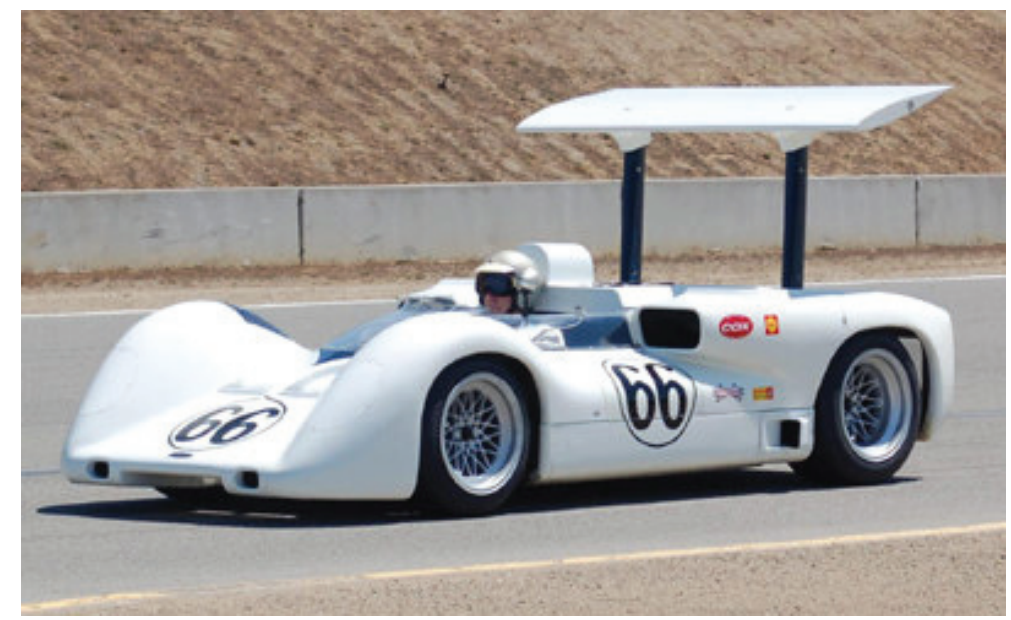

FIGURA 4: Chaparral 2E, o primeiro protótipo de competição com asas geradoras de downforce.

FONTE: www.petroleummuseum.org/Gallery/Chaparral2E.html

Nos anos que se seguiram, diversas equipes de Fórmula 1, entre elas a Ferrari e Lótus, apresentavam aerofólios em seus veículos. O ganho de desempenho, traduzido pelos tempos de voltas menores nos circuitos, foi exponencial. E a partir desse ponto, a aerodinâmica, focada não somente na redução do arrasto, como também na geração de sustentação negativa, passou a ser considerada uma das ciências chaves da indústria automobilística.

O método de "Otimização de Formas", que teve seu início da década de 70, foi também aplicado nos carros de competição. Existiu, porém, uma diferença entre a forma de aplicação na indústria automotiva e na automobilística. Enquanto na automotiva, o início do processo se dava a partir de "corpos básicos" e sobre eles, vários detalhes eram melhorados até se obter o formato final (ou ótimo), na automobilística, semelhantemente à aeronáutica, aperfeiçoavam-se as superfícies geradoras de sustentação, observando-se a razão $\mathrm{Cl} / \mathrm{Cd}$, no qual $\mathrm{Cl}$ é o coeficiente de sustentação e Cd o de arrasto, e estas partes juntamente com o corpo principal do veículo formavam "corpo básico". Com esse modelo, vários testes eram realizados para se estudar a interação entre os componentes e as modificações inseridas, até que se obtivesse um formato que melhor atendesse aos requisitos de desempenho.

Por volta de 1980, observou-se que as ferramentas utilizadas para estes ensaios forneciam coeficientes aerodinâmicos diferentes, consequentemente respostas diferentes, quando comparadas àquelas do protótipo, quando exposto às condições reais. Seja para carros de competição ou convencionais, havia a necessidade de se melhorar as ferramentas de análise aerodinâmica. 
Novos túneis de vento automotivos surgiram com o intuito de melhor representar as condições reais. Esses apresentavam esteiras rolantes e/ou métodos para controle da camada limite da superfície sob o protótipo, instrumentos de medição mais precisos, como balanças com seis graus de liberdade, geradores de turbulência que preferencialmente possuíam escala real. Na Figura 5 se apresenta o modelo de Túnel de vento dotado de esteira rolante e braços para sustentação e realização dos movimentos da roda de forma independente do chassi. Apresenta ainda, uma haste vertical conectada a uma balança com seis graus de liberdade.
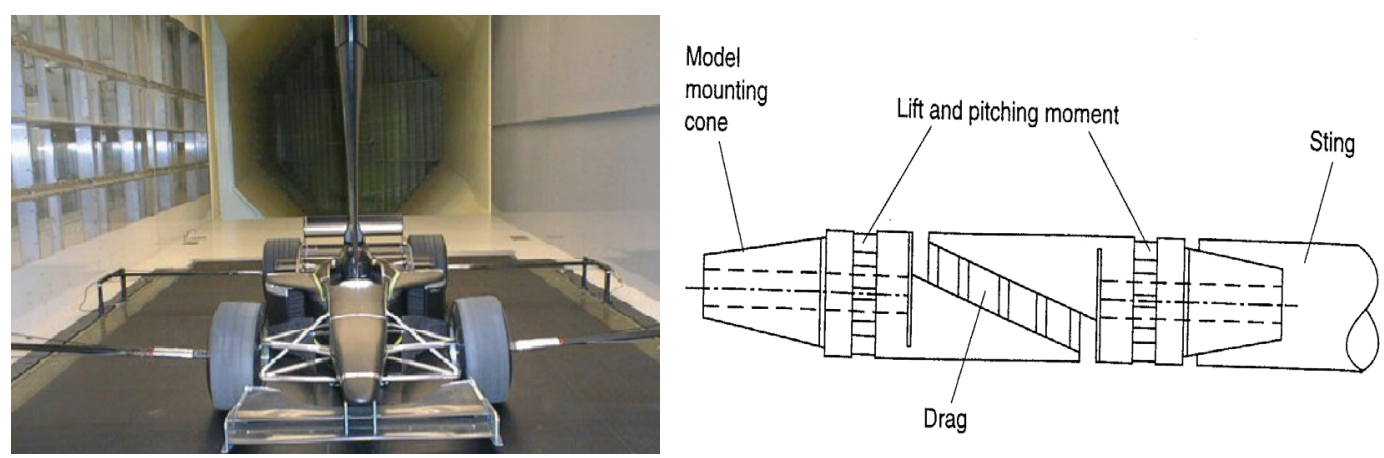

FIGURA 5: Túnel de vento dotado de esteira rolante e uma haste vertical conectada a uma balança com seis graus de liberdade. A direita um esquemático desta balança.

FONTE: KATZ (1995).

Grandes incentivos foram dados para criação de novos códigos computacionais que melhor representassem as características tri-dimensionais do escoamento ao redor do protótipo. O contínuo crescimento da capacidade de processamento dos computadores tem contribuído para que diversos trabalhos fossem publicados voltados para análise em CFD, desenvolvendo métodos de análises, modelos de turbulências, escoamentos térmicos, geração de malhas, entre outros, visando melhor representação do ambiente real.

\subsection{Dispositivos aerodinâmicos provedores de sustentação negativa (downforce)}

\subsubsection{Aerofólios}

Os aerofólios foram os primeiros dispositivos utilizados nos carros de corrida visando o aumento do peso aparente sobre os componentes pneumáticos. Como um legado da engenharia aeronáutica, havia um grande acervo de trabalhos acerca das forças de sustentação 
e arrasto geradas por perfis de aerofólios. Utilizados como asas em aeronaves, sua geometria era modificada visando o melhor compromisso entre sustentação e arrasto. Para tanto se buscava maximizar a razão entre seus coeficientes, $\mathrm{Cl} / \mathrm{Cd}$.

Para utilização desses dispositivos na indústria automobilística, novas convenções relativas aos sentidos das forças as quais os veículos estão submetidos, devem ser adotadas. Entre elas merece destaque a elaborada pela Sociedade dos Engenheiros Automotivos (SAE) em 1987, o SAEJ1594 (1987), documento que visa padronizar os trabalhos realizados sobre a aerodinâmica veicular.

Os aerofólios quando posicionados próximos ao solo tem suas características aerodinâmicas ampliadas. Segundo Katz (1995), um aerofólio, independente de sua geometria ou ângulo de ataque, pode ser colocado a distâncias menores que a metade de sua corda, e podendo até mesmo dobrar sua sustentação. É o caso dos aerofólios dianteiros utilizados nos carros de competição.

Esse estudo ainda evidenciou que os aerofólios traseiros por estarem localizados distantes do solo, para conferir valores de sustentação semelhantes aos dos aerofólios dianteiros, apresentam comprimentos, áreas, arqueamento e ângulos de ataque maiores. Seu dimensionamento e por consequiência sua efetividade depende do escoamento incidente, que em geral degrada sua eficiência. Este escoamento é caracterizado como turbulento devido aos vórtices desprendidos de outras superfícies anteriores a do veículo. O efeito prejudicial dessas superfícies sobre a sustentação negativa do aerofólio foi a justificativa apresentada por Johansson e Katz (2002) para o fato de esse perfil proporcionar maior sustentação negativa, quando submetido a certo ângulo de guinada, o qual é dotado de um escoamento incidente menos degradado.

Outra maneira de se conseguir superfícies de sustentação mais eficientes é a adoção de aerofólios com múltiplos elementos. A interação entre estes aerofólios pode ser definida como um aumento virtual de sua área quando os perfis estão posicionados em um mesmo ângulo de ataque e um aumento em seu arqueamento ao conferir diferentes ângulos de ataque para cada perfil do conjunto.

Os benefícios da sustentação negativa têm ampliado o uso desses adereços de forma que, cada vez mais, modelos convencionais são equipados com aerofólios visando um aumento de estabilidade e redução da espessura de sua esteira. 


\subsubsection{Assoalho do veículo}

O Efeito Solo é um conceito que não ficou restrito somente às asas dos carros de competição. Geometrias semelhantes a estas foram propostas para o assoalho desses veículos e eram conhecidas como Venturis ou difusores. $\mathrm{O}$ uso de difusores foi rapidamente difundido na Fórmula 1. A Lotus Type 78, em 1977, foi o primeiro carro a apresentar este efeito de solo no assoalho. Wright (1983) demonstrou que os contornos dessa superfície eram responsáveis por $80 \%$ da sustentação negativa dos carros de Fórmula 1 da época, sendo essa sustentação duas vezes maior do que o próprio peso do veículo a uma velocidade de $290 \mathrm{~km} / \mathrm{h}$.

$\mathrm{O}$ termo Venturi se deve ao fato do escoamento entre o assoalho e o solo possuir uma variação do coeficiente de pressão, $\mathrm{Cp}$, semelhante à observada em um tubo convergente-divergente, conhecido como Tubo de Venturi. Esta variação de pressão é explicada pelas equações da Continuidade, Eq. 3.1, e de Bernoulli, Eq. 3.2, um caso particular da Equação de Conservação de Energia, onde o escoamento é considerado invíscido, incompressível, que não realiza trabalho sobre as fronteiras do domínio e se encontra em regime permanente.

$$
\begin{aligned}
& \rho_{1} \cdot V_{1} \cdot A_{1}=\rho_{2} \cdot V_{2} \cdot A_{2} ; \\
& \frac{p_{1}}{\rho}+\frac{\bar{V}_{1}^{2}}{2}+g \cdot z_{1}=\frac{p_{2}}{\rho}+\frac{\bar{V}_{2}^{2}}{2}+g \cdot z_{2} ;
\end{aligned}
$$

Onde $\rho$ é a densidade do ar, $V$ a velocidade, $A$ a área da seção transversal, $p$ pressão, $g$ a aceleração gravitacional e $z$ a altitude considerada.

Considerando a região (1) da relação acima, aquela sob o assoalho, onde a distância entre o veículo e o solo é mínima e constante, a região (2) aquela, a qual ocorre o aumento desta distância, a seguinte interpretação física pode ser enunciada: balanço mássico entre estes dois pontos, garantido pela equação da Continuidade, promove uma relação inversa entre as áreas das seções transversais e as velocidades do ar. Uma vez que o ar possui velocidade maior no ponto (1), região de menor área, para satisfazer a equação 3.2, é preciso que neste local se tenha uma pressão menor se comparada à região (2). Sendo esta última dotada de uma área transversal maior e velocidade do escoamento menor.

A sustentação, no sentido para baixo, gerada pelo Venturi depende basicamente de dois aspectos na geometria do assoalho: a distância do mesmo em relação ao solo e de sua razão de convergência e divergência. Na Figura 6, nota-se que a sustentação aumenta na 
medida em que o protótipo é aproximado do solo, atingindo seu valor máximo a uma distância equivalente a $3 \%$ de seu comprimento. Observa-se ainda que, durante esta aproximação, o arrasto sofre um pequeno acréscimo, insignificante se comparado com o ganho na sustentação.

Ainda na Figura 6, verifica-se um ângulo de difusão constante igual a $10^{\circ}$. Na medida em que se aumenta este ângulo, o ar sofre uma desaceleração maior, levando a valores de sustentação negativa maiores. A partir de certo valor de ângulo de abertura observa-se uma queda na sustentação devido ao descolamento do escoamento e este dispositivo para a não ser mais efetivo.

A grande influência observada pela distância entre o solo e a superfície sobre a eficiência deste sistema de geração de sustentação negativa, foi responsável por alguns incidentes ocorridos no automobilismo na década de oitenta. Devido ao fato dos carros passarem sobre obstáculos que delimitam a pista, popularmente chamados de "zebra", estes assumiam distâncias em relação ao solo, nas quais o efeito solo não era tão evidente, vindo a ocorrer uma redução na força sobre os pneumáticos e, em consequiência, a aderência.

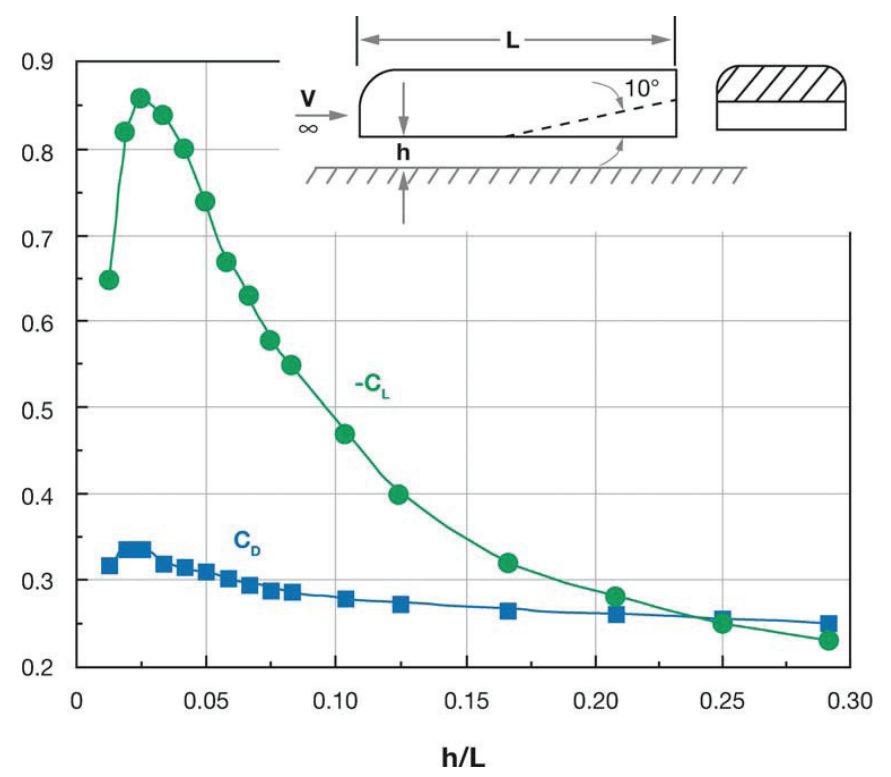

FIGURA 6: Variação dos coeficientes de sustentação, $\mathrm{Cl}$, e arrasto, $\mathrm{Cd}$, em função da distância entre o protótipo e o solo,

FONTE: KATZ (2006).

Um estudo acerca de incidentes ocorridos na Fórmula Indy conduzido por Katz, Garcia e Sluder (2004), demonstrou como se comportam os coeficientes aerodinâmicos perante essas situações inusitadas. Constatou-se que um ângulo de arfagem de $5^{\circ}$ positivos, no 
sentido de erguer a região dianteira do veículo, seria suficiente para estes protótipos apresentarem uma sustentação positiva e, consequentemente, uma condição de instabilidade.

$\mathrm{O}$ fato de o Venturi ser um conceito eficiente no aumento da sustentação com um mínimo aumento de arrasto torna esta ferramenta não somente aplicável a carros de competição, mas também aos modelos convencionais, conferindo maior estabilidade direcional aos mesmos.

\subsection{Túneis de Vento}

A partir da década de 80, a busca por coeficientes de arrastos cada vez menores, levou as montadoras a investirem na construção de túneis de ventos automotivos, uma vez que, até então, eram utilizados túneis aeronáuticos, ou túneis com escalas menores, para a aplicação dos métodos de "Otimização dos Detalhes e Formas" nos veículos.

As diferenças entre um túnel de vento voltado para a indústria aeronáutica e um automotivo não está em sua estrutura, mas sim no modelo analisado. O fato dos automóveis serem corpos rombudos, promovendo grandes perturbações no escoamento, e se movimentarem próximos ao chão, apresentando o chamado "Efeito Solo", exige que algumas modificações sejam feitas para uma melhor análise aerodinâmica (KATZ,1995).

Os Túneis de Vento, de uma forma geral, são divididos em dois grupos devido a diferenças geométricas: túneis de circuito aberto e túneis de circuito fechado. Enquanto os abertos estão constantemente renovando o ar utilizado durante o ensaio, em um circuito fechado não há a priori esta renovação.

Os túneis abertos apresentam uma geometria semelhante a um tubo de Venturi, sendo constituídos basicamente por uma seção convergente, a seção de testes, um difusor e na parte final do duto, um motor, que juntamente ao ventilador, promove o fluxo de ar. $\mathrm{O}$ ar é captado na atmosfera, passa por uma espécie de tela, ou "colméia," que visa diminuir sua turbulência, é acelerado na parte convergente para, em seguida, envolver o protótipo analisado e gerar os esforços aerodinâmicos. Depois sofre uma expansão gradativa e é devolvido à atmosfera pelas hélices do motor (KATZ, 1995).

De acordo com Hucho (1998, Capítulo 13), no circuito fechado, esta massa de ar ao passar pelas hélices é conduzida novamente à região convergente, não havendo iteração com o ar atmosférico. Para que não haja um aumento na temperatura do ar decorrente do atrito nas paredes e no motor, durante testes que demandam grandes intervalos de tempo, um 
trocador de calor é posicionado na região que antecede a seção convergente. Uma vantagem dessa configuração, se comparada à aberta, é uma menor potência necessária do motor para movimentar a massa de ar, que possui certa velocidade, o que reduz seu custo operacional.

As geometrias automotivas, por apresentarem grandes regiões de separação promovendo um afunilamento das linhas de correntes contra as paredes da seção de teste, introduziram uma nova variável a estes dois tipos de túneis: os túneis de vento com seção de teste aberta. A região de teste se constitui por uma câmara de grande volume, onde o protótipo é alojado e, em um dos lados fica localizada a seção convergente, a qual conduz o jato na direção do protótipo, enquanto no lado oposto se encontra o coletor responsável por direcionar o ar para o duto na saída da câmara, conduzindo-o a seção divergente, como pode ser verificado na Figura 7. O túnel com circuito fechado e seção de teste aberta é conhecido como tipo Gottingen, uma homenagem à cidade alemã onde foi criado. $\mathrm{O}$ de circuito aberto é denominado de tipo Eiffel, nome do seu criador (HUCHO, 1998, Capítulo 13).

Túneis, mais avançados, apresentam uma seção de teste com características intermediárias à seção aberta e fechada, sendo denominados túneis de vento de parede eslotada. Estes túneis permitem que parte do ar, o qual o protótipo pressiona contra as paredes, passe por elas, de forma que as linhas de correntes não sofram alterações que comprometam a análise aerodinâmica. Tais paredes são compostas por placas articuladas e ajustadas dependendo das dimensões do protótipo estudado. Nestes túneis "até 30\% da área das paredes podem ser abertas para se testar protótipos maiores”. (KATZ, 1995).
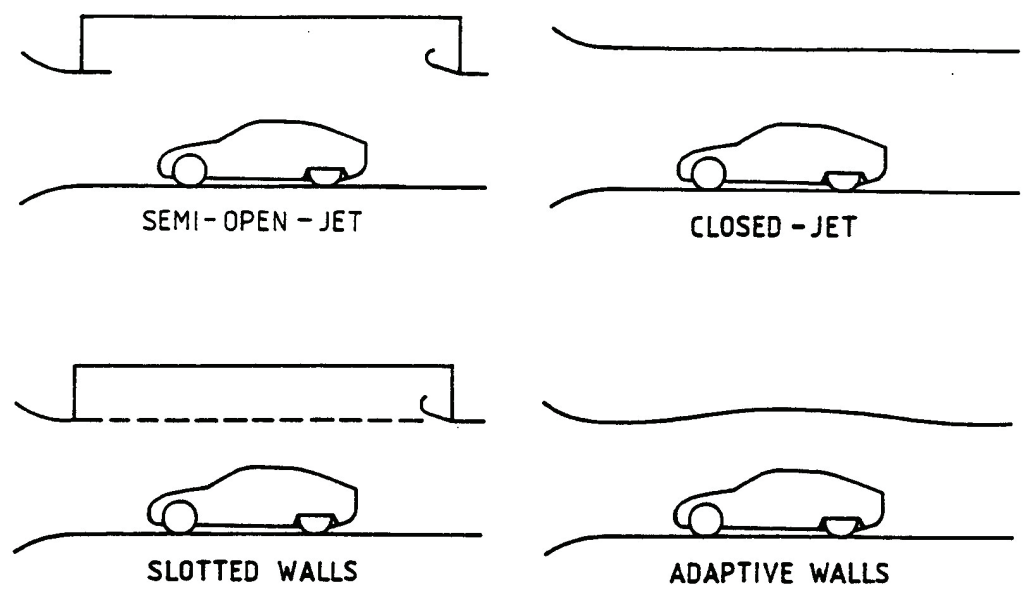

FIGURA 7: Diferentes seções de testes em túneis de ventos utilizados na indústria automotiva,

FONTE: SAEJ2084 (1993). 
A parede eslotada e a seção de teste aberta mostrados na Figura 7, são configurações que visam solucionar o problema da chamada razão de bloqueio ( $\varphi=\mathrm{Ap} / \mathrm{An})$. Esta razão é definida como o quociente entre a área característica do protótipo (Ap) analisado e a área na saída da seção convergente (An). Herança da engenharia aeronáutica, os ensaios em túnel de vento com seção fechada, eram conduzidos utilizando-se uma razão de bloqueio igual a 0,05 (ou 5\%). Este valor era necessário para que não houvesse o afunilamento das linhas de corrente, entre o protótipo e a seção de teste, e consequentemente, a medição de coeficientes aerodinâmicos não condizentes com a realidade. Em contrapartida, os túneis de vento de seção aberta e parede eslotada, permitem a passagem de parte do volume de ar para uma câmara de dimensões maiores e, portanto, a utilização de razões de bloqueio de até $20 \%$ sem que haja tal afunilamento. (KATZ, 1995)

Um estudo acerca da razão de bloqueio nos túneis de vento de circuito aberto foi proposto em SAEJ2071 (1990). Concluiu-se que a razão de bloqueio dependia não somente das áreas da seção transversal do objeto analisado e da seção de teste, mas sim de diversos parâmetros geométricos do túnel como a razão de convergência, volume da seção de teste e o comprimento. Por esta razão, as equações para correção da razão de bloqueio são características específicas pertencentes ao projeto do túnel especificamente, não sendo possível uma generalização. Por outro lado, expressões para correlação entre túneis podem ser propostas analisando o mesmo protótipo, nas mesmas condições de teste, nos diferentes túneis de vento em questão.

Além da razão de bloqueio, outro problema existente ao se tentar reproduzir as condições de tráfego real no túnel de vento, corresponde à velocidade relativa entre o pavimento e o protótipo analisado. Em condições reais, a velocidade do ar e do pavimento, se comparadas com o veículo em trânsito, apresentam diferenças muito pequenas, as quais podem ser desprezadas, em decorrência disso, observa-se o não surgimento da camada limite no pavimento. Por outro lado, em um teste em túnel de vento, a superfície sob o protótipo se encontra estática enquanto o ar escoa com certa velocidade. Apresentando, desta maneira, dois perfis de camadas limites: uma no objeto em análise e outra na superfície. (SAEJ2084, 1993).

Uma vez que a análise dos coeficientes aerodinâmicos é feita a partir da soma da distribuição de esforços sobre e sob o veículo, a presença de camada limite no solo impõe certas discrepâncias a esses coeficientes. Devido à presença de duas camadas limites sob o modelo, a perda de momento linear no escoamento é maior, o que tende a provocar um 
coeficiente de arrasto nesta região maior do que o real. Esta perda de momento tem como conseqüência um menor fluxo de ar sob o veículo levando a um menor coeficiente de sustentação.

SAEJ2084 (1993) equacionou uma estimativa para espessura da camada limite em um ensaio de túnel de vento vazio, como se pode verificar através da Equação 3.3. Esta estimativa é uma aproximação para a camada limite desenvolvida em um escoamento bidimensional turbulento à pressão constante. Sabe-se que a presença do protótipo tende a afunilar as linhas de corrente entre este e a superfície inferior da seção de ensaio, ainda assim, recomenda-se utilizar a mesma aproximação para espessura (ס), deslocamento $\left(\delta^{*}\right)$ e momento da camada limite $(\theta)$.

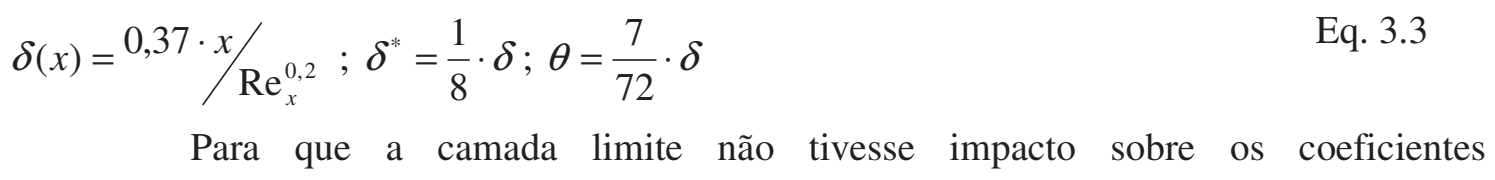
aerodinâmicos, SAEJ2084 (1993) recomendou que sua espessura não fosse superior a 10\% da distância do protótipo analisado à superfície inferior estática.

A fim de se obter uma melhor reprodução das condições de teste reais algumas técnicas são utilizadas para se anular a camada limite, controlar sua espessura, de forma a não comprometer os resultados do estudo. Entre essas, pode-se citar como as mais eficazes, o uso de esteiras rolantes sob o protótipo, a presença de orifícios sugadores de ar antes e sob o veículo e o uso de jatos de ar paralelos à superfície (HUCHO, 1998, Capítulo 13).

Berndtsson, et al (1988) apresentaram dados, nos quais o protótipo é ensaiado mediante três situações: solo estacionário, esteira rolante e soprando-se ar rente ao solo, conforme apresenta a Figura 8. Neste estudo é analisada a distribuição do coeficiente de pressão em relação à distância total do solo ao assoalho do protótipo. Pelos dados gerados observa-se que a esteira é a configuração de teste que melhor representa as condições reais de pista, com um coeficiente de pressão próximo da unidade. 


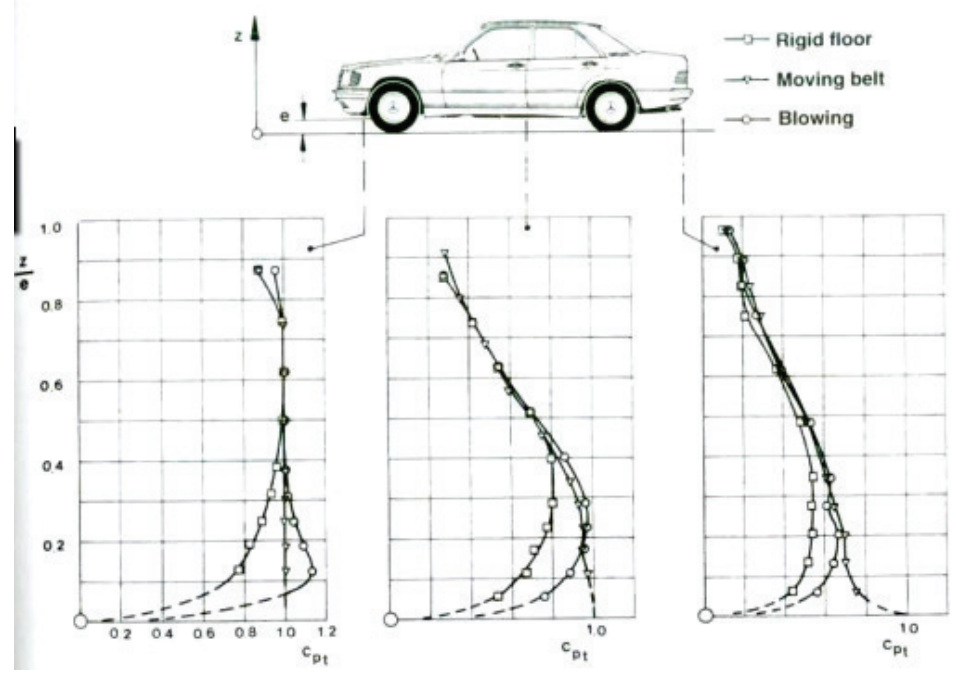

FIGURA 8: Perfil de velocidade em um escoamento sob o veículo quando simulado em chão rígido, esteira rolante e vento tangencial.

FONTE: BERNDTSSON, et al (1988).

A utilização da esteira apresenta uma desvantagem se na simulação for analisado um protótipo com rodas girantes presas à estrutura do mesmo: vibrações na esteira rolante são transmitidas pelo sistema de suspensão ao protótipo causando distorções na medição dos esforços aerodinâmicos. A solução para este problema seria a adoção de quatro estruturas fixas às rodas responsáveis por sua rotação, e uma quinta estrutura para suportar o chassi do modelo conectando-o à balança. Um exemplo desta configuração pode ser visto na Figura 5 deste material.

A simulação das rodas do veículo em movimento de fato é um desafio a mais na tentativa de se reproduzir condições reais em túnel de vento. Nos últimos 30 anos, estudos têm sido direcionados para a tentativa de caracterização do escoamento ao redor das rodas e seu compartimento nos veículos. Zhang et al (2006) apresentaram uma análise dos resultados destes trabalhos, ressaltando a incapacidade, até então, de se caracterizar quantitativamente este escoamento turbulento. Isto, apesar de grandes avanços tecnológicos nos instrumentos de medição e em simulações computacionais ter ocorridos deste Fackrell e Harvey (1975) e Cogotti (1983), que estudaram as cargas aerodinâmicas em uma roda isolada. Nestes estudos, ficou clara a influência da distância da roda à superfície e os efeitos provenientes de sua rotação.

À medida que a roda era aproximada ao solo, observava-se um maior pico de pressão negativa, porém quando em contato com o solo, um coeficiente de pressão positiva era observado na região anterior à área de contato com o pavimento, em seguida uma queda 
abrupta e pressão negativa na região posterior a esta área. A distribuição de pressão descrita neste caso pode ser observada na Figura 9.

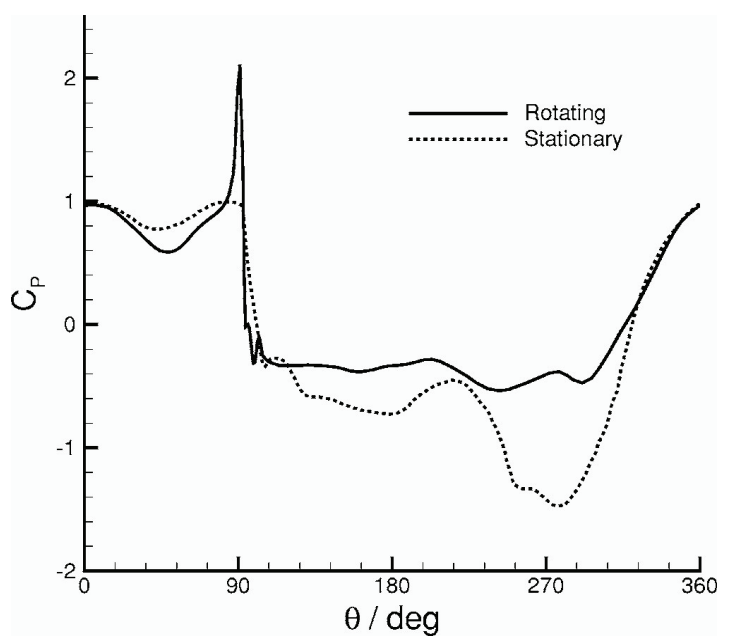

FIGURA 9: Coeficiente de pressão ao longo da linha central na superfície da roda, $\theta$ medido no sentido anti-horário.

FONTE: FACKRELL; HARVEY (1975)

Regert e Lajos (2007) e Zhang et al (2006) demonstraram através de experimentos em túnel e simulações computacionais o desprendimento de dois pares de vórtices contrarotativos: um próximo à região de contato com o solo e outro na parte superior da roda. Além disso, neste último trabalho ilustrou-se o impacto sobre a sustentação e o arrasto da roda de acordo com a geometria de seu compartimento. Zhang et al (2006) concluiu que se o espaço entre as rodas e seus compartimentos são maiores do que a camada de ambos, não há grandes distorções no escoamento nesta região, e que o fato de haver carenagem na superfície lateral da roda não trazia grandes ganhos em termos de arrasto.

A tentativa de se reproduzir as condições de pista no túnel de vento é a motivação para os estudos da razão de bloqueio e o tratamento da camada limite sob o modelo analisado. Ainda assim não é possível garantir que uma geometria trabalhada em túnel de vento, a qual apresenta menor coeficiente de arrasto, possui igual comportamento em pista. Isso é devido ao fato dos estudos, em túnel de vento, serem realizados, em sua maioria, sob escoamento laminar ou com níveis de turbulência baixos.

SAEJ2084 (1993) recomendou que o nível de turbulência não fosse superior a $0,5 \%$ nos túneis de vento. Por outro lado, os veículos trafegando em rodovias, estão sujeitos a escoamentos turbulentos. A principal diferença entre o escoamento laminar e um escoamento turbulento está na influência direta deste último sobre o gradiente de pressão, promovendo diferentes regiões de separação da camada limite. 
Cogotti (2003) difundiu a idéia de que os ensaios em túneis de vento deveriam ser feitos, em determinada fase de projeto aerodinâmico, perante escoamentos turbulentos. Para isso, realizou um estudo de caracterização do vento atmosférico e introduziu no túnel de vento em escala real da Pininfarina (empresa italiana localizada na cidade de Turin), dispositivos geradores de vórtices, como mostrado na Figura 10. Este estudo evidenciou a importância da medição dos níveis de turbulência a alturas em relação ao solo, compatíveis às dos veículos, ou seja, no ponto de estagnação. Isto porque turbulências medidas a alturas superiores a três metros apresentavam diferentes características. O resultado desta pesquisa levou à elaboração de geradores de vórtices com intensidade de 7 a 9\% e comprimento de 0,7 a 1,3 metros.

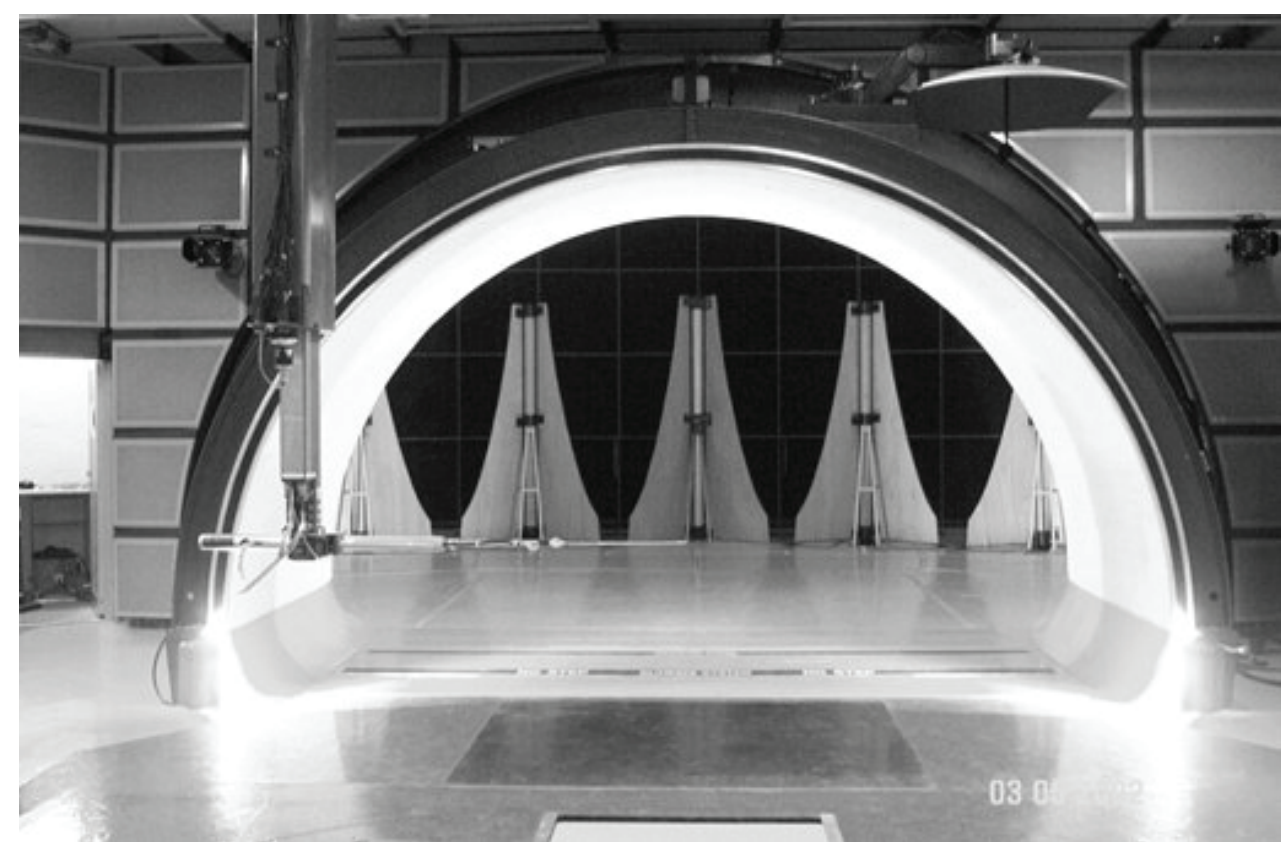

FIGURA 10: Geradores de vórtices propostos por Cogotti após analisar a intensidade e comprimento dos vórtices a alturas compatíveis aos automóveis.

FONTE: COGOTTI (2003).

Nos parágrafos anteriores, evidenciou-se a perícia requerida no projeto e construção dos túneis de vento para se obter valores de coeficientes aerodinâmicos condizentes aos reais. Como consequiência, é preciso empregar um grande capital para se obter esta ferramenta de análise aerodinâmica. Esta quantia é proporcional às dimensões do túnel, uma vez que maior quantidade de material e motores mais potentes são necessários. Em decorrência disso, somente grandes organizações possuem túneis de vento automotivos em 
escala real, como por exemplo: MIRA, Pininfarina, DNW e as grandes montadoras em geral. (SAEJ2084, 1993)

Grande parte dos estudos, voltados para aerodinâmica veicular, são conduzidos em túneis de vento com escala reduzida, por ter um custo de instalação e operação menor. Porém, é preciso ter algum cuidado sobre a confiabilidade dos dados gerados nestes túneis menores, pois os fenômenos fluidodinâmicos estão ligados às características geométricas analisadas. Além de detalhes geométricos incapazes de serem reproduzidos em escalas menores, a relação entre a velocidade do escoamento e as dimensões do protótipo, quando alterada, leva a uma estimativa errônea para os coeficientes aerodinâmicos (SAEJ2084, 1993).

O número de Reynolds é o parâmetro adimensional que traduz esta dependência entre o modelo analisado e velocidade do fluxo, como verificado pela Equação 3.4.

$\operatorname{Re}_{x}=\frac{\rho \cdot V \cdot x}{\mu}$

Eq. 3.4

Onde $\rho$ é densidade do fluido, $\mu$ a viscosidade, $V$ velocidade e $\mathrm{x}$ a dimensão do protótipo tomada como referência.

Um estudo em túnel de vento com escala reduzida, para produzir resultados representativos, deve ser conduzido mantendo-se o número de Reynolds o mais próximo possível do automóvel em escala real. Esta recomendação encontra-se em SAEJ2084 (1993). Um exemplo da importância deste fato pôde ser constatado nos estudos de Foux (1985) que comparou coeficientes de arrasto obtidos em um túnel com escala menor com os obtidos nos testes em pista. Enquanto o modelo reduzido, simulado a Re igual a 2,0x $10^{5}$, apresentou um Cd igual a 0,38 , obteve-se com o veículo, protótipo, rodando a $\mathrm{Re}$ igual a $3,5 \times 10^{6}$ e Cd igual a 0,47 .

Uma vez que as dimensões do objeto analisado são menores que as reais, para que o número de Reynolds se mantenha, é preciso que a velocidade seja maior que a real. Muitas vezes isto não é possível, pois demanda motores de grande potência, os quais têm um custo bastante elevado.

Outro fator que se deve atentar ao realizar estudos em escala é o número de Mach, em outras palavras, a velocidade do ar relativa à velocidade do som, em que o ensaio é realizado. A razão disso é que o escoamento, submetido à velocidade maior que $30 \%$ da velocidade do som, apresenta características relacionadas à compressibilidade. Fato que pode ser desconsiderado em estudos com escala real, uma vez que a maior parte dos veículos automotivos não ultrapassa $250 \mathrm{~km} / \mathrm{h}$. Este compromisso necessário entre os números de 
Reynolds e Mach é o principal motivo para que os estudos feitos em escala sejam, em geral, maiores ou iguais a 1/5. (SAEJ2084, 1993)

\subsection{Simulação Fluidodinâmica Computacional (CFD)}

Testes em pista, ainda que configurem a representação mais próxima das condições de tráfego de um veículo, possuem grandes variações nas condições ambientes e por isso, uma caracterização aerodinâmica se torna difícil, sendo possível somente com uso de ferramentas estatísticas.

Por outro lado, os túneis de vento se configuram como um ambiente controlado e de fácil alocação dos instrumentos de medição, permitindo o levantamento de características aerodinâmicas com considerada precisão. Logo, possuem extrema importância na análise aerodinâmica de um modelo durante sua fase de projeto.

Para que esta precisão seja garantida, fatores como a razão de bloqueio, a camada limite da superfície de sustentação, o movimento das rodas, as turbulências presentes no escoamento e o número de Reynolds, principalmente para ensaios em escalas menores, devem ser controlados de forma a se obter um ambiente o mais próximo possível do real. Estes fatores tornam o custo operacional do túnel de vento elevado e demandam uma grande quantidade de ensaios com diferentes configurações geométricas até se obter uma boa correlação entre coeficientes aerodinâmicos.

A necessidade de se conferir maior dinamismo ao projeto aerodinâmico proporcionou o surgimento de uma terceira forma de simulação das condições reais de tráfego de um veículo. Denominada Análise Fluidodinâmica Computacional (em inglês Computational Fluid Dynamics - CFD), esta ferramenta transforma o ambiente real em computacional com o uso de desenhos tri-dimensionais, tornando mais rápido o manejo dos fatores cuidadosamente tratados nos ensaios em túnel de vento.

A facilidade em se manipular as condições de teste e geometria do modelo fez com que a análise computacional se transformasse em uma ferramenta fundamental para o desenvolvimento aerodinâmico, principalmente nas primeiras etapas de projeto, onde se busca a otimização das formas geométricas do modelo.

Gaylard (2009) destacou que a simulação CFD, assim como a análise em túnel de vento possui vantagens e desvantagens, por isso deve ser encarada como uma ferramenta complementar ao túnel e não concorrente. Sua maior contribuição está no acesso a dados 
quantitativos acerca das linhas de corrente que envolvem o modelo estudado, permitindo que as proposições para modificações geométricas sejam mais consistentes e não baseadas em tentativas e erros.

Outro bom exemplo da utilização da simulação CFD para caracterização do escoamento em regiões de difícil acesso, como o compartimento do motor, é o estudo feito por Zielinski e Eccles (2008). Neste trabalho avaliou-se o escoamento interno na refrigeração do motor e o escoamento sob o veículo. Através da visualização das linhas de corrente foi possível avaliar zonas provedoras de arrasto, propor modificações e observar as melhorias no coeficiente de arrasto.

A simulação computacional consiste na divisão do volume de controle e da superfície do modelo em inúmeros volumes infinitesimais. Sobre tais volumes, constituídos por poliedros, são aplicados cálculos numéricos para solucionar as equações de Navier-Stokes (equação da Continuidade, Conservação do Momento e da Energia), determinando-se a pressão e os esforços aerodinâmicos em cada célula geométrica com formato definido. Através de técnicas como diferenças finitas, volumes finitos ou elementos finitos, as características nas superfícies e no interior de cada um dos volumes infinitesimais são analisadas e tomadas como um todo, de forma a determinar os esforços aerodinâmicos aplicados sobre o protótipo.

Este processo de discretização é de fato o grande desafio na simulação computacional. Isto porque os fluidos e os sólidos, em uma abordagem macroscópica, são considerados meios contínuos e, portanto, para que os pequenos volumes, que configuram a malha do sistema, representem os fenômenos físicos dos mesmos, é preciso uma divisão em um número de células maior possível. Quanto maior for esta quantia, maior será o esforço computacional demandando, assim como o tempo de simulação. Um exemplo de malha refinada encontra-se em Holloway et al (2009) utilizou em seu estudo uma malha com 26 milhões de elementos, com certa de 1,5 mm de comprimento.

As equações de Navier-Stokes que descrevem o comportamento dos fluidos são geralmente classificadas como diferenciais parciais não-lineares. Devido ao elevado grau de complexidade, a solução desses sistemas de equações é possível somente perante algumas hipóteses simplificadoras. São estas simplificações, que diferenciam os métodos de análise fluidodinâmica computacional.

Os métodos mais utilizados na indústria automotiva podem ser divididos em lineares e não-lineares. Como exemplo de métodos lineares cita-se: Vortex Lattice e o Método 
dos Painéis. Nesta abordagem o fluido é considerado incompressível, invíscido e irrotacional (também conhecido como Escoamento Potencial). Ao aplicar tais simplificações sobre as equações de Navier-Stokes, tem-se um sistema linear conhecido como Equações de Laplace. A solução desses métodos é baseada na discretização da superfície e a superposição de soluções analíticas nos nós, ou seja, nos pontos de fronteira entre as células da malha. (HOUGHTON e CARPENTER, 2003)

O Método de Euler é uma aplicação das equações de Navier-Stokes a um escoamento invíscido. As equações que descrevem este modelo (de Euler e da Continuidade) constituem um sistema diferencial parcial não linear de $1^{\text {a }}$ ordem. Tais equações, aplicadas sobre um volume de controle discretizado, se baseiam nas técnicas de volumes finitos. Sua solução se dá pela transformação do sistema diferencial em equações algébricas sobre as quais são impostas condições de contorno. A convergência deste método é garantida pela adoção de termos dissipativos durante as sucessivas interações, responsáveis por evitar oscilações numéricas. Observa-se o surgimento de pequenos vórtices nos nós, sobre os quais são aplicados estes termos, como uma forma de compensação da energia dissipada. Isto explica a presença de vorticidade e circulação em um meio invíscido.

A busca por uma modelagem que permitisse maior aproximação do ambiente real, turbulento, o qual os veículos estão expostos, promoveu o surgimento de um modelo baseado em uma solução média temporal das equações de Navier-Stokes. Este modelo foi denominado Reynolds Averaged Navier-Stokes (RANS) e consistia em caracterizar determinada componente do escoamento por uma parcela permanente, independente do tempo, e outra flutuante conforme a Equação 3.5. A componente $\bar{X}$ representa os valores médios, já $X^{\prime}$ suas flutuações.

$X=\bar{X}+X$

Eq. 3.5

Representando neste formato as componentes da velocidade e pressão nas equações de Navier-Stokes, constatou-se o surgimento de novas variáveis relacionadas aos termos flutuantes. Essas novas variáveis receberam a denominação de tensões de Reynolds. Uma vez que o número de variáveis era maior do que o de equações, fez-se necessário a utilização de novas equações denominadas Modelos de Turbulência aliados ao método RANS.

Estes modelos de turbulência, de uma forma geral, demonstram um aumento "virtual" da viscosidade do fluido devido às tensões de Reynolds e podem ser divididos em dois grupos: Viscosidade Eddy, o qual estabelece que este aumento da viscosidade é 
isotrópico, ou seja, de igual magnitude em qualquer direção; e viscosidade Não-Eddy, sendo este aumento tratado como um tensor com suas componentes direcionais. Na Figura 11 a seguir, é possível observar os diferentes modelos de turbulência existentes.

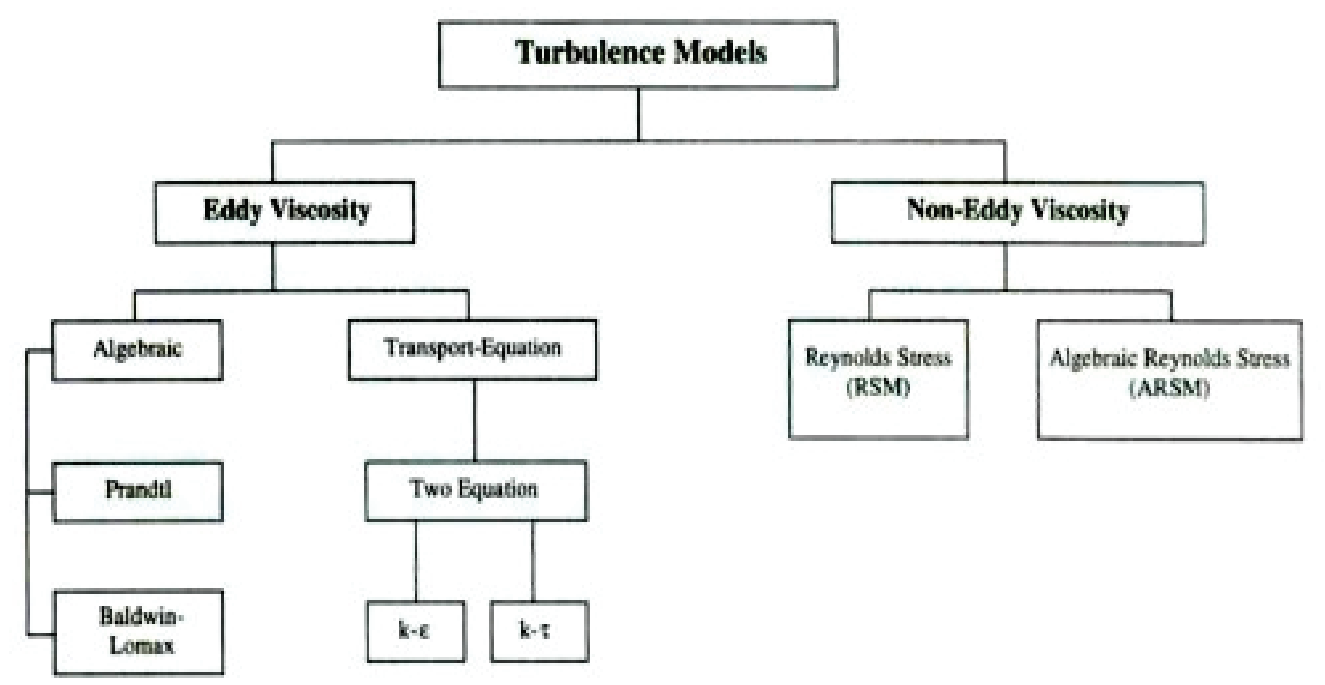

FIGURA 11: Hierarquia dos modelos de turbulência.

FONTE: HUCHO (1998, Capítulo 15).

Os modelos algébricos, nos quais se enquadram o de Prandtl e Baldwin-Lomax, utilizam parâmetros conhecidos do escoamento (gradiente de velocidade, distância em relação a superfície e geometria da camada limite) para estimar o coeficiente de viscosidade turbulenta.

Estes modelos, por possuírem um alto grau de empirismo e uma aplicabilidade limitada em escoamentos complexos, não são muito utilizados na indústria automotiva. Por outro lado, observa-se uma grande quantidade de estudos aerodinâmicos utilizando modelos de Equações de Transporte $\kappa-\varepsilon$ e $\kappa-\omega$, os quais empregam os próprios conceitos físicos de turbulência (energia cinética, $K$, e dissipação, $\varepsilon$ e $\omega$ ) para descrever a viscosidade turbulenta.

Estes estudos demonstram proximidade entre coeficientes aerodinâmicos determinados por uma simulação utilizando o modelo $\kappa-\varepsilon$ e resultados experimentais em túnel de vento, principalmente em regiões anteriores à separação da camada limite. Existe, porém, certa limitação na aplicação deste modelo a escoamentos com alto grau de vorticidade e recirculação. Um exemplo desta aplicação pode ser vista em Huminic e Huminic (2008).

Os modelos anisotrópicos como: Reynolds Stress Model (RSM) e sua variante algébrica ARSM, por considerar a viscosidade turbulenta como um tensor, o qual é 
decomposto e derivável em diferentes componentes (seis componentes, no caso de escoamento tri-dimensional), tende a ser mais preciso em relação aos modelos isotrópicos. Porém, um elevado esforço computacional é preciso ao se utilizar este modelo, tornando as simulações demoradas de forma a tornar inviável seu uso.

Estudos de Guilmineuau (2008) corresponde a um exemplo da utilização do modelo de turbulência ARSM e de sua boa aproximação quando comparado com dados experimentais. Este estudo possui uma singularidade, pois trabalha a incidência de um escoamento com certo ângulo de yaw não de forma estática, mas sim variando periodicamente seu valor $\left(\Delta \beta=10^{\circ}\right.$ e $\left.30^{\circ}\right)$. Verifica-se a inversão do sentido dos vórtices contidos na esteira do modelo relativo à variação do ângulo de guinada (yaw). Devido ao caráter transiente do experimento, é utilizado o modelo de solução numérica URANS (Unsteady Reynolds Average Navier-Stokes).

Entre os métodos baseados nas Equações de Navier-Stokes em regimes não permanentes, os quais apresentam variações em relação ao tempo, destacam-se o Large Eddy Simulation (LES) e a Simulação Numérica Direta (do inglês Direct Numerical Simulation DNS).

O método LES trabalha os vórtices de uma simulação em duas categorias: os grandes vórtices e os pequenos vórtices. Em um escoamento turbulento os grandes vórtices apresentam características variáveis com o tempo e as condições de contorno. Possuem o papel de absorver parte da energia (cinética ou potencial) desse escoamento e propagar os momentos de turbulência, sendo que, as estruturas variam a cada caso estudado. Em contrapartida, os pequenos vórtices apresentam características isotrópicas, imutáveis e independentes das condições de teste. Este método, portanto, consiste em realizar a simulação direta dos vórtices maiores e trabalhar com modelos para os pequenos vórtices. A dependência de relações adicionais para descrição da turbulência configura-se como um obstáculo para utilização deste método. Apesar disso, é um método que utilizado cada vez mais, por apresentar uma menor complexidade em relação ao DNS e maior robustez em relação ao método de RANS.

A Simulação Direta Computacional (DNS) é um método que não emprega modelos adicionais para se representar fenômenos como a turbulência. Este método exige grande esforço computacional, uma vez que são necessárias malhas demasiadamente refinadas para se representar os pequenos vórtices. Pesquisadores como Kataoka et al (1991) realizaram estudos em um protótipo com geometria similar a veículos de produção e 
obtiveram resultados muito próximos aos experimentais. Cerca de 5\% de discrepância entre os Cds, e menos de $2 \%$ entre os Cls, obtidos na simulação e no túnel de vento. Apesar desta elevada capacidade de predição dos coeficientes aerodinâmicos a utilização deste método é menor na indústria automotiva se comparado ao RANS, devido aos longos tempos de simulação. Ono et al (1992), ao estudar o escoamento externo e interno ao compartimento de um motor simplificado levou cerca de cinco semanas para desenvolver a malha e algo entorno de um mês para terminar a simulação.

Recentemente, um outro modelo tem sido utilizado na indústria automotiva, conhecido como método Zonal. Este método consiste em dividir o domínio em três subdomínios: nas proximidades do corpo em análise no qual o escoamento se encontra colado; região distante ao corpo; e a região de esteira onde há presença de vórtices. Em cada uma dessas zonas é aplicado um método de simulação diferente como método dos painéis para regiões distantes, método RANS com modelo de desenvolvimento da camada limite na proximidade do corpo e LES na região de esteira. Estas zonas se interagem de forma que na região de fronteira os dados dos pontos em uma região são utilizados como condições de contorno na outra. A grande vantagem deste método é o emprego do método apropriado ao escoamento e que melhor o caracteriza, evitando que se tenha exigência de grande esforço computacional em todo o domínio de simulação.

\subsection{Arrasto Aerodinâmico}

O crescente apelo ambientalista aos altos índices de poluição mundial aliado as especulações acerca do volume restante das reservas de petróleo, impulsionam a indústria automotiva à busca por motores e automóveis mais eficientes. Por estas razões, pesquisas acerca de novos lubrificantes e combustíveis advindos de fontes renováveis, como é o caso do etanol no Brasil, buscam melhorar o desempenho dos motores atuais sem, contudo, comprometer o meio ambiente. Um exemplo é o estudo sobre o aquecimento do etanol a fim de garantir sua flamabilidade em temperaturas abaixo de $20^{\circ} \mathrm{C}$. Castejon et al (2010) demonstrou a aplicabilidade deste conceito a motores monocilíndricos, que operam segundo o ciclo Otto.

Além de motores, a necessidade de se obter veículos com maior penetrabilidade no ar atmosférico, mais eficientes, uma vez que dissipam menor quantidade de energia gerada 
pelo grupo moto-propulsor, é o motivo pelo qual o desenvolvimento aerodinâmico tem ganhado maior importância durante o projeto e concepção de um novo modelo.

A definição de um veículo aerodinamicamente bem projetado está intimamente ligada ao seu arrasto. Uma razão para isto é o fato do arrasto influenciar diretamente no consumo de combustível do automóvel. Foux et al (1985) evidenciou esta relação ao realizar modificações geométricas em um veículo de produção, modelo 1973 e obter uma variação no coeficiente de arrasto de $51 \%$, o que condizia a uma redução de $12,7 \%$ no consumo de combustível. Hucho (1998, Capítulo 3) demonstrou que um veículo (massa $=1000 \mathrm{~kg}$ ) submetido ao ciclo de emissões, determinado pela EPA (Environmental Protection Agency), apresenta cerca de $40 \%$ da variação do arrasto convertida em variação no consumo para um motor Otto.

Esta estimativa justifica o interesse da indústria automotiva em se reduzir o arrasto veicular. Para que esta redução seja possível e efetiva, sem comprometer a estabilidade do veículo é preciso saber como ele é formado, sua composição e a partir de então, traçar métodos para sua redução.

O arrasto, assim como todos os esforços que compõe a mecânica dos fluidos, é baseado nas Equações de Conservação do Momento de Navier-Stokes. Estas equações têm como princípio a Segunda Lei de Newton, representada pela Equação 3.6, a qual enuncia que a resultante das forças aplicadas sobre um corpo é igual ao produto de sua massa pela aceleração.

$\vec{F}=m \cdot \vec{a}$

Eq. 3.6

Estas forças podem ser divididas em dois grupos de acordo com sua natureza: forças de campo (gravitacional, magnética) e forças de contato (aplicadas nas superfícies de controle). A massa é representada pelo produto da densidade e o volume de controle e a aceleração por diferenciais parciais das componentes da velocidade.

Em livros textos como o de Anderson (1995) e Schilichting (1979) há demonstrações da equação de conservação de momento em sua forma diferencial não conservativa aplicada a um volume de controle infinitesimal e em um escoamento incompressível no eixo x, como visualizado pela Equação 3.7:

$\rho \cdot \frac{D u}{D t}=F_{D}-\frac{\partial P}{\partial x}+\mu \cdot\left(\frac{\partial^{2} u}{\partial x^{2}}+\frac{\partial^{2} u}{\partial y^{2}}+\frac{\partial^{2} u}{\partial z^{2}}\right)$ 
Na equação acima $\frac{D u}{D t}$ é o derivativo da componente da velocidade u e representa a variação temporal de u em relação à posição considerada. Em termos matemáticos o derivativo pode ser expresso da seguinte forma:

$$
\frac{D u}{D t}=\frac{\partial u}{\partial t}+\frac{\partial u}{\partial x}+\frac{\partial u}{\partial y}+\frac{\partial u}{\partial z}
$$

Ainda, $F_{D}$ é a força de arrasto, $\mathrm{P}$ pressão e $\mu$ a viscosidade dinâmica do fluido. Esta forma de representar a equação de momento é utilizada em métodos de simulação computacional onde as diferenças parciais são transformadas em relações algébricas.

A equação de momento também pode ser representada por sua forma integral. Este formato, utilizado para análises em grandes volumes de controle, conceitualmente, se baseia no somatório dos esforços aplicados sobre os diversos volumes infinitesimais que o constitui. Quando aplicado em análises de túnel de vento, permite a caracterização do escoamento auxiliado por instrumentos de medição. Um exemplo é a predição do coeficiente de arrasto pela análise das componentes de velocidade e coeficiente de pressão na esteira, conforme as Equações 3.9 e 3.10 .

$$
\begin{aligned}
& C_{D}=\frac{1}{A_{F}}\left[\int_{S}\left(1-C_{P T o t a l}\right) d S-\int_{S}\left(1-\frac{u}{V}\right)^{2} d S+\int_{S}\left[\left(\frac{v}{V}\right)^{2}+\left(\frac{w}{V}\right)^{2}\right] d S\right] \\
& D=1 / 2 \cdot \rho \cdot V^{2} \cdot C_{D} \cdot A_{F}
\end{aligned}
$$

Atualmente não existe solução analítica para o cálculo do arrasto veicular por meio das equações de Navier-Stokes, seja em seu formato integral, ou diferencial. Isto se deve aos complexos fenômenos tri-dimensionais característicos dos corpos rombudos e à geometria complexa dos automóveis incluindo seus apêndices, impossibilitando sua representação por funções geométricas contínuas.

Por outro lado, estudos acerca da quantificação e abordagem qualitativa têm sido feitos focados na natureza do arrasto e em suas fontes. Em um destes, Morelli (2000) definiu o coeficiente de arrasto longitudinal de um veículo, de forma análoga ao estudo em aerofólios, como sendo a composição de dois outros coeficientes: de arrasto viscoso (ou de fricção) e o de arrasto de pressão. Este último se subdivide em duas outras componentes como o arrasto induzido e o arrasto de forma, Equação 3.11.

$$
C_{D}=C_{F}+\left(C_{i}+C_{S}\right)
$$


$\mathrm{O}$ arrasto viscoso se deve à característica do ar atmosférico conhecida como viscosidade. Este consiste em uma força de adesão entre as camadas de determinado fluido, a qual estabelece uma proporcionalidade entre o escorregamento das camadas e a força aplicada. Este princípio foi descoberto por Newton e os fluidos que apresentam esta característica são denominados Fluidos Newtonianos. Uma vez que as moléculas de ar em contato com determinado veículo não apresentam escorregamento em relação a sua superfície e devido à viscosidade, um perfil de velocidade decrescente é observado nas camadas de ar na medida em que estas se aproximam de sua superfície. A esta camada de ar que apresenta velocidades menores quando comparadas ao escoamento livre dá-se o nome de camada limite. Morelli (2000) apontou que o arrasto viscoso era conseqüência do desenvolvimento da camada limite e configurava cerca de 5 a $10 \%$ do arrasto total de um veículo.

$\mathrm{O}$ arrasto induzido é definido como a parcela do arrasto relacionado à sustentação. Este conceito é herança da indústria aeronáutica e é determinado pela componente da força de sustentação na direção do deslocamento. Para os modelos atuais representa algo em torno de 10 a $15 \%$ do arrasto total.

A maior parte do arrasto veicular é devido ao arrasto de forma, o qual é oriundo da perda de energia que os vórtices impõem ao escoamento nas regiões de separação da camada limite. Estas regiões podem ser abertas, como a esteira do veículo, ou fechadas, como regiões posteriores aos retrovisores e entre o capô e o pára-brisa do veículo. Estima-se que entre 75 a $80 \%$ do arrasto seja ocasionado pelo descolamento da camada limite e, portanto é de grande importância tentar minimizar estas regiões para se obter veículos aerodinamicamente mais eficientes.

Uma forma de se minimizar o arrasto total do veículo é determinar os locais onde ocorrem estes descolamentos e buscar uma geometria que impeça que isto aconteça. Este é o método de "Otimização dos Detalhes e/ou da Forma", já mencionados anteriormente.

Ao incidir no veículo em sua região frontal, o ar tende a escoar por seus vértices superiores e laterais, uma vez que, devido ao efeito solo, o ponto de estagnação tende a se localizar na parte inferior da seção frontal do veículo. Buchhein et al (1981) estudou a relação entre o posicionamento do ponto mais adiantado do veículo, pára-choque, tomando o solo como referência e a variação do coeficiente de arrasto. Este estudo evidenciou que o melhor posicionamento seria a uma distância menor ou igual a 10\% da distância entre o capô e o solo.

Gilhaus e Renn (1986) concluíram que uma inclinação positiva da superfície frontal do veículo, no sentido horário, vide Figura12, apresentava menor arrasto se comparada 
à inclinação vertical ou negativa. Hucho, Jansen e Emmelmann (1976) realizando sucessivas modificações nesta superfície alcançaram uma redução de $14 \%$ em relação ao arrasto gerado pela geometria inicial. No mesmo estudo, observou-se que uma curvatura no vértice superior frontal com raio de $40 \mathrm{~mm}$ seria suficiente para garantir a não separação do escoamento nesta região.

Outra região importante para redução do arrasto gerado na região frontal do veículo se refere aos ângulos formados entre o pára-brisa e o capô, onde há a formação de uma bolha (zona de recirculação fechada) devido à separação, a geometria do pilar A e o ângulo entre o pára-brisa e o teto do veículo, também ilustrado na Figura 12. Bucchein et al (1981) observou uma diminuição no arrasto aumentando-se a inclinação do párabrisa,tomando-se como referência o plano vertical para ângulos menores ou iguais a $60^{\circ}$. Para ângulos maiores que este, não haveria grandes melhorias em relação ao arrasto e a partir dessa inclinação fenômenos de refração começariam a comprometer a visibilidade do motorista.

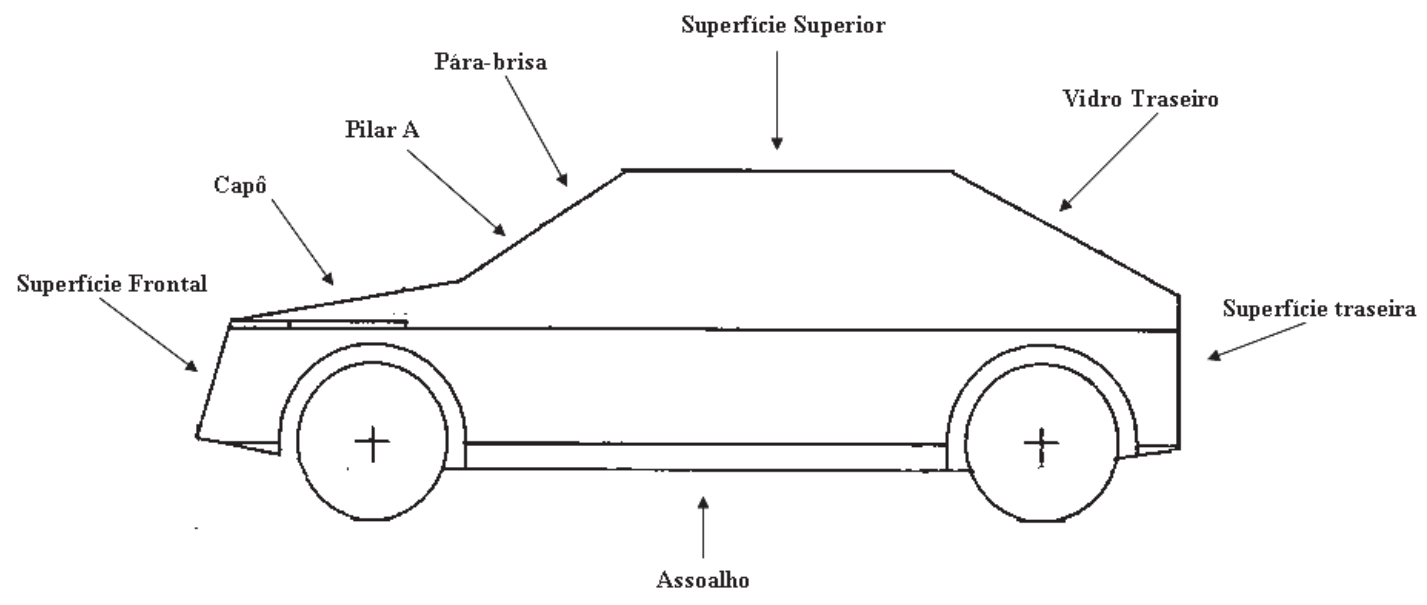

FIGURA 12: Regiões do veículo que geralmente são modificadas para obtenção de menor arrasto.

FONTE: GILHAUS; RENN (1986).

A adoção de uma inclinação maior no vidro frontal além de levar a formação de uma bolha menor entre este e o capô e um menor gradiente de pressão em sua junção com a superfície superior do veículo, de forma indireta proporciona a formação de vórtices de menor intensidade em torno do pilar A, levando a uma menor dissipação de energia nesta região. (GILHAUS e RENN, 1986)

Uma forma de se evitar a separação da camada limite na junção entre o vidro dianteiro e o teto do veículo seria a adoção de uma chapa curvilínea de forma a tornar não 
somente nessa, mas também na região de transição entre o teto e o vidro traseiro, o gradiente de pressão mais uniforme. Para isto, os vidros e teto deveriam formar uma curva contínua. Existem algumas dúvidas em relação à adoção desse procedimento para redução do arrasto, pois ao tornar o teto curvilíneo ao mesmo tempo em que existe o beneficio em relação ao Cd, a área aparente $A_{F}$ do veículo sofre um acréscimo de forma que seu produto, o qual compõe parte da fórmula de cálculo do arrasto, aumenta.

O estudo da geometria traseira é de fundamental importância para redução de arrasto, uma vez que a partir dela se origina uma região, onde o escoamento se encontra separado, denominada Esteira. Para reduzir o arrasto, objetiva-se uma pressão dinâmica o mais próxima da pressão no escoamento livre e uma região de esteira mais afilada possível. Uma forma de se alcançar isto é promovendo o afilamento da região traseira do veículo.

Esta abordagem segue os preceitos estabelecidos por Jaray nos anos 30, porém conforme mencionado anteriormente, veículos demasiados longos se tornam inviáveis ao mercado. A adoção de um ângulo de afilamento ideal junto a arredondamentos nos vértices ao redor da superfície traseira seria a melhor resposta para se obter melhores coeficientes aerodinâmicos nos veículos atuais. Alguns estudos apontam para o ângulo de $10^{\circ} \mathrm{de}$ convergência como sendo um valor ideal. Este valor seria aplicado nas superfícies laterais, no teto e como um difusor no assoalho.

Uma importante forma de redução de arrasto em torno da região traseira consiste na adoção de uma inclinação ideal para o vidro traseiro em veículos do tipo fastback. Ahmed et al (1979) realizando ensaios em um corpo básico, obteve o valor em torno de $15^{\circ}$ de inclinação para obtenção do menor arrasto. Este valor também foi obtido por Hucho, Jansen e Emmelmann (1976). Observou-se nesta inclinação o surgimento de dois vórtices contrarotativos, os quais induzem o escoamento a se manter colado no vidro traseiro, tornando a esteira mais estreita. Para ângulos maiores que este, o coeficiente de arrasto aumentava, devido a maior intensidade dos vórtices levando a uma maior dissipação de energia. Adotando-se ângulos em torno de $30^{\circ}$ era observada uma descontinuidade na curva do coeficiente de arrasto em relação à inclinação. Isto porque a esta inclinação, os vórtices contra-rotativos não possuem energia suficiente para manter o escoamento "colado", levando a um fenômeno semelhante ao estol em aerofólios, ou melhor, a uma perda de sustentação devido ao elevado ângulo em relação ao escoamento, havendo portanto o descolamento da camada limite. 
Efeito semelhante é encontrado em carros do tipo notchback. A diferença está ao se adotar inclinação maior para o vidro traseiro, havendo uma zona de recirculação (região de separação fechada), estando o escoamento colado na superfície sobre o porta-malas. Gilhaus e Renn (1986) apresentaram uma relação entre o arrasto e a altura e alongamento do portamalas. Quanto mais elevado e alongado menor era o arrasto observado.

O emprego de superfícies curvadas, ou cambadas, nas laterais dos veículos, assim como o teto, pode auxiliar na redução do coeficiente de arrasto em até $3 \%$, porém, deve-se mais uma vez, ressaltar que isso não deve implicar em um aumento da área frontal do veículo, a qual é utilizada na fórmula de cálculo do arrasto.

Além das superfícies citadas acima, é preciso analisar a geometria dos retrovisores, o recuo dos vidros laterais e o compartimento das rodas ao se fazer uma análise do arrasto. Por serem aspectos mais específicos, devem ser trabalhados caso a caso.

As modificações geométricas propostas acima em um primeiro momento são feitas perante ensaios em túneis de vento, ou simulações computacionais, com escoamento incidente coincidente com a direção longitudinal do veículo analisado. Porém, análises posteriores devem ser conduzidas observando os impactos ocasionados por escoamentos que incidem com certos ângulos em relação ao eixo vertical (ângulo de yaw) e horizontal (ângulo de arfagem) do modelo sobre o arrasto total.

Sovran (1984) enunciou em seu estudo que a geometria correspondente ao menor coeficiente de arrasto não necessariamente apresenta menor arrasto, quando submetida a ventos laterais. Ao expor certa geometria a escoamentos não coincidentes ao eixo longitudinal do automóvel, ele observou a variação do $\mathrm{Cd}$ em função do ângulo formado entre estas direções. Neste trabalho, demonstrou-se um aumento no coeficiente de arrasto à medida que se aumentava o ângulo entre o escoamento e o veículo. Valores máximos para o coeficiente de arrasto foram encontrados para ângulos entre $30^{\circ}$ e $50^{\circ}$.

Uma relação analítica para a variação do coeficiente de arrasto em função da variação do coeficiente de sustentação foi proposta por Howell (2005), analisando estes parâmetros para diferentes ângulos de arfagem, segundo a Equação 3.12.

$$
C_{d}^{\prime}=k_{v} \cdot\left(C_{L}^{\prime}\right)^{2}
$$

Onde $\mathrm{k}_{\mathrm{v}}$ é o coeficiente de arrasto induzido por vórtices. A definição do arrasto induzido por vórtices configura-se como uma das componentes arrasto de pressão, definida anteriormente no presente trabalho. Considerou-se a sustentação e o arrasto como a somatória da vorticidade e seu módulo, respectivamente presentes na esteira do modelo em análise. 
Neste estudo, manteve-se constante, em um primeiro instante, a distância entre o modelo, denominado Rover, e o solo. Uma importante conclusão deste trabalho se deve ao fato de diferentes configurações geométricas para superfície traseira proporcionarem funções analíticas semelhantes, tornando a relação entre a variação do arrasto e sustentação, uma função relacionada somente ao ângulo de arfagem.

\subsection{Estabilidade Direcional}

Ao trafegar em velocidades elevadas, como exemplo, a velocidade limite das rodovias brasileiras de $110 \mathrm{~km} / \mathrm{h}$, um veículo está exposto não somente à força de arrasto, mas também sustentação, forças laterais e momentos de arfagem, guinada e rolagem. Todos estes esforços aerodinâmicos influenciam a estabilidade direcional do mesmo.

A estabilidade direcional consiste na reação do veículo, ou de seu condutor, a estes esforços externos, de forma a não comprometer a segurança de seus ocupantes. Tais esforços são aplicados sobre a área de contato de cada componente pneumático com o pavimento e não devem exceder a força de atrito máxima entre estas superfícies. Para que esta condição seja garantida, é preciso prever os esforços aerodinâmicos em diferentes situações de tráfego e as alterações na distribuição do carregamento normal nos eixos dianteiro e traseiro do veículo.

Em condições ideais durante a fase de projeto, os veículos, ou seus protótipos, são submetidos a escoamentos simétricos em túneis de vento e em simulações computacionais, porém nas condições reais de tráfego os escoamentos são, em geral, assimétricos. Durante manobras de ultrapassagem, tráfego em rodovias curvilíneas, ou perante rajadas de vento laterais, a direção do eixo longitudinal do veículo não mais coincide com o vetor velocidade do escoamento. O ângulo formado entre os vetores velocidade do veículo e velocidade do escoamento é denominado ângulo de yaw ( ou guinada). À medida que este ângulo aumenta o escoamento ao redor do veículo assume características assimétricas, alterando os valores das forças e momentos, aos quais o veículo está submetido.

Fazendo-se uma analogia entre o ângulo de yaw e o ângulo de ataque na teoria de aerofólios tem-se que: as forças de sustentação e de guinada são proporcionais aos respectivos ângulos de incidência, como mostrado na Figura 13. Este fenômeno é explicado pelo surgimento de regiões de baixa pressão nas superfícies opostas ao escoamento incidente, as quais aumentam conforme ocorre o aumento do ângulo de incidência. A partir de certos 
valores de ângulos esta proporcionalidade deixa de ser observada, sendo estes conhecidos como ângulos de estol.
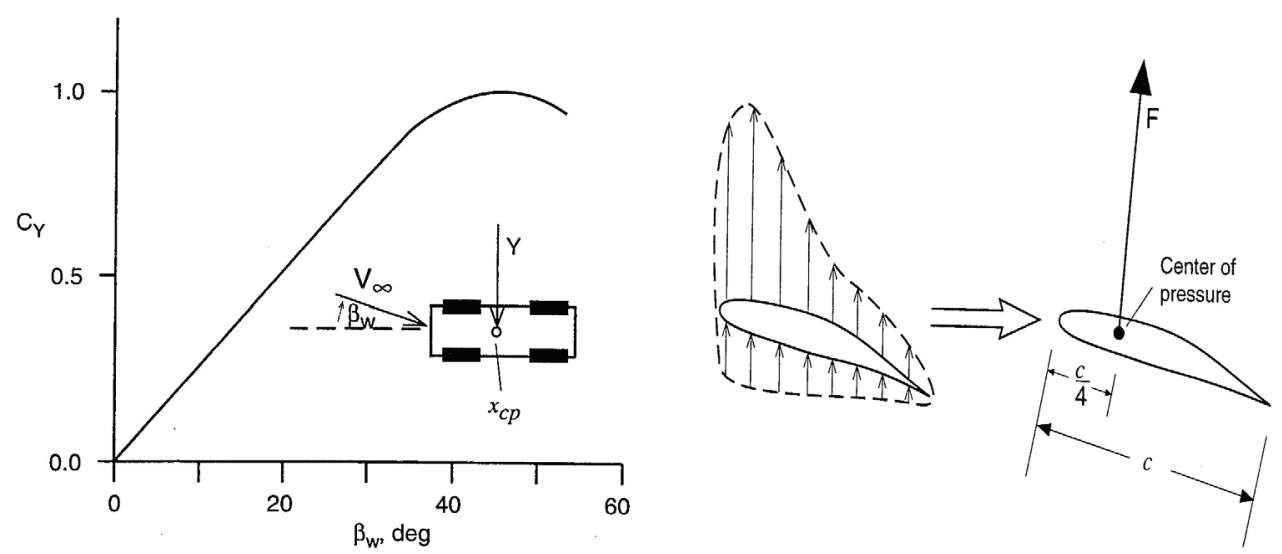

FIGURA 13: Analogia da proporcionalidade existente entre as forças de sustentação e de yaw em função dos ângulos de incidência. Características justificadas pelo aumento das zonas de baixa pressão.

FONTE: KATZ (1995)

Importante observar na Figura 13, a existência do centro de pressão, ponto pelo qual o somatório dos momentos oriundos de esforços aerodinâmicos é nulo. Este é o ponto onde as forças aerodinâmicas são representadas e seu posicionamento em relação ao centro de massa (ou gravidade) do corpo é, juntamente com a relação de sustentação dianteiro-traseira, que determinam sua estabilidade (KATZ, 1995). Em algumas análises convém fazer uso do centro aerodinâmico, já que este não varia com força lateral, em escoamentos assimétricos. Pela teoria aplicada a aerofólios, sabe-se que os centros aerodinâmicos e de pressão coincidem quando a força de sustentação tende a zero. Isto seria análogo a força lateral nula nos veículos.

Para melhor compreender o que foi enunciado nos parágrafos acima, uma abordagem analítica é apresentada a seguir.

\subsubsection{Equacionamento Aerodinâmico e Modelo Dinâmico Single-Track}

Uma representação dos esforços aerodinâmicos que envolvem o veículo em deslocamento, proposta pela Sociedade dos Engenheiros Automotivos (SAE - Society of Automotive Engineers), a qual é seguida no presente trabalho, pode ser vista na Figura 14. 


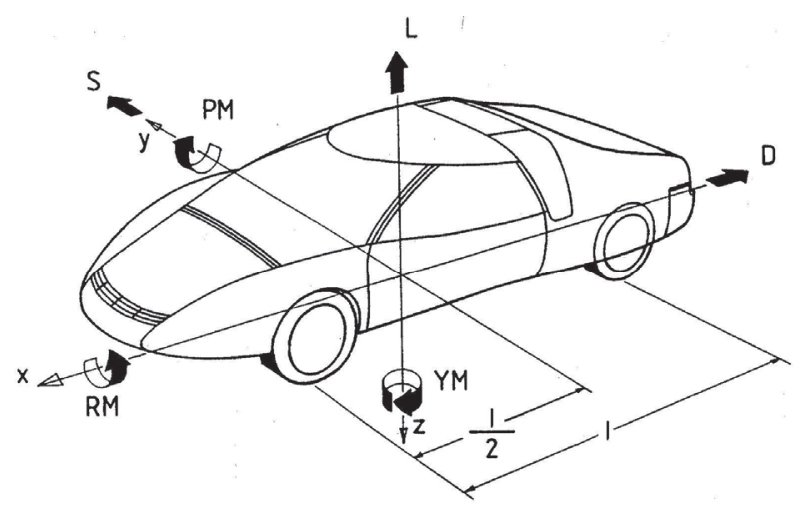

FIGURA 14: Sistema de Coordenadas para estudos dos esforços aerodinâmicos. FONTE: SAEJ1594 (1987).

Para um determinado ângulo de yaw ( $\beta$ ), têm-se as Equações 3.13 a 3.18 sobre os esforços aerodinâmicos aplicados sobre o veículo, onde $A$ é sua área frontal e $l$ seu comprimento característico.

Sustentação: $L=c_{L}(\beta) \cdot \rho / 2 \cdot V^{2} \cdot A$;

Arrasto: $D=c_{D}(\beta) \cdot \rho / 2 \cdot V^{2} \cdot A$;

Momento de Arfagem: $P M=c_{M}(\beta) \cdot \rho / 2 \cdot V^{2} \cdot A \cdot l$;

Eq. 3.15

Força Lateral: $S=c_{S}(\beta) \cdot \rho / 2 \cdot V^{2} \cdot A$;

Eq. 3.16

Momento de $\operatorname{Yaw}\left(\mathrm{YM}\right.$ ou N): $N=c_{N}(\beta) \cdot \rho / 2 \cdot V^{2} \cdot A \cdot l$;

Eq. 3.17

Momento de Rolagem: $R M=c_{R}(\beta) \cdot \rho / 2 \cdot V^{2} \cdot A \cdot l$;

Eq.3.18

HUCHO (1998, Capítulo 5) enunciou que para ângulos $\beta \leq 20^{\circ}$, é razoável a aproximação linear dos coeficientes de força lateral e momento de yaw. De forma que $\beta$ pode ser determinado pelas Equações 3.19 e 3.20.

$$
\begin{aligned}
& c_{S}(\beta)=c_{S}^{\prime}(\beta) \cdot \beta ; \\
& c_{N}(\beta)=c_{N}^{\prime}(\beta) \cdot \beta ;
\end{aligned}
$$

Portanto os mesmos podem ser expressos com relação ao centro gravitacional como nas Equações 3.21 e 3.22.

Força Lateral: $S=c_{S}^{\prime}(\beta) \cdot \beta \cdot \rho / 2 \cdot V^{2} \cdot A$; 
$=K_{W} \cdot \beta \cdot V^{2}$

Momento de Yaw: $N=c_{N}^{\prime}(\beta) \cdot \beta \cdot \rho / 2 \cdot V^{2} \cdot A \cdot l$;

Eq. 3.22

$=K_{W} \cdot e_{S} \cdot \beta \cdot V^{2}$

Onde $e_{S}$ é definido como a distância longitudinal entre os centros de pressão e gravitacional.

Tendo em vista que o carregamento aerodinâmico aplicado sobre o veículo é transferido ao solo através dos quatro pneumáticos, o pavimento exerce forças reativas nestas superfícies de contato. Um modelo simplificado utilizado na análise da dinâmica veicular por Milliken (1995), conhecido como Single Track Model, pode ser visualizado na Figura 15.

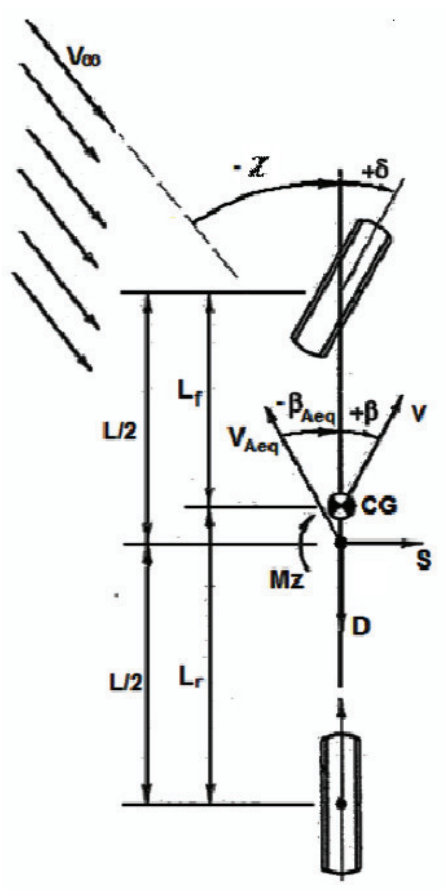

FIGURA 15: Modelo Single Track representando o sistema de suspensão e direção de um veículo.

FONTE: Miliken (1995). $\chi$

Nele, assume-se que as duas rodas do mesmo eixo (dianteiro e traseiro) possuem as mesmas cargas e, portanto os quatro pneumáticos são representados por apenas dois. Sendo a força lateral no pneumático proporcional ao seu ângulo de escorregamento, o qual pode ser descrito pelas Equações 3.23 e 3.24. 
Força no eixo frontal: $F_{T F}=-c_{F} \cdot \alpha_{F}$;

Força no eixo traseiro: $F_{T R}=-c_{R} \cdot \alpha_{R}$;

Aplicando-se as equações de equilíbrio de forças laterais e momentos em relação ao centro de massa, têm-se as Equações 3.25 a 3.30 para descrever o equilíbrio.

$\sum F_{S}: F_{y}=F_{T F}+F_{T R}+S$

$F_{y}=-c_{F} \cdot\left(\beta+\frac{L_{F} \cdot \psi}{V}-\delta\right)-c_{R} \cdot\left(\beta-\frac{L_{R} \cdot \psi}{V}\right)+1 / 2 \cdot c_{S}^{\prime}\left(\beta_{\text {aeq }}\right) \cdot \beta_{\text {aeq }} \cdot \rho \cdot V_{\text {aeq }}^{2} \cdot A ;$

Eq. 3.26

$F_{y}=\frac{1}{V}\left(-c_{F} \cdot L_{F}+c_{R} \cdot L_{R}\right) \psi-\left(c_{F}+c_{R}\right) \beta+c_{F} \cdot \delta+K_{W} \cdot \beta \cdot V_{a e q}^{2}$.

$\sum M_{z}: M_{Z}=F_{T F} \cdot L_{F}-F_{T R} \cdot L_{R}-S \cdot \frac{\left(L_{R}-L_{F}\right)}{2}+N ;$

$M_{Z}=-c_{F} \cdot\left(\beta+\frac{L_{F} \cdot \psi}{V}-\delta\right) \cdot L_{F}-c_{R} \cdot\left(\beta-\frac{L_{R} \cdot \psi}{V}\right) \cdot L_{R}+\rho / 2 \cdot c_{M}^{\prime}\left(\beta_{\text {aeq }}\right) \cdot \beta_{\text {aeq }} \cdot V_{\text {aeq }}^{2} \cdot A$

$M_{Z}=\frac{1}{V}\left(-c_{F} \cdot L_{F}^{2}+c_{R} \cdot L_{R}^{2}\right) \psi-\left(c_{F} \cdot L_{F}+c_{R} \cdot L_{R}\right) \beta+c_{F} \cdot L_{F} \cdot \delta+K_{W} \cdot e_{S} \cdot \beta_{\text {aeq }} \cdot V_{\text {aeq }}^{2}$

Sabendo que a aceleração lateral do veículo, descrita pela Equação 3.26, é composta pela soma da aceleração centrípeta com a variação da velocidade lateral do centro de massa devido à força de inércia, esta pode ser expressa pela Equação 3.32. Impondo-se também a relação entre o momento resultante e a aceleração angular, a Equação 3.29 é reescrita na forma da Equação 3.34, como pode ser visto a seguir:

$F_{y}=m \cdot\left(\frac{V^{2}}{R}+\dot{v}\right)=m \cdot V \cdot(\dot{\psi}+\dot{\beta})$

$m \cdot V \cdot \dot{\beta}+\frac{1}{V}\left(m \cdot V^{2}+c_{F} \cdot L_{F}-c_{R} \cdot L_{R}\right) \psi+\left(c_{F}+c_{R}\right) \beta-c_{F} \cdot \delta+K_{W} \cdot \beta_{\text {aeq }} \cdot V_{\text {aeq }}^{2}=0$

$\mathrm{E} M_{Z}=I_{Z} \cdot \ddot{\psi}, \log \mathrm{O}$

$I_{Z} \cdot \ddot{\psi}+\frac{1}{V}\left(c_{F} \cdot L_{F}^{2}+c_{R} \cdot L_{R}^{2}\right) \psi-\left(c_{F} \cdot L_{F}-c_{R} \cdot L_{R}\right) \beta-c_{F} \cdot L_{F} \cdot \delta+K_{W} \cdot e_{S} \cdot \beta_{\text {aeq }} \cdot V_{a e q}^{2}=0$

Eq.

Através destas equações pode-se prever o ângulo de esterço $(\delta)$ necessário para se manter a trajetória, quando o veículo estiver submetido a esforços laterais. Quanto menor for este ângulo, menor sua sensibilidade a estes esforços.

Hucho (1998, Capítulo 5) cita um exemplo de um veículo movimentando-se em trajetória retilínea, exposto a forças laterais. Sua aceleração angular $(\ddot{\psi})$, velocidade angular 
$(\dot{\psi})$ e escorregamento lateral ( $\dot{\beta}$ ) são nulos. Pelas relações de equilíbrio Eq. 3.32 e Eq. 3.34, tem-se a Equação 3.44.

$\delta=\beta \cdot V_{\text {aeq }}^{2} \cdot \frac{K_{W}}{L} \cdot \frac{c_{R}\left(L_{R}+e_{S}\right)-c_{F}\left(L_{F}-e_{S}\right)}{c_{F}+c_{R}}$

A relação acima evidencia que o ângulo de esterço é diretamente proporcional ao coeficiente de força lateral e à distância entre os centros de pressão e o centro de massa. Estes parâmetros determinam a grandeza da força lateral e do momento angular, aos quais o automóvel está sujeito. Estes esforços constituem dois parâmetros de grande importância na estabilidade veicular.

$\mathrm{O}$ coeficiente de força lateral origina-se devido ao descolamento observado à medida que o escoamento incide com certo ângulo de yaw sobre as superfícies frontais e traseiras do veículo.

Em geral a força lateral aplicada no eixo dianteiro tem magnitude maior comparada com a força no eixo traseiro. Por isso o centro de pressão aerodinâmica se localiza mais próximo do eixo dianteiro. De onde se conclui que para se aumentar a estabilidade direcional, é preciso deslocar o centro de massa o mais próximo possível do eixo dianteiro e prover mudanças na geometria do automóvel, de forma a diminuir a diferença entras as forças laterais observadas em cada eixo de rolagem.

Um veículo é considerado estável, se o centro gravitacional do veículo localiza-se a frente do centro aerodinâmico e de pressão, tomando como base a superfície frontal. Neste caso o modelo possui características understeer (ao incidir um escoamento lateral, forma-se um ângulo de escorregamento no mesmo sentido do fluxo). Aqueles que possuem características contrárias a este são considerados instáveis e oversteer.

Finalmente, é preciso considerar a razão das forças de sustentação nos eixos do automóvel, pois uma mudança nessa razão leva a uma alteração no peso aparente do veículo sobre aquele eixo e consequentemente o centro de pressão se desloca na direção longitudinal. Sua posição em relação ao centro gravitacional é alterada e o veículo que antes era considerado estável, passa a uma condição de instabilidade. Dominy et al (2000) analisando incidentes ocorridos em Le Mans, constatou que protótipos estáveis, com grande sustentação negativa, quando submetidos a um ângulo positivo de arfagem, apresentaram sustentação positiva, comprometendo dessa forma sua estabilidade.

Estes esforços aerodinâmicos que influenciam na estabilidade do veículo são oriundos da distribuição de pressão ao longo da superfície do veículo. Diferentes 
configurações geométricas afetam esta distribuição de pressão e são capazes de tornar o veículo mais estável ou não. Este tópico é apresentado no parágrafo a seguir.

\subsection{Modificações Geométricas}

A indústria automotiva se caracteriza pela diversidade de modelos que oferece ao mercado consumidor. Essa diversidade é motivada pelos diferentes estilos, moda, e está em constante mudança de tendência. Apesar disso, aerodinamicamente estes veículos possuem características que permitem dividi-los em três grupos, considerando sua geometria traseira: notchback, fastback e squareback (onde se inclui os hatchback). Os notchback são veículos que apresentam um bagageiro, usualmente chamado "porta-malas". Os fastback são aqueles que possuem um afilamento suave da geometria traseira, com inclinação do vidro traseiro em relação a horizontal geralmente menor que $30^{\circ}$. Os squareback possuem uma geometria traseira com grandes ângulos de inclinação e quase não apresentam afilamento. Para ilustrar melhor estas definições, segue uma tabela com exemplos de carros presentes no mercado brasileiro, separados por grupos como verificado na Tabela 1 .

TABELA 1: Exemplos de carros presentes no mercado brasileiro, divididos em notchback, fastback e squareback, de acordo com sua geometria traseira.

\begin{tabular}{ll}
\hline Classificação: & Exemplos: \\
\hline Notchback & Chevrolet Vectra, Ford Focus, Volkswagen Jetta, Fiat \\
& Línea, etc. \\
Fastback & Chevrolet Astra, Citroen C3, etc. \\
Squareback & Volkswagen Spacefox, Fiat Palio, Ford Fiesta, \\
& Chevrolet Agile,etc. \\
\hline
\end{tabular}

Devido às diferenças geométricas existentes entre estes grupos de veículos, estes apresentam distintos carregamentos aerodinâmicos. Hucho (1998, Capítulo 5) apresenta um comparativo entre estes modelos, quando submetidos a um escoamento incidente com ângulos de yaw ( $\beta$ ) variando de $0^{\circ}$ a $25^{\circ}$ em relação ao eixo longitudinal dos mesmos. Os protótipos analisados apresentavam a mesma geometria frontal, de forma que as diferenças eram determinadas somente pela geometria traseira.

Nesse estudo, evidenciou-se uma considerável semelhança nos coeficientes aerodinâmicos dos modelos fastback e notchback. Isto se deve a formação de uma região de 
descolamento fechada entre o vidro traseiro e o bagageiro, o que torna o escoamento em um veículo notchback semelhante ao de um perfil fastback. Concluiu-se que o modelo squareback apresenta características favoráveis a maior estabilidade direcional. Isto por apresentar menor sustentação e momento de yaw, além de momento de arfagem mais próximo a zero.

Um importante estudo relacionando diferentes parâmetros geométricos com a estabilidade e o arrasto veicular foi proposto por Gilhaus e Renn (1986). Parte desse estudo foi baseada na adoção de um protótipo com formato básico, compostos por superfícies planas e vértices pontiagudos. A partir deste, foram realizados sucessivos arredondamentos dos vértices e verificados seus impactos sobre os coeficientes aerodinâmicos. A Figura 16 demonstra que junções arredondadas favorecem o aumento a sustentação $(\mathrm{Cz})$, principalmente no eixo dianteiro, aumentando o momento de arfagem. Além disso, o arredondamento favorece o aumento do momento de yaw $(\mathrm{Cmz})$, sem grandes mudanças na força lateral. Uma exceção neste aumento do momento de yaw se dá pelo arredondamento dos vértices laterais da superfície sobre o motor e do vidro frontal (pontos 5 e 6) por promover menor força lateral frontal.
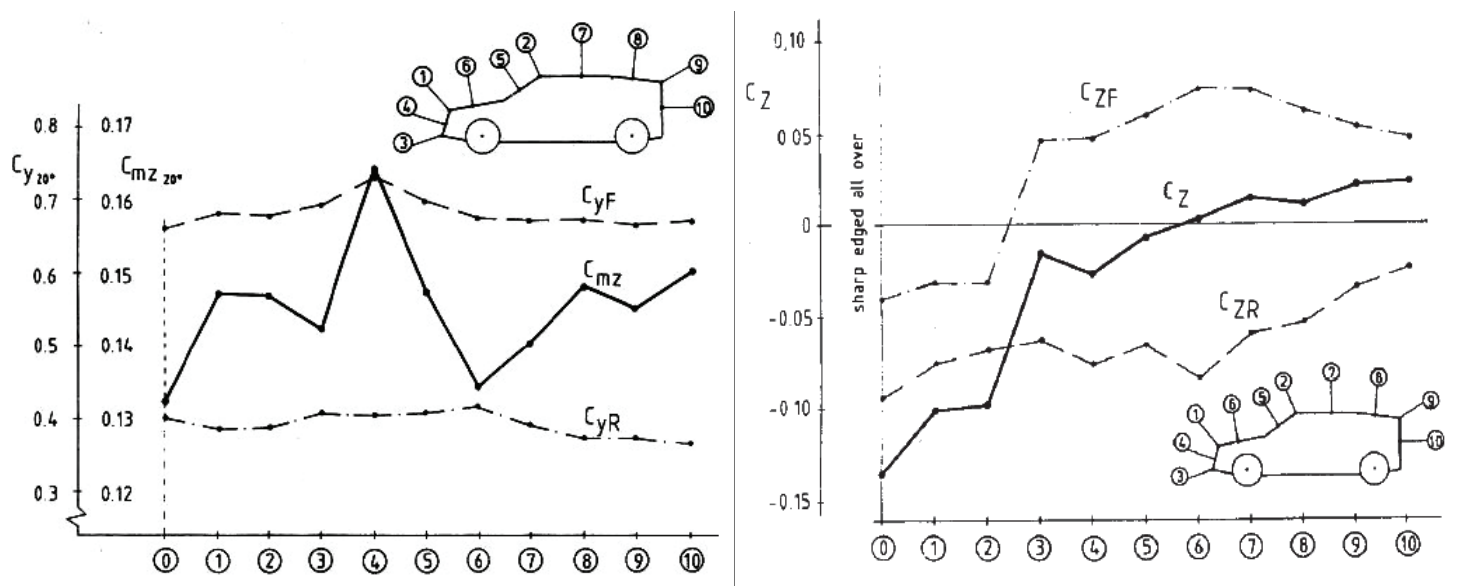

FIGURA 16: Influência dos arredondamentos dos vértices de um protótipo de formado básico, sobre a força lateral, momento de yaw e a força de sustentação.

FONTE: GILHAUS e RENN (1986).

Ao promover o arredondamento do vértice localizado abaixo do ponto de estagnação frontal, observa-se um aumento na sustentação no eixo dianteiro, ou frontal. Este fato contradiz a teoria de que aumentando o escoamento sob o veículo, devido ao Efeito Venturi, uma maior sustentação negativa é gerada. Segundo Gilhaus e Renn (1986), o Efeito Venturi ocorre em protótipos com a superfície do assoalho lisa, porém os veículos, em geral, 
possuem superfícies provedoras de separação do escoamento, levando a uma maior pressão sob os mesmos e, por isso, a uma maior sustentação.

Uma importante conclusão deste estudo é que as superfícies arredondadas promovem a redução do arrasto e do momento de rolagem, ao passo que se bem trabalhadas não geram uma perda de estabilidade por aumento na sustentação e no momento de yaw. Grandes acréscimos no momento de yaw são observados ao se arredondar as superfícies traseiras (pilares C s D) e os vértices frontais laterais (vértice 4 da Figura 16).

Outros parâmetros foram analisados no mesmo material, tais como: a altura do capô, o ângulo do vidro frontal, a inclinação das superfícies laterais, o comprimento e altura do bagageiro, mostrados na Figura 17. Uma maior sustentação frontal e momento de yaw são observados com capô mais elevado. Por outro lado, o vidro frontal mais inclinado, vide configuração 3, na parte superior direita da Figura 17, reduz estes esforços.

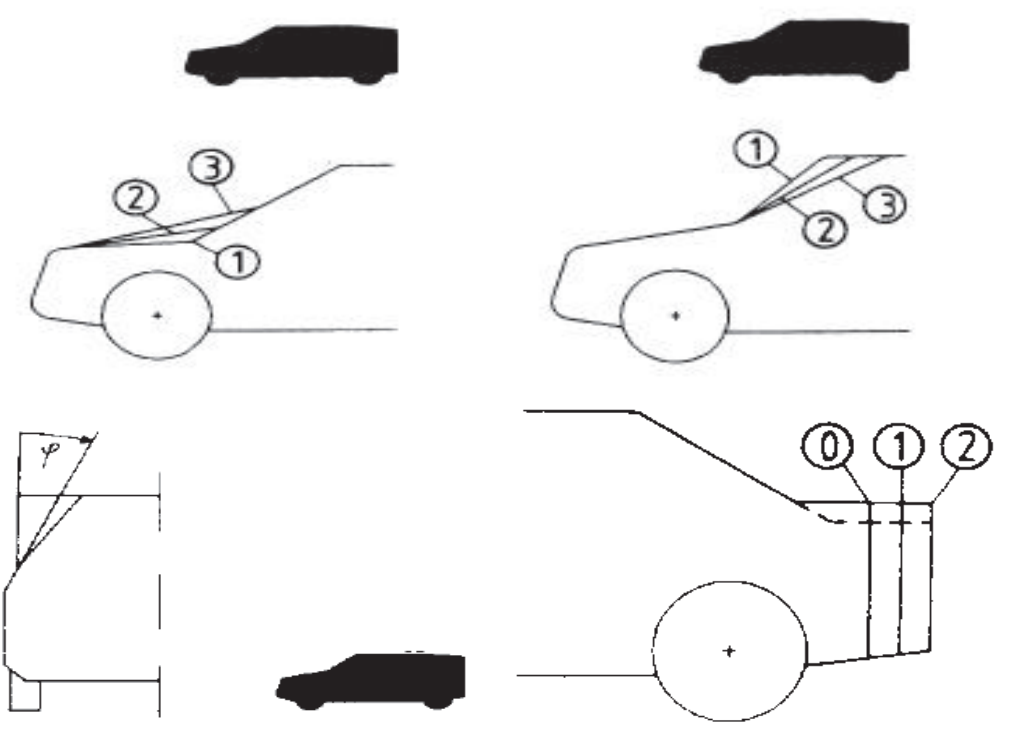

FIGURA 17: Altura do capô, ângulo do vidro frontal, inclinação lateral, altura e comprimento do bagageiro, outros parâmetros analisados.

FONTE: GILHAUS; RENN (1986).

Em veículos notchback e fastback, onde a separação do escoamento se dá na extremidade do bagageiro, a maior elevação e alongamento deste, parte inferior direita da Figura 17, conduzem a um menor arrasto e sustentação traseira, porém um maior momento de yaw. Pouca influência sobre esses parâmetros foi constatada aumentando-se a inclinação das superfícies laterais, sendo o momento de rolagem o único esforço diretamente influenciado por esta modificação geométrica. 
Os veículos comercializados apresentam, além dos parâmetros citados acima, outros adereços que influenciam na estabilidade veicular. Os vidros retrovisores externos, as rodas, a geometria do assoalho, o escoamento no compartimento do motor são alguns exemplos. Dentre esses, vale ressaltar a interação entre o escoamento interno no motor sobre a aerodinâmica do veículo.

Nos primeiros estágios do desenvolvimento aerodinâmico, o protótipo é analisado não havendo escoamento interno, porém é preciso ter em mente o impacto aerodinâmico desta variante. Trabalhos feitos acerca deste impacto elucidam um aumento no arrasto em torno de cinco por cento. Considerando a sustentação frontal, esta porcentagem dobra e como conseqüência, o momento de arfagem é alterado, assim como o centro de pressão e a estabilidade direcional.

A fim de se minimizar este impacto, estudos demonstram que a canalização do ar incidente no compartimento do motor para o radiador, aumenta sua eficiência no resfriamento do motor e ainda promove uma redução pela metade da porcentagem citada no parágrafo anterior (HUCHO,1998, Capítulo 5)

Fica evidente, pelos parágrafos acima, que uma série de possibilidades de modificações geométrica promove uma melhoria na estabilidade veicular sem comprometer o arrasto. O trabalho de Broadley e Garry (2000) é um exemplo que utilizou superfícies planas provedoras de separação na região traseira de um protótipo para se demonstrar a possibilidade de se trabalhar o posicionamento do centro de pressão, sem alterar significativamente o arrasto e a sustentação do mesmo.

\subsection{Disposições Analíticas}

\subsubsection{As equações de Navier-Stokes}

A caracterização de um fluido newtoniano compressível em movimento se dá através de suas componentes de velocidade nos eixos de coordenadas (no caso tridimensional), de sua densidade e pressão. Esta cinco variáveis variam com o tempo e com sua localização dentro do volume de controle. Para que estes parâmetros tenham valores conhecidos, é necessária a adoção de cinco equações que as relacionem. Estas equações são conhecidas como Equações de Navier-Stokes e são caracterizadas pela equação da continuidade (ou conservação da Massa), três equações de Conservação de Movimento (Conforme a $2^{\mathrm{a}}$ Lei de Newton) e uma equação de estado termodinâmico. 
As três equações descritas abaixo, Equação 3.36, referem-se à Conservação do Momento.

$$
\begin{aligned}
& \rho \cdot \frac{D u}{D t}=F_{X}-\frac{\partial p}{\partial x}+\frac{\partial}{\partial x}\left[\mu\left(2 \frac{\partial u}{\partial x}-\frac{2}{3} \cdot \operatorname{div} w\right)\right]+\frac{\partial}{\partial y}\left[\mu\left(\frac{\partial u}{\partial y}+\frac{\partial v}{\partial x}\right)\right]+\frac{\partial}{\partial z}\left[\mu\left(\left(\frac{\partial w}{\partial x}+\frac{\partial u}{\partial z}\right)\right]\right. \\
& \rho \cdot \frac{D v}{D t}=F_{y}-\frac{\partial p}{\partial y}+\frac{\partial}{\partial y}\left[\mu\left(2 \frac{\partial u}{\partial y}-\frac{2}{3} \cdot \operatorname{div} w\right)\right]+\frac{\partial}{\partial z}\left[\mu\left(\frac{\partial v}{\partial z}+\frac{\partial w}{\partial y}\right)\right]+\frac{\partial}{\partial x}\left[\mu\left(\left(\frac{\partial w}{\partial y}+\frac{\partial v}{\partial x}\right)\right]\right. \\
& \rho \cdot \frac{D w}{D t}=F z-\frac{\partial p}{\partial z}+\frac{\partial}{\partial z}\left[\mu\left(2 \frac{\partial w}{\partial z}-\frac{2}{3} \cdot \operatorname{div} w\right)\right]+\frac{\partial}{\partial x}\left[\mu\left(\frac{\partial w}{\partial x}+\frac{\partial u}{\partial z}\right)\right]+\frac{\partial}{\partial y}\left[\mu\left(\left(\frac{\partial v}{\partial z}+\frac{\partial w}{\partial y}\right)\right]\right.
\end{aligned}
$$

A Equação 3.37 é referente à equação de Conservação da massa.

$$
\frac{\partial p}{\partial t}+\frac{\partial \rho u}{\partial x}+\frac{\partial \rho v}{\partial y}+\frac{\partial \rho w}{\partial z}=0
$$

\section{Onde,}

$\frac{D}{D t}=\frac{\partial}{\partial t}+u \frac{\partial}{\partial x}+v \frac{\partial}{\partial y}+w \frac{\partial}{\partial z}:$ é o derivativo do escalar;

$u, v, w:$ as componentes da velocidade no eixo coordenados;

$\mathrm{F}_{\mathrm{x}}, \mathrm{F}_{\mathrm{y}}, \mathrm{F}_{\mathrm{z}}=$ forças externas atuantes nos eixos coordenados;

$\mu=$ a viscosidade dinâmica do fluido;

Se o processo é isotermal, pode-se adotar a Equação de Estado dos Gases Ideais como aproximação que relaciona a pressão e a densidade. Caso contrário utiliza-se a $1^{\mathrm{a}}$ Lei da Termodinâmica, equação da Conservação de Energia, a qual realiza um balanço entre o calor e a energia mecânica.

No presente estudo é adotada a velocidade de $40 \mathrm{~m} / \mathrm{s}$ para o escoamento, caracterizando um número de Mach menor que 0,2 e, portanto, um escoamento incompressível. Para este tipo de escoamento, admitindo-se que não há variação de temperatura e, portanto, a viscosidade é constante, tem-se a Equação 3.38 composta por três equações diferencias.

$$
\begin{aligned}
& \rho\left(\frac{\partial u}{\partial t}+u \frac{\partial u}{\partial x}+v \frac{\partial u}{\partial y}+w \frac{\partial u}{\partial z}\right)=F_{x}-\frac{\partial p}{\partial x}+\mu\left(\frac{\partial^{2} u}{\partial x^{2}}+\frac{\partial^{2} u}{\partial y^{2}}+\frac{\partial^{2} u}{\partial z^{2}}\right) ; \\
& \rho\left(\frac{\partial v}{\partial t}+u \frac{\partial v}{\partial x}+v \frac{\partial v}{\partial y}+w \frac{\partial v}{\partial z}\right)=F_{y}-\frac{\partial p}{\partial y}+\mu\left(\frac{\partial^{2} v}{\partial x^{2}}+\frac{\partial^{2} v}{\partial y^{2}}+\frac{\partial^{2} v}{\partial z^{2}}\right) ; \\
& \rho\left(\frac{\partial u}{\partial t}+u \frac{\partial w}{\partial x}+v \frac{\partial w}{\partial y}+w \frac{\partial w}{\partial z}\right)=F_{z}-\frac{\partial p}{\partial z}+\mu\left(\frac{\partial^{2} w}{\partial x^{2}}+\frac{\partial^{2} w}{\partial y^{2}}+\frac{\partial^{2} w}{\partial z^{2}}\right) ;
\end{aligned}
$$

$$
\text { E, a Equação 3.39. }
$$

Eq. 3.36

$$
\text { (1) }
$$


$\frac{\partial u}{\partial x}+\frac{\partial u}{\partial y}+\frac{\partial u}{\partial z}=0$

Estas equações constituem a forma diferencial das equações de Navier-Stokes. Uma outra forma de enunciar estas equações seria através de sua forma integral a qual é descrita na Equação 3.40:

$$
\begin{aligned}
& \int_{V} \frac{\partial \rho \phi}{\partial t} d V+ \oint \rho \phi \vec{v} \cdot d \vec{A}=\oint \Gamma_{\phi} \nabla_{\phi} \cdot d \vec{A}+\int_{V} S_{\phi} d V ; \\
& \text { Onde, } \\
& \rho=\text { densidade } \\
& \Phi=\text { grandeza escalar; } \\
& \vec{v}=\text { vetor velocidade }(u, v, w) ; \\
& \vec{A}=\text { vetor área do volume de controle; } \\
& \Gamma_{\phi}=\text { coeficiente de difusão para } \Phi ; \\
& \nabla_{\phi}=\text { gradiente de } \Phi ; \\
& S_{\phi}=\text { fonte de } \Phi \text { por unidade de volume. }
\end{aligned}
$$

A forma diferencial das equações de Navier-Stokes e é utilizada para discretização pelo método de diferenças finitas. Este método baseia-se na criação de uma malha, e caracterização do escoamento pelas características nos nós da malha.

O método de discretização utilizado pelo Fluent é conhecido como Volumes Finitos. Este utiliza as equações de conservação do momento na sua forma integral. Este método consiste na soma das propriedades de todos os volumes de controle infinitesimais os quais compõe a malha.

A necessidade destes métodos se deve à complexa geometria do modelo automotivo, para o qual não é possível descrever uma função geométrica analítica e realizar sua integração na área ou no volume.

\subsubsection{Método Numérico de Discretização das Equações de Navier- Stokes}

A partir das equações de Navier-Stokes em sua forma integral, o Fluent realiza uma discretização e apresenta solução baseada no método dos volumes finitos. Este método se baseia no seguinte procedimento: divisão do volume de controle em volumes infinitesimais 
através da geração de uma malha; solução de todas as propriedades físicas dentro destes pequenos volumes de controle gerados com seus pontos de fronteira bem definidos e posterior soma destas propriedades em todos os volumes de controle gerados, dando origem a um sistema discretizado de equações; e por fim, a linearização deste sistema discretizado e a solução do sistema de equações lineares. Uma descrição detalhada do processo de solução do Fluent encontra-se em ANSYS FLUENT 12.0/12.1 Theory Guide.

Tomando como base o número de Reynolds utilizado neste trabalho, o qual pode ser considerado baixo se comparado a escoamentos sônicos ou supersônicos (Re igual a $2,9 \times 10^{6}$ ), utilizou-se como método de correção para erros devido à discretização, aquele baseado na correção da pressão. Este consiste em uma equação oriunda de manipulações analíticas das equações da continuidade e conservação de momento, a qual corrige as grandezas relacionadas ao campo de pressão e velocidades no volume discretizado em cada passo de iteração. Estes novos valores devem satisfazer a equação da continuidade para em seguida começar a iteração seguinte.

O processo de solução, de uma forma geral, se resume em cinco passos: atualizar as propriedades do fluido (densidade, viscosidade, calor especifico, etc); resolver as equações de momento uma após a outra utilizando os valores atualizados das propriedades do fluido; resolver a equação de correção da pressão, utilizando os novos valores de pressão e fluxo de massa; recalcular os valores das propriedades do fluido com base no novo valor de pressão; calcular os demais parâmetros físicos (energia, turbulência, etc); verificar a convergência do método pela análise dos resíduos.

A discretização é feita sobre a equação N-S em sua forma integral, obtendo a Equação 3.41.

$$
\begin{aligned}
& \frac{\partial \rho \phi}{\partial t} d V+\sum_{f}^{N \text { faces }} \rho_{f} \vec{v}_{f} \phi_{f} \cdot \vec{A}_{f}=\sum_{f}^{N \text { faces }} \Gamma_{\phi f} \nabla_{\phi f} \vec{A}_{f}+S_{\phi} V ; \\
& \text { Onde, } \\
& \frac{\partial \rho \phi}{\partial t}=\frac{F(\phi)}{V \rho} ; \text { que em uma discretização de segunda ordem é expresso por: } \\
& F(\phi)=\frac{3 \phi^{n+1}-4 \phi^{n}+\phi^{n-1}}{2 \Delta t} \text {, sendo } \phi \text { a quantidade escalar, } \mathrm{n}+1 \text { valor da próxima iteração em } \\
& t+\Delta t, \mathrm{n} \text { a iteração no tempo } t, \mathrm{n}-1 \text { a iteração no tempo } t-\Delta t \\
& \mathrm{~N}_{\text {faces }}=\text { número de faces que compõe a célula } \\
& \phi_{\mathrm{f}}=\text { valor } \phi \text { na face } \mathrm{f} ;
\end{aligned}
$$


$\rho_{f} \vec{v}_{f} \phi_{f} \cdot \vec{A}_{f}=$ fluxo de massa na face;

$\vec{A}_{f}=$ área da face;

$\nabla_{\phi f}=$ gradiente de $\phi$ na face $f$.

$V=$ volume da célula.

A ilustração a seguir, Figura 18, demonstra duas células vizinhas, as quais possuem uma face em comum, que conforme a Equação 3.41, relaciona as propriedades dessa face com as do centro de cada célula.

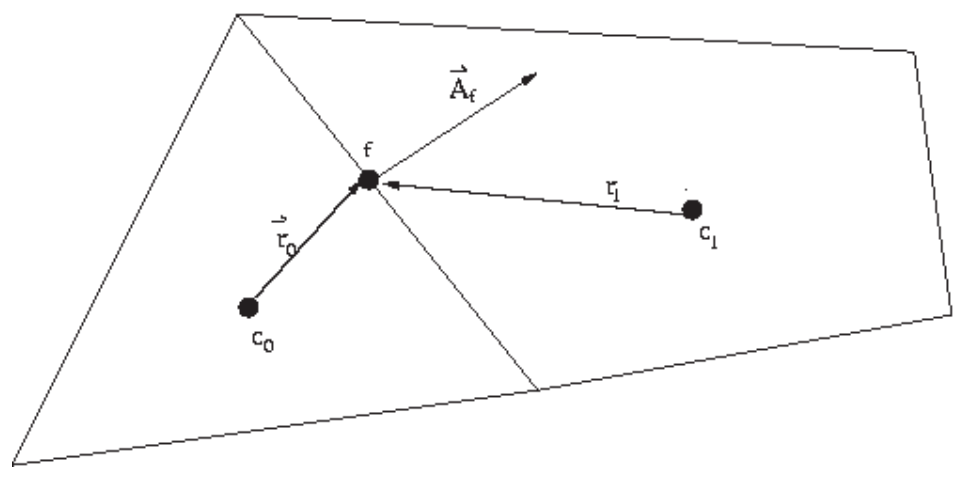

FIGURA 18: Exemplo de volume de controle infinitesimal discretizado. FONTE: Fluent Theory Guide, versão 12.1, capítulo 18.

A Equação 3.41 apresenta a grandeza escalar $\phi$ tomada no centro de cada célula e em suas faces. Em geral esta equação possui um comportamento não linear em relação a esta grandeza, portanto uma forma linearizada desta equação é reescrita de acordo com a Equação 3.42 .

$a_{p} \phi=\sum_{a d j} a_{a d j} \phi_{a d j}+b$

Onde,

Adj $=$ representa células adjacentes, assume valores 1, 2, 3, etc., dependendo do número de células ao redor da célula de referência;

$a_{p}, \mathrm{a}_{\mathrm{adj}}=$ coeficientes lineares;

$\phi, \phi_{\text {adj }}=$ grandeza escalar na célula tomada como referência e em suas células adjacentes.

Considerando a equação acima, aplicada a todas as células da malha temos um sistema algébrico de equações lineares. Sua solução no software Ansys Fluent é feita através do método implícito, chamado Gauss-Seidel, e o método explícito, Algebric Multigrid (AMG). 
O método AMG se baseia na solução de um sistema de equações lineares, em uma malha menos refinada, para o controle dos erros numéricos, provenientes do método de solução implícita de Gauss-Seidel.

O método de solução de Gauss-Seidel é baseado na solução da equação algébrica de cada célula separadamente e sequencialmente. A informação da célula adjacente, determinada no passo anterior, é então utilizada para se determinar a solução da célula referência. Para isso são utilizados os passos preditor e corretor a cada etapa da solução.

$\mathrm{O}$ passo preditor aplicado à célula $i$ no passo $k+1 / 2$ pode ser equacionado através da Equação 3.43.

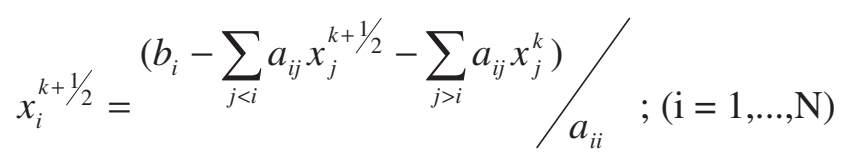

Onde $\mathrm{N}$ é o numero de variáveis desconhecidas.

O passo corretor é em seguida aplicado à célula $i$ para determinação do passo $k+1$, obtendo-se a Equação 3.44 .

$x_{i}^{k+1}={ }^{\left(b_{i}-\sum_{j<i} a_{i j} x_{j}^{k+1 / 2}-\sum_{j>i} a_{i j} x_{j}^{k+1}\right) / a_{i i}}$

Ao aplicar estas equações em todas as células da malha, o método de Gauss-Seidel é expresso pela Equação 3.45 na forma matricial.

$\left(D_{A}+L_{A}\right) D_{A}^{-1}\left(D_{A}+U_{A}\right)\left(x^{k+1}-x^{k}\right)=b-A x^{k}$

$\mathrm{D}_{\mathrm{A}}, \mathrm{L}_{\mathrm{A}}$ e $\mathrm{U}_{\mathrm{A}}$ representam as matrizes: diagonal, tri-diagonal inferior e tri-diagonal superior da matriz A, respectivamente. Este sistema é então solucionado para determinação das características das células no passo k+1.

\subsubsection{Modelagem Analítica da Turbulência}

O escoamento em torno de um corpo apresenta variações de suas características entre suas linhas de corrente. Estas variações podem ser expressas em termos de valores médios e suas flutuações durante um intervalo de tempo. Dessa forma, os termos das equações de transporte e continuidade podem ser expressos pelas Equações 3.46 e 3.47 .

$$
\begin{aligned}
& u_{i j}=\overline{u_{i j}}+u_{i j}^{\prime} ; v_{i j}=\overline{v_{i j}}+v_{i j}^{\prime} ; w_{i j}=\overline{w_{i j}}+w_{i j}^{\prime} \\
& p_{i j}=\overline{p_{i j}}+p_{i j}^{\prime}
\end{aligned}
$$


Generalizando para uma grandeza escalar qualquer: $\phi_{i j}=\overline{\phi_{i j}}+\phi_{i j}^{\prime}$

A equação de momento na direção x é exemplificada pela Equação 3.48.

$\frac{\partial \rho \overline{u_{i}}}{\partial t}+\frac{\partial\left(\rho \overline{u_{i}} \overline{u_{j}}\right)}{\partial x_{j}}=F_{x}-\frac{\partial p}{\partial x_{i}}+\frac{\partial}{\partial x_{j}}\left[\mu\left(\frac{\partial \overline{u_{i}}}{\partial x_{j}}+\frac{\partial \overline{u_{j}}}{\partial x_{i}}+\frac{2}{3} \delta_{i j} \frac{\partial u_{1}}{\partial x_{1}}\right)\right]+\frac{\partial}{\partial x_{j}}\left(-\rho \overline{u_{i}^{\prime} u_{j}^{\prime}}\right)$

A equação acima tomada nas três dimensões ortogonais representa a método de solução denominado RANS (Reynolds Averaged Navier-Stokes).

A componente $-\rho \overline{u_{i}^{\prime} u_{j}^{\prime}}$ simboliza as flutuações da velocidade em x, neste caso, e é conhecida como Tensões de Reynolds.

\subsubsection{Modelo de turbulência SST K- $\omega$}

Ao se representar as grandezas das equações de Navier-Stokes por valores médios e flutuações novas variáveis são inseridas neste sistema algébrico. É preciso então obter novas relações para estas grandezas. Para suprir esta necessidade alguns modelos de turbulência empíricos foram criados.

Um exemplo desses modelos são as equações de transporte SST k- $\omega$. Estas equações modelam a energia cinética turbulenta $(\mathrm{k})$ e a taxa de dissipação de energia específica $(\omega)$. Esta modelagem possui as características do modelo padrão k- $\omega$ para representação da turbulência a baixos Reynolds, em geral em regiões perto das paredes, e do modelo k- $\varepsilon$ para regiões longe das paredes. Nas regiões de transição entre estes dois modelos utiliza-se um vetor de interpolação. Estas características conferem robustez e acuracidade a este método perante escoamentos turbulentos.

As equações que o descrevem estão enunciadas nas Equações 3.49 e 3.50 .

$$
\begin{aligned}
& \frac{\partial}{\partial t}(\rho k)+\frac{\partial}{\partial x_{i}}\left(\rho \omega u_{i}\right)=\frac{\partial}{\partial x_{j}}\left(\Gamma_{k} \frac{\partial k}{\partial x_{j}}\right)+\tilde{G}_{k}-Y_{k}+S_{k} \\
& \frac{\partial}{\partial t}(\rho \omega)+\frac{\partial}{\partial x_{i}}\left(\rho \omega u_{i}\right)=\frac{\partial}{\partial x_{j}}\left(\Gamma_{\omega} \frac{\partial \omega}{\partial x_{j}}\right)+G_{\omega}-Y_{\omega}+D_{\omega}+S_{\omega}
\end{aligned}
$$

Nas quais,

$\tilde{G}_{k}:$ geração de energia cinética de turbulência

$G_{\omega}:$ geração de $\omega$

$\Gamma_{\omega}$ e $\Gamma_{k}$ : difusividade de $\mathrm{ke} \omega$ 
$Y_{k}$ e $Y_{\omega}:$ dissipação de k e $\omega$

$D_{\omega}:$ difusão

Estas novas variáveis apresentadas nas equações acima estão desenvolvidas e melhor explicadas no Apêndice A deste trabalho.

Para solução destas equações desenvolvidas no método SST k- $\omega$, é necessário adotar valores empíricos para as seguintes variáveis:

$$
\begin{aligned}
& \sigma_{\mathrm{k}, 1}=1,176 ; \sigma_{\omega, 1}=2,0 ; \sigma_{\mathrm{k}, 2}=1,0 ; \sigma_{\omega, 2}=1,168 ; \\
& \mathrm{a}_{1}=0,31 ; \beta_{\mathrm{i}, 1}=0,075 ; \beta_{\mathrm{i}, 2}=0,0828
\end{aligned}
$$




\section{Capítulo 4}

\section{Metodologia}

Conforme apresentado nos parágrafos anteriores o arrasto veicular é composto em grande parte pelo arrasto de pressão. Este tipo de arrasto tem sua origem no desprendimento de vórtices na esteira do veículo. Uma das maneiras de se reduzir este esforço é trabalhar a geometria traseira do veículo, de forma a se manter o escoamento colado à superfície do mesmo e, então, obter uma esteira mais afilada.

No presente trabalho é apresentado um método de redução de arrasto, através da imposição de um ângulo de convergência para superfície superior traseira de um protótipo veicular. Este pode ser considerado um método clássico na aerodinâmica veicular e bastante explorado nas primeiras etapas de projeto aerodinâmico dos automóveis comerciais.

Utilizando um modelo geométrico proposto pela Sociedade dos Engenheiros Automotivos, foram analisados parâmetros aerodinâmicos não somente referentes ao arrasto, mas também a estabilidade veicular, relacionados à sustentação, momento de guinada, momento de arfagem e força lateral.

\subsection{Geometria Analisada}

No estudo utilizou-se uma geometria de referência conhecida como Modelo SAE. Essa geometria foi proposta por uma comissão de profissionais renomados, que possuem trabalhos reconhecidos dentro da ciência aerodinâmica voltada a estudos do comportamento de veículos, e reportados no relatório técnico Aerodynamic Testing of Road Vehicles in Open Jet Wind Tunnels, SAEJ2071.

A utilização de modelos de referência de formatos básicos, em estudos aerodinâmicos, é uma técnica bastante difundida na aerodinâmica veicular. A simplicidade dos modelos, o fácil arranjo, a facilidade em se construir réplicas em modelos físicos e computacionais, o grande volume de trabalhos científicos feitos acerca destes modelos e a praticidade em modificar estas geometrias são os fatores que promovem esta grande aceitação.

O modelo estudado neste trabalho pode ser considerado relativamente novo, quando comparado a modelos clássicos como de Ahmed, Rover e Davis, uma vez que estes 
foram propostos por volta dos anos 80 e o modelo SAE foi publicado em uma revisão do artigo citado acima no ano de 1997.

É possível constatar similaridades entre o Modelo SAE e seus antecessores no que diz respeito a: diferentes configurações para a geometria traseira do modelo, com diversos ângulos de convergência; a presença de vértices arredondados de forma a garantir a não separação da camada limite nestas regiões; e proporções geométricas semelhantes. Estas similaridades se justificam pelo fato destes modelos representarem veículos de produção de pequeno porte no padrão europeu.

Há atualmente uma tendência de mercado, considerando o continente europeu e sul-americano, para o aumento nas vendas de veículos do tipo hatchback. Esta é a principal razão do uso desse modelo para análise no presente trabalho.

As principais características do Modelo SAE estão listadas e mostradas na Figura 19.

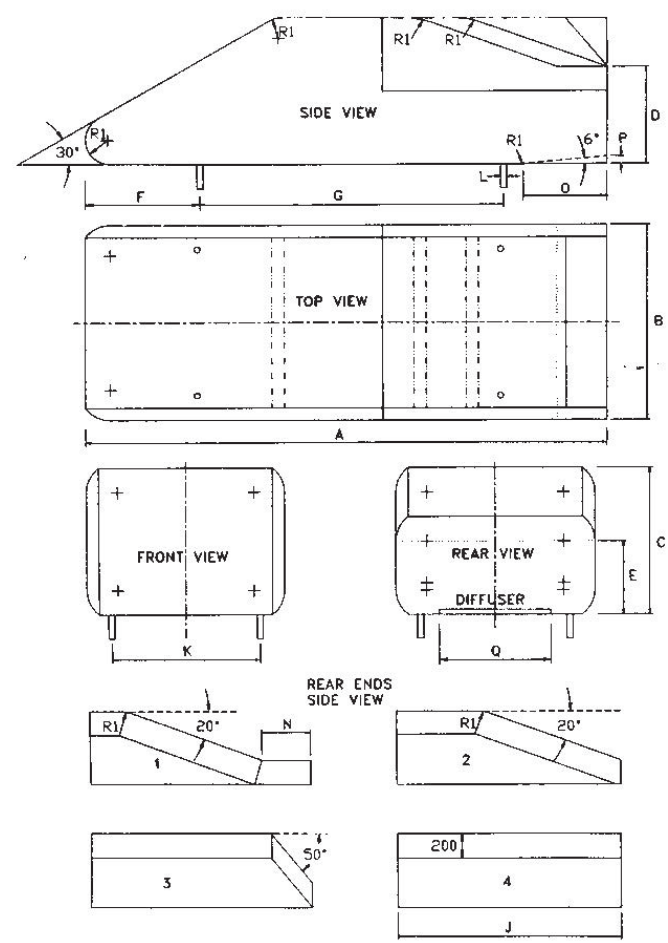

\begin{tabular}{|c|c|c|c|c|c|c|c|c|}
\hline & \multirow[t]{2}{*}{ MODEL DIMENSION } & \multicolumn{7}{|c|}{ MODEL SCALE } \\
\hline & & $1,2: 1$ & $1: 1$ & $1: 1,414$ & $1: 2$ & $1: 3$ & $1: 4$ & $1: 5$ \\
\hline & Overall length & 5040 & 4200 & 2970 & 2100 & 1400 & 1050 & 840 \\
\hline & Overall width & 1920 & 1600 & 1131 & 800 & 533 & 400 & 320 \\
\hline c: & Body Height & 1440 & 1200 & 849 & 600 & 400 & 300 & 240 \\
\hline 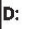 & Reor Deck Helght & 960 & 800 & 566 & 400 & 267 & 200 & 160 \\
\hline & Split Line Height & 720 & 600 & 424 & 300 & 200 & 150 & 120 \\
\hline . & Front Overhang & 1110 & 925 & 654 & 462.5 & 308 & 231 & 185 \\
\hline G: & Wheelbase & 2940 & 2450 & 1732 & 1225 & 817 & 613 & 490 \\
\hline H: & Ground Cleareance & 240 & 200 & 141 & 100 & 67 & 50 & 40 \\
\hline J: & SpHit Line from Rear & 2160 & 1800 & 1273 & 900 & 600 & 450 & 360 \\
\hline : & Irack & 1500 & 1250 & 884 & 625 & 417 & 313 & 250 \\
\hline 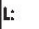 & Leg Diamefer & 60 & 50 & 35 & 25 & 17 & 13 & 10 \\
\hline $\mathrm{N}:$ & Rear Deck Lengin & 480 & 400 & 283 & 200 & 133 & 100 & 80 \\
\hline o: & Rear Diffuser length & 756 & 630 & 445 & 315 & 210 & 158 & 126 \\
\hline P: & Rear Difuser Helght & 78 & 65 & 46 & 32.5 & 22 & 16 & 13 \\
\hline Q: & Rear Dwfinser Width & 1080 & 900 & 636 & 450 & 300 & 225 & 180 \\
\hline R1: & Radlus of Cross Edges & 240 & 200 & 141 & 100 & 67 & 50 & 40 \\
\hline R2: & Rodius of Side Edges & 300 & 250 & 177 & 125 & 83 & 63 & 50 \\
\hline 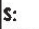 & frontal Area (w/o legs) & 2.730 & 1.896 & 0.948 & 0.474 & 0.211 & 0.118 & 0.076 \\
\hline
\end{tabular}
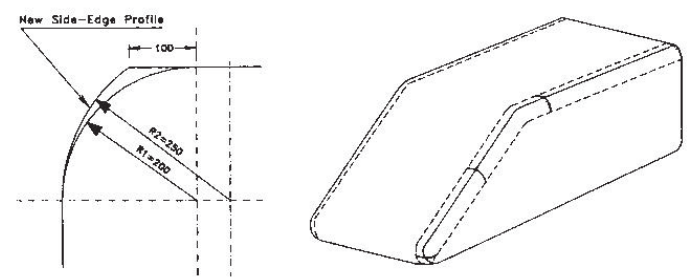

FIGURA 19: Especificações das medidas propostas para o Modelo SAE. FONTE: SAE Paper 2004-01-1308.

O modelo SAE utilizado para análise está em escala 1:4, visto que, nessa proporção é possível manter um número de Reynolds próximo tanto no estudo em escala, quanto em condições reais. Dessa forma, garante-se que as zonas de separação no modelo 
estudado representem este mesmo efeito no modelo em tamanho real. Seguindo estas especificações, o seguinte modelo computacional foi criado e pode ser visualizado através da Figura 20 a e b.

a)

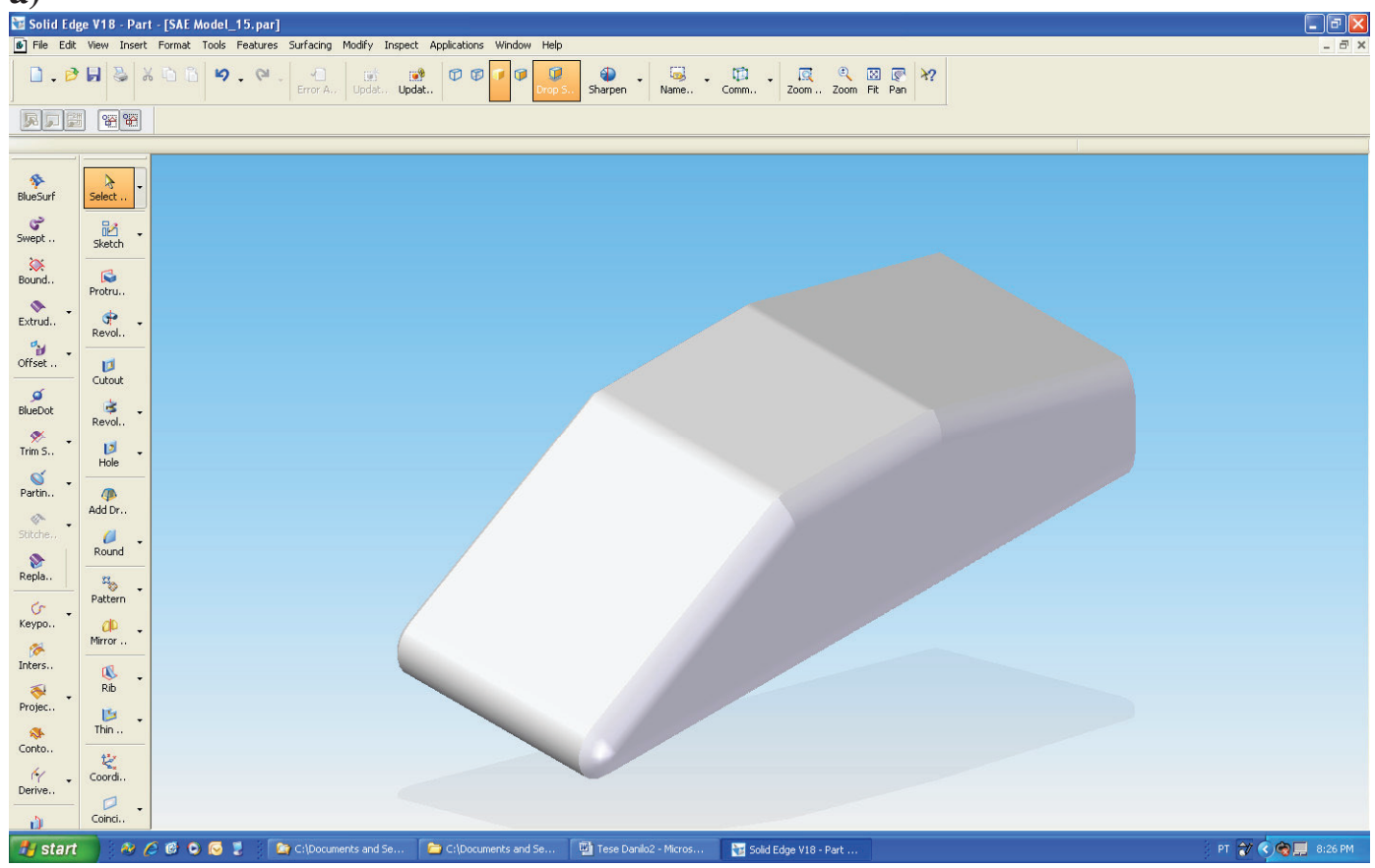

b)

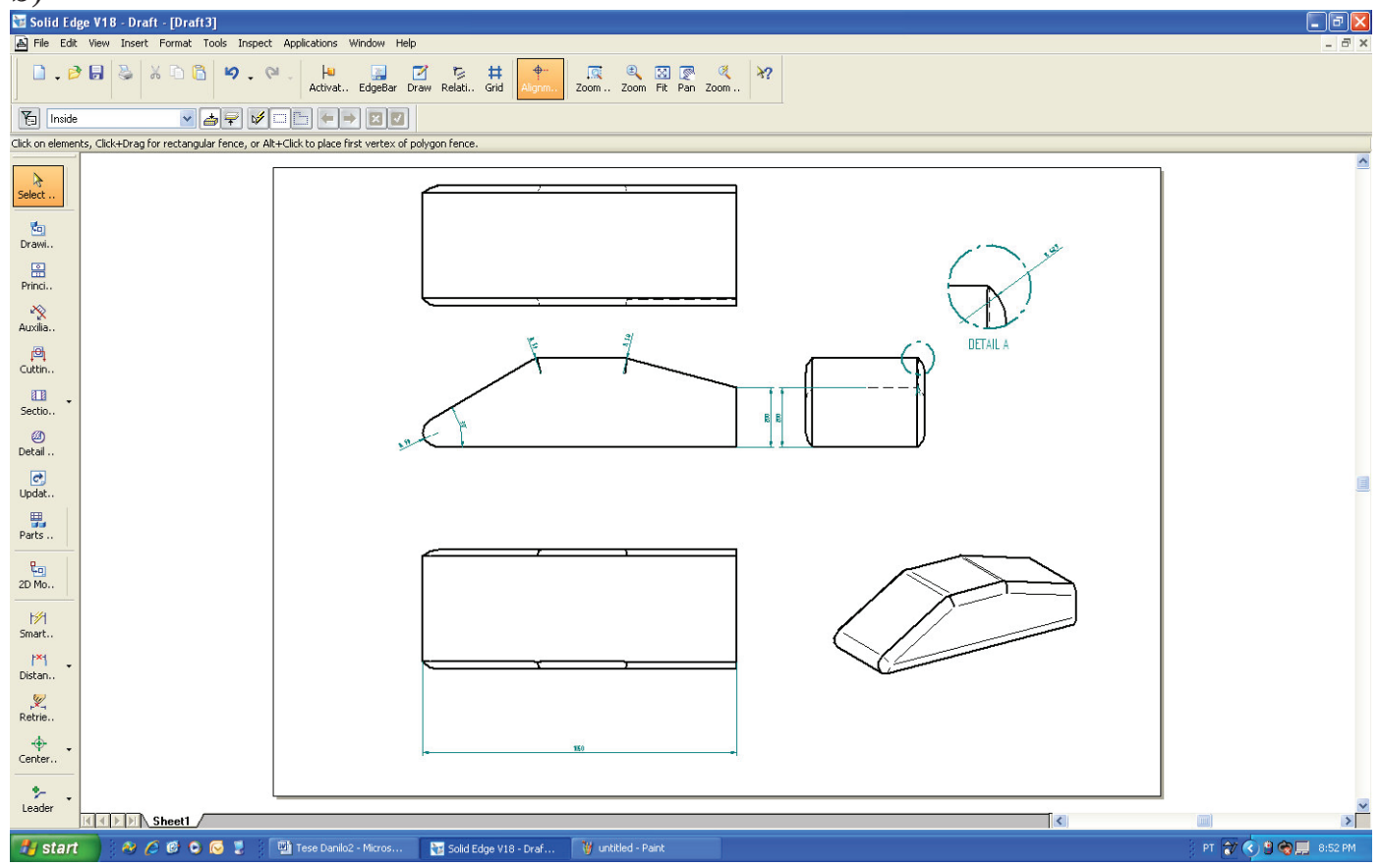

FIGURA 20: Réplica computacional do Modelo SAE em escala 1:4, considerando-se um ângulo de convergência de $15^{\circ}$. a) Modelo Tri-dimensional; b) Modelo Uni-dimensional. FONTE: Solid Edge v.18. 
Os modelos utilizados nas análises possuem algumas peculiaridades em relação ao Modelo SAE proposto em SAEJ2071. Optou-se por não se utilizar os quatro suportes inferiores a fim de melhorar a praticidade durante as simulações; e os ângulos de convergência adotados a partir da superfície superior do modelo foram $0^{\circ}, 10^{\circ}, 15^{\circ}, 20^{\circ}, 25^{\circ}$, $35^{\circ}$, como verificado na Tabela 2.

TABELA 2: Modelo SAE aplicado ao estudo sobre os ângulos de convergência.

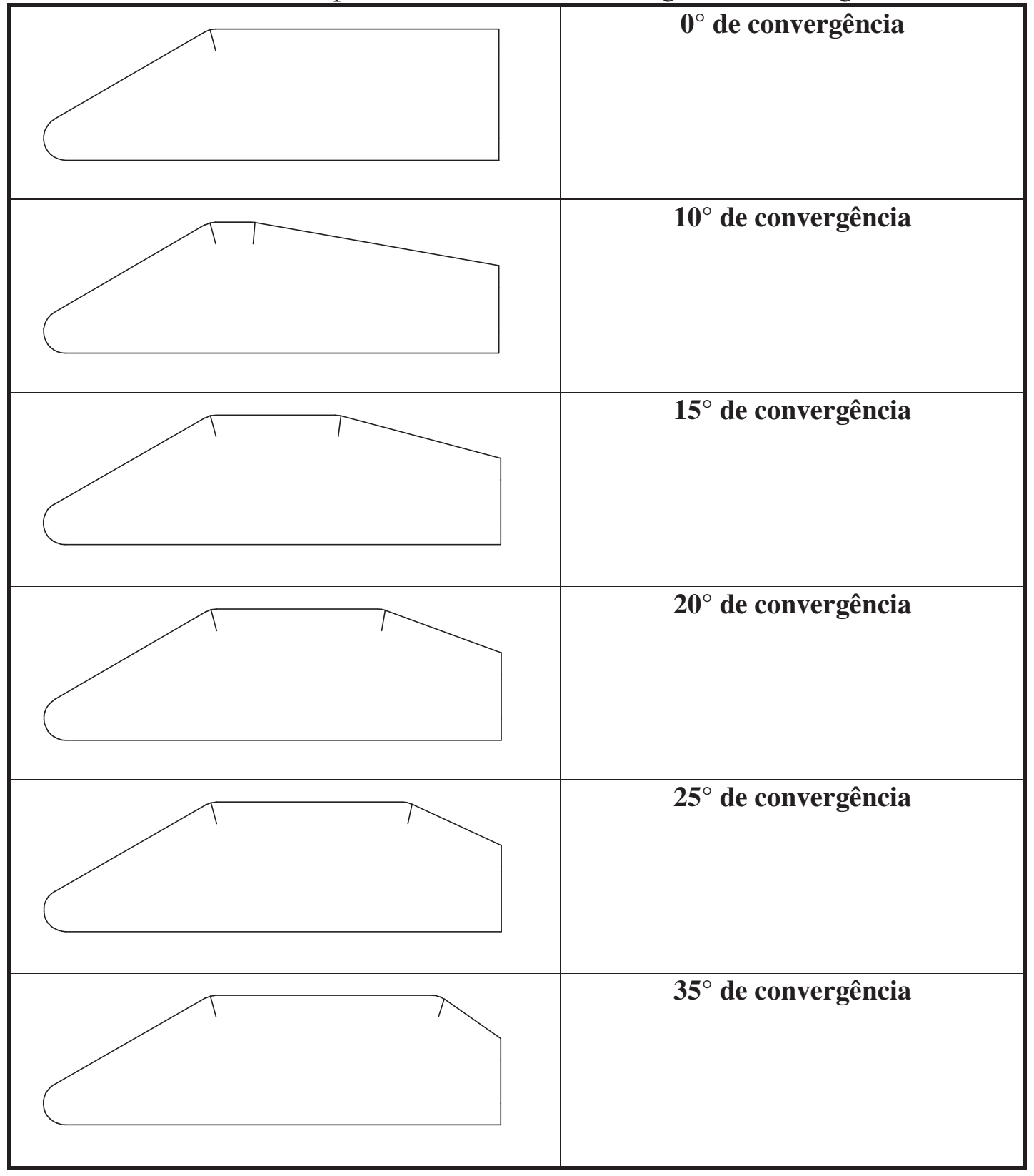

Estes ângulos correspondem a valores explorados em estudos acerca dos Modelos de Ahmed, e Rover (AHMED, 1979; HUCHO et al, 1976; HOWELL, 2005), objetivando o 
aumento do acervo bibliográfico sobre a caracterização dos modelos de referência na aerodinâmica veicular.

\section{2 Ângulos de Divergência}

Observando a seqüência de análises apresentada na Tabela 2, é possível prever que o aumento no ângulo de convergência da superfície superior na região traseira do modelo, tende a proporcionar um aumento na sustentação, principalmente sobre o eixo traseiro.

Com intuito de se manter a estabilidade veicular, obtendo-se valores de sustentação e momento de arfagem semelhantes àqueles da geometria inicial, fez-se uso da adoção de geometrias para o assoalho baseadas no Efeito Venturi, discutido no Parágrafo 3.3.2.

Analisou-se a adoção de ângulos de divergência na superfície inferior do veículo com valores de $6^{\circ}$ e $10^{\circ}$. O caso em que foi utilizado um ângulo de divergência de $6^{\circ}$ pode ser observado na Figura 21.

Pretendeu-se comprovar que a manutenção da estabilidade veicular é conferida pela diminuição da sustentação, ao se adotar ângulos de divergência, juntamente com o melhor ângulo de convergência, que promovesse o menor arrasto veicular.

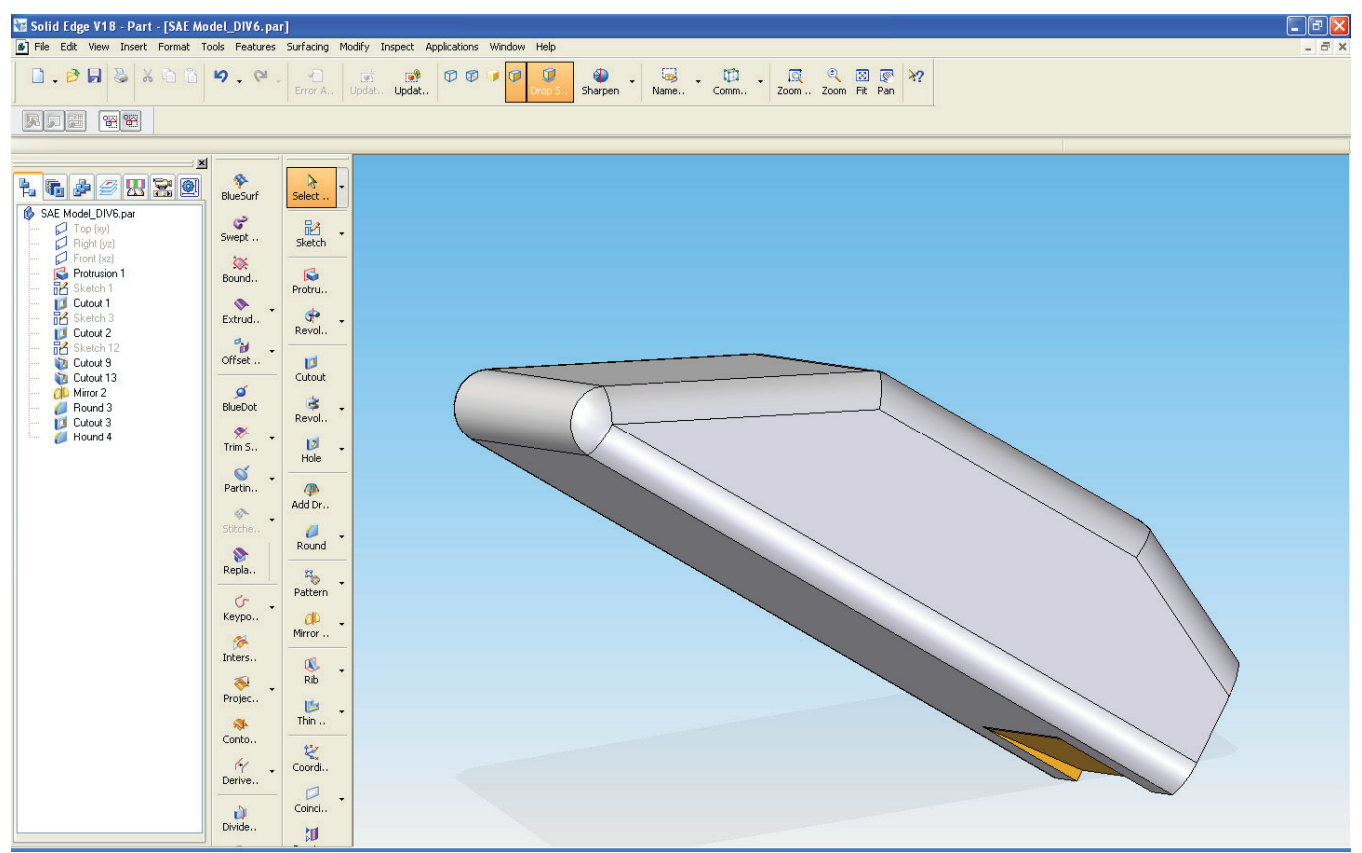

FIGURA 21: Réplica computacional do Modelo SAE em escala 1:4. Visualização do ângulo de divergência adotado a fim de impor melhorias na estabilidade direcional.

FONTE: Software de desenho técnico computacional Solid-Edge v18. 


\subsection{Influência de Ângulos de Guinada sobre o escoamento do modelo}

\subsection{1 Ângulo de Guinada}

Uma vez constatado o efeito benéfico da adoção de um ângulo de divergência, contrapondo a sustentação gerada pelo ângulo de convergência, era preciso avaliar se a estabilidade era mantida ao submeter o modelo a um escoamento assimétrico. Alterações na estabilidade seriam constatadas rotacionando a geometria em torno do eixo y, ao promover o surgimento de um ângulo de yaw entre o protótipo e o escoamento. Sendo o escoamento não mais paralelo ao eixo longitudinal, esperava-se o surgimento de uma força lateral e um momento em torno do eixo vertical, conhecido como Momento de Yaw.

Além de influenciar diretamente a estabilidade veicular, a existência de um ângulo entre o escoamento e o eixo longitudinal tende a alterar os valores dos coeficientes aerodinâmicos até então obtidos para um escoamento simétrico. O arrasto, por exemplo, apresenta uma tendência a aumentar de maneira linear e proporcional ao ângulo de guinada, se esse assume valores pequenos.

Um método para se determinar valores razoáveis para o ângulo de guinada consiste no somatório vetorial dos vetores velocidade do veículo e do vento. O ângulo entre a velocidade resultante e a velocidade do veículo seria o valor procurado. Para uma velocidade de $40 \mathrm{~m} / \mathrm{s}$ para o veículo e tomando um valor máximo de $50 \mathrm{~km} / \mathrm{h}$ para ventos laterais incidindo de forma perpenticular a velocidade do modelo obtida, corresponde a um valor $\Psi=$ $19,149^{\circ}$. Portanto, para a avaliação dos efeitos da assimetria sobre o arrasto e a estabilidade veicular é razoável a adoção de ângulos entre $0^{\circ}$ e $21^{\circ}$. Neste experimento optou-se por utilizar passos de $3^{\circ}$.

\subsection{Discretização do Modelo SAE}

Com intuito de reproduzir as condições experimentadas durante um ensaio de túnel de vento real, o Modelo SAE foi posicionado dentro de um volume de controle, o qual apresentava dimensões semelhantes a uma seção de teste real, segundo orientações contidas em SAEJ2071. Adotaram-se as seguintes medidas para o volume gerado:

- Razão de bloqueio = 0,05

- A proporcionalidade de medida entre a largura e altura do modelo foi mantida para geração do túnel virtual. Neste caso aproximadamente 1,333. 
- O modelo foi posicionado dentro do volume de forma a se guardar uma distância de duas de vezes o seu comprimento para a região anterior e quatro vezes esta medida para a região de esteira do modelo.

Obtiveram-se as seguintes características para a seção de teste, como verificado na Tabela 3.

TABELA 3: Dimensionais da seção de testes virtual utilizada na simulação computacional.

\begin{tabular}{|l|c|c|}
\hline Dimensionais do experimento: & Valor & Unidade de medida \\
\hline Altura do Protótipo & 0,300 & $\mathrm{~m}$ \\
\hline Largura do Protótipo & 0,400 & $\mathrm{~m}$ \\
\hline Razão de Aspecto do Protótipo & 1,333 & n.a. \\
\hline Razão de Bloqueio & 0,050 & n.a. \\
\hline Área da seção transversão do protótipo sem arredondamentos & 0,120 & $\mathrm{~m}^{2}$ \\
\hline Área da seção transversão do protótipo com arredondamentos & 0,118 & $\mathrm{~m}^{2}$ \\
\hline Área da seção transversal do túnel sem considerar os arredondamentos & 2,400 & $\mathrm{~m}^{2}$ \\
\hline Área da seção transversal do túnel considerando os arredondamentos & 2,370 & $\mathrm{~m}^{2}$ \\
\hline Área considerada do túnel & 2,370 & $\mathrm{~m}^{2}$ \\
\hline Altura do Túnel & 1,333 & $\mathrm{~m}$ \\
\hline Largura do Túnel & 1,778 & $\mathrm{~m}$ \\
\hline Razão de Aspecto do Túnel & 1,333 & n.a. \\
\hline
\end{tabular}

O volume gerado, mostrado na Figura 22, foi discretizado de forma que o volume do Modelo SAE foi excluso do volume interno ao paralelepípedo que compõe o túnel de vento virtual. Esta estratégia é usual em análises computacionais quando se pretende analisar somente o escoamento externo ao veículo desconsiderando o fluxo no compartimento do motor. 


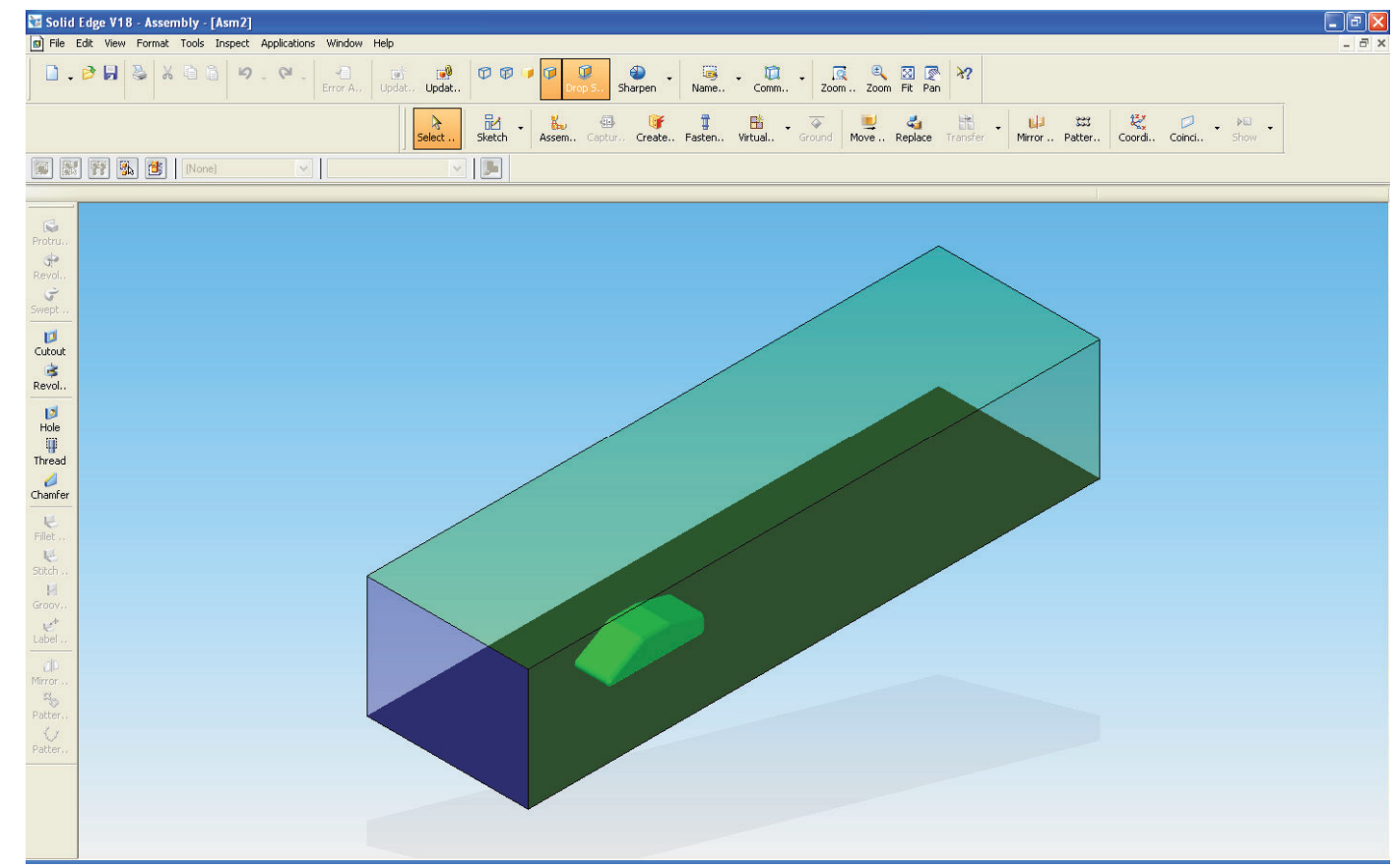

FIGURA 22: Réplica computacional do Modelo SAE em escala 1:4. Ilustração do Modelo SAE posicionado no interior do túnel de vento virtual.

FONTE: Software de desenho técnico computacional Solid-Edge v18.

Para a confecção da malha, optou-se por adotar uma malha triangular nas superfícies do túnel e do modelo, além de células tetraédricas para a malha volumétrica. Esta escolha se deve a maior praticidade, que este tipo de malha oferece para realizar seu refino localmente, utilizando o software de geração de malha Meshing, também oferecido pela Ansys, juntamente com o Fluent.

A malha mais refinada foi aplicada em regiões onde há grandes variações das propriedades físicas do escoamento, como regiões turbulentas e de fluxo confinado entre paredes próximas. Este refino favorece a convergência da simulação e sua precisão.

O refinamento referido segue, neste caso, condições para as dimensões de suas células, as quais são estabelecidas no modelo de turbulência adotado e que estão explicitadas no Apêndice A. Tomando como exemplo o primeiro caso analisado, as dimensões máximas para o túnel virtual eram iguais a $80 \mathrm{~mm}$ e, para o Modelo SAE, $12 \mathrm{~mm}$.

Este refino pode ser constatado nas Figuras 23 e 24 em toda a superfície do modelo e na superfície inferior do túnel em torno da geometria em análise. 


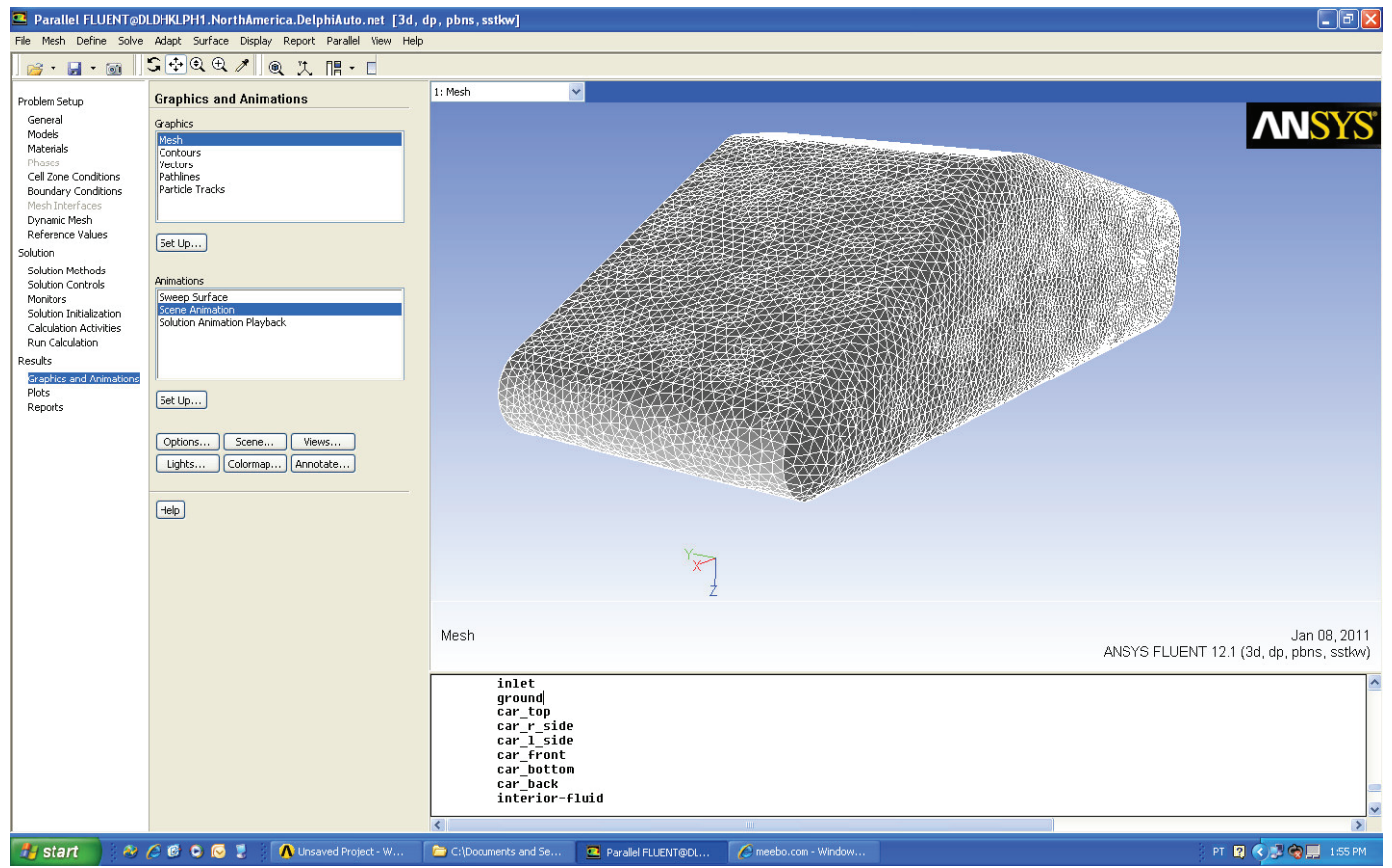

FIGURA 23: Malha bi-dimensional triangular aplicada na superfície do Modelo SAE. FONTE: ANSYS Fluent v12.1

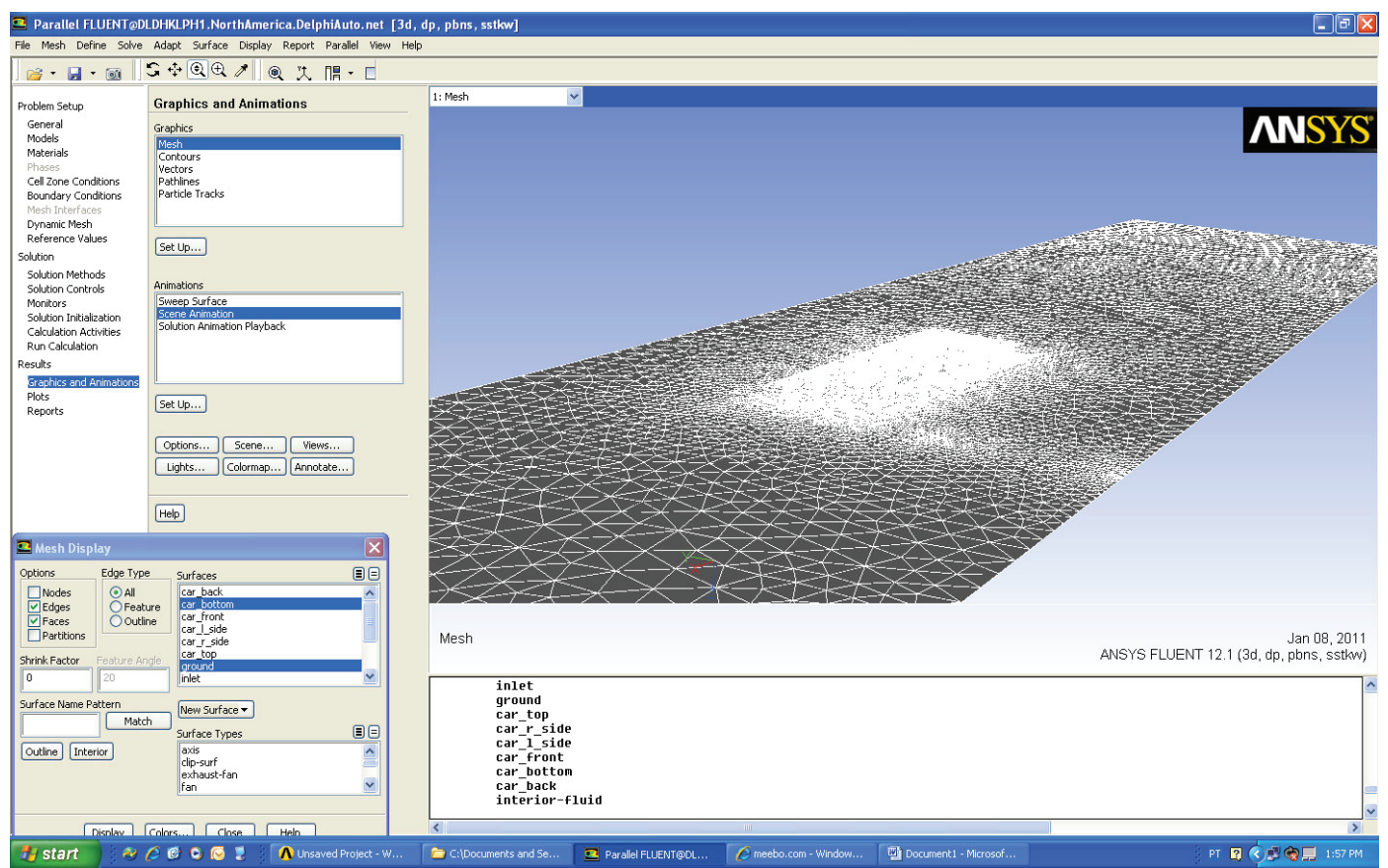

FIGURA 24: Malha bi-dimensional triangular aplicada na superfície inferior do túnel de vento virtual. Detalhe do refinamento imposto na região localizada sob o Modelo. FONTE: ANSYS Fluent v12.1

Para garantir que a malha criada seja considerada de boa qualidade, esta foi criada seguindo o principio de Delaunay (ANSYS FLUENT 12.0/12.1 Documentation Files, Theory Guide), o qual impõe a condição para o caso bi-dimensional, que: para cada uma das 
células superficiais triangulares do domínio, deve existir um círculo que a circunscreve. No caso tri-dimensional este princípio se aplica ao estabelecer que cada célula tetraédrica deva estar inscrita em uma esfera.

Este princípio visa estabelecer geometrias o mais próximo possível de figuras geométricas isométricas, de forma que a solução iterativa seja conduzida sobre deslocamentos iguais ou semelhantes, em uma malha uniforme, tornando, desse modo, este processo iterativo mais estável.

No Apêndice B, estão apresentadas as características pertencentes à malha gerada para a geometria padrão, aquela que não apresenta convergência e divergência, primeira linha da Tabela 2 deste material. Nota-se que a malha foi formada por 2,1 milhões de células e 4,7 milhões de faces entre as mesmas. Uma quantidade de células superior à apresentada por Huminic e Huminic (2008) em uma simulação computacional sob condições semelhantes (regime permanente, método de solução RANS e modelo de turbulência k- $\omega$ ), onde foi ensaiada uma geometria de um carro de competição, logo mais com complexa..

\subsection{Simulação Computacional}

Uma vez criada a malha, é preciso configurar o Fluent, estabelecendo as condições do experimento, a fim de garantir a convergência da simulação. É preciso caracterizar o fluido, as condições iniciais e as condições de contorno, além de especificar o método de solução e modelo de turbulência utilizados.

Para o experimento, citado nos parágrafos anteriores, optou-se por utilizar o método de correção pressure-based, indicado para escoamentos com baixo número de Reynolds, a simulação tri-dimensional com dupla precisão. A dupla precisão é necessária devido ao elevado grau de turbulência existente na esteira do modelo utilizado. (Fluent 12.0 User's Guide).

$\mathrm{Na}$ simulação deste experimento, optou-se pela análise do escoamento completamente desenvolvido, de forma que os efeitos transientes fossem desconsiderados, por esta razão, o regime de solução permanente foi escolhido e o método RANS aplicado.

As demais configurações podem ser vistas na Tabela 4, tais como: fatores de relaxação, os quais relacionam as grandezas calculadas na iteração atual àquelas estimadas no passo anterior; método de solução do domínio espacial discretizado (semi-implícito para o acoplamento pressão-velocidade, mínimos quadrados para o gradiente entre as células, e 
método explícito para as estimativas do momento e dos parâmetros do modelo de turbulência).

TABELA 4: Configuração utilizada no Fluent v12.1 para a simulação do experimento.

\begin{tabular}{|c|c|}
\hline Tipo de escoamento & Tri-dimensional \\
\hline Método de solução utilizado & N-S, Pressure-based, com dupla precisão. \\
\hline Formulação da Velocidade & Absoluta \\
\hline Regime da solução & Permanente (RANS) \\
\hline Intensidade de Turbulência & $0,5 \%$ \\
\hline Modelo de Turbulência & SST k- $\omega$ \\
\hline Composição do escoamento & $\begin{array}{l}\text { Fluido }- \text { ar (única fase): } \\
\mathrm{T}=288,15 \mathrm{~K}, \mathrm{P}=101,325 \mathrm{KPa}, \rho=1,225 \mathrm{~kg} / \mathrm{m}^{3} \text {, } \\
\mu=1.7894 * 10^{-5} \mathrm{~kg} / \mathrm{m}-\mathrm{s}, \gamma=1.4\end{array}$ \\
\hline $\begin{array}{l}\text { Métodos de solução espacial } \\
\text { (volume discretizado) }\end{array}$ & 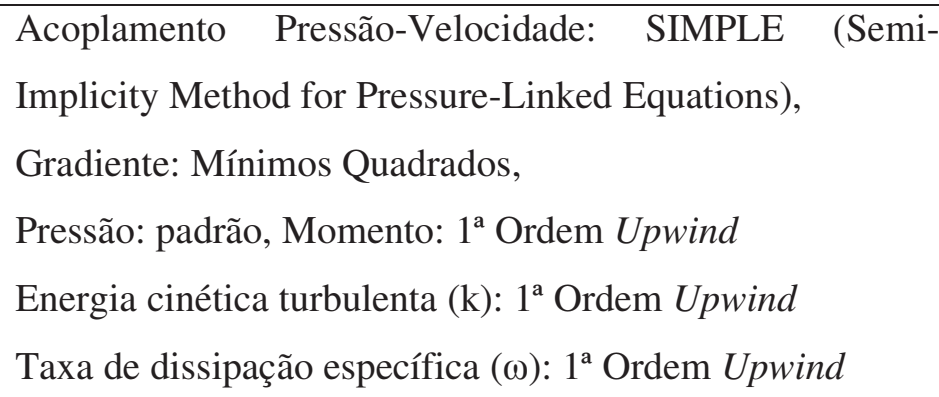 \\
\hline Fatores de Relaxação: & $\begin{array}{l}\text { Pressão: } 0,3 \\
\text { Densidade: } 1 \\
\text { Força: } 1 \\
\text { Momento: } 0.7 \\
\text { Energia cinética turbulenta (k): } 0.8 \\
\text { Taxa de dissipação específica }(\omega): 0.8 \\
\text { Viscosidade Turbulenta: } 1\end{array}$ \\
\hline Condições Iniciais & $\mathrm{Vx}=40 \mathrm{~m} / \mathrm{s}, \mathrm{Vy}=\mathrm{Vz}=0$ \\
\hline Condições de contorno & $\begin{array}{l}\text { Vparedes }=0 \mathrm{~m} / \mathrm{s}, \\
\text { Vsolo }=40 \mathrm{~m} / \mathrm{s}, \\
\text { Vsuperficie do Modelo }=0 \mathrm{~m} / \mathrm{s} . \\
\mathrm{k}_{\mathrm{o}}=0,06 \mathrm{~m}^{2} / \mathrm{s}^{2} \\
\omega_{0}=4107,5221 / \mathrm{s}\end{array}$ \\
\hline Critério de convergência & $10^{-5}$ \\
\hline
\end{tabular}




\section{Capítulo 5 \\ RESUlTAdOS E DisCUSSÕES}

\subsection{Métodos de Diminuição do Arrasto Veicular Aplicados ao Modelo} SAE

A primeira posposta deste trabalho se concentra na redução do arrasto veicular. Para isso foi utilizado um método que teve sua origem no início da década de 20, quando Jaray e Klemperer, realizaram experimentos com perfis aerofólios na proximidade do solo e começaram a difundir a idéia de que uma geometria esbelta, na sua região posterior, gerava menor arrasto.

Realizando as simulações sobre os diferentes ângulos de convergência, para a geometria traseira, os seguintes resultados podem ser visto pela Tabela 5:

TABELA 5: Resultados obtidos na simulação decorrente de diferentes ângulos de convergência utilizados no Modelo SAE.

\begin{tabular}{|c|r|c|c|c|c|c|}
\hline Ângulo de Convergência: & Sustentação & Cl & Arrasto & Cd & Momento de Arfagem & CP \\
\hline Graus & {$[\mathrm{N}]$} & n.a & {$[\mathrm{N}]$} & n.a & {$[\mathrm{Nm}]$} & \\
\hline 0 & 18.8 & 0.162 & -51.7 & -0.445 & -15.3 & -0.277 \\
\hline 10 & -6.1 & -0.052 & -38.3 & -0.330 & -17.2 & -0.443 \\
\hline 15 & -15.4 & -0.133 & -39.7 & -0.342 & -22.2 & -0.520 \\
\hline 20 & -24.0 & -0.206 & -42.4 & -0.365 & -26.3 & -0.539 \\
\hline 25 & -30.9 & -0.266 & -45.2 & -0.390 & -29.5 & -0.539 \\
\hline 35 & -37.4 & -0.322 & -47.1 & -0.406 & -33.4 & -0.556 \\
\hline
\end{tabular}

Uma importante observação deve ser feita a respeito dos sinais negativos encontrados na Tabela 5. As simulações foram conduzidas considerando as orientações dos eixos coordenados indicados pela SAE no documento SAEJ1594, Figura 14, onde os valores positivos de esforços em x estão direcionados para frente do modelo, em y para o lado direito e em z para baixo. Como o arrasto está direcionado para posição posterior do veículo, ou seja, direção contrária à orientação do eixo x, este assume valores negativos. A mesma coisa acontece com a sustentação, considerada positiva para valores negativos de $\mathrm{z}$, e o momento de arfagem, positivo no sentido de erguer a região anterior do modelo. 
Utilizando os coeficientes de arrasto da Tabela 5, é possível visualizar o seguinte gráfico:

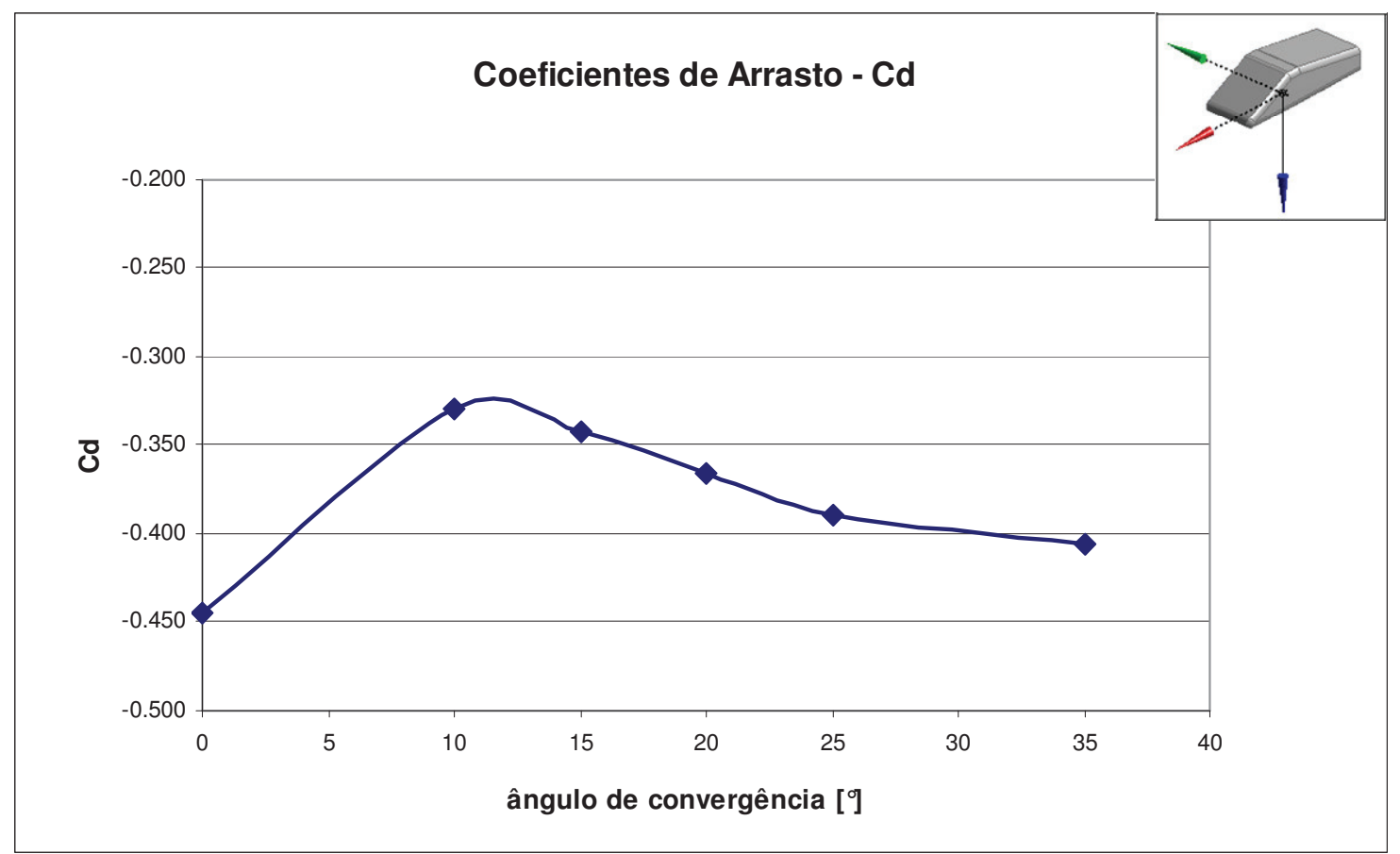

FIGURA 25: Coeficientes de arrasto gerados a partir dos dados obtidos para diferentes ângulos de convergência.

Pela Figura 25 pode-se constatar que a presença de um ângulo de convergência, favorece a redução do arrasto. Esta grandeza alcança um valor mínimo ao se adotar, dentre os casos estudados, o ângulo de $10^{\circ}$ de convergência e volta a aumentar para angulações maiores. Pelas informações do gráfico observa-se uma redução percentual máxima de aproximadamente $25 \%$ no coeficiente de arrasto do modelo inicial.

Este resultado enfatiza o fato do arrasto veicular ser influenciado prioritariamente pela geometria traseira de um modelo. Estudos como este, foram realizados anteriormente sobre os modelos de Ahmed e Rover em Hucho e Sovran (1993) e Howell (2005), respectivamente. De forma semelhante, nestes trabalhos também se obteve o menor coeficiente de arrasto, ao impor uma convergência entre $10^{\circ}$ e $15^{\circ}$, o que fortalece a argumentação que este valor possa ser generalizado e aplicado a geometrias de automóveis em produção.

No Modelo de Ahmed, segundo Hucho e Sovran (1993), constatou-se a presença de uma descontinuidade em torno de um ângulo entre $27^{\circ}$ e $32^{\circ}$. A curva de interpolação, representada no gráfico acima, pode vir a apresentar tal descontinuidade, porém seria analisar uma quantidade maior de casos, considerando ângulos de convergência mais acentuados. 
Para verificar se a adoção de ângulos de convergência na superfície superior do Modelo SAE poderia comprometer os parâmetros ligados à estabilidade veicular, foram plotados os gráficos das Figuras 26, 27 e 28, que descrevem a variação da sustentação e do momento de arfagem em função do ângulo de convergência adotado, assim como a posição do centro de pressão.

Como o escoamento incidente não possui ângulo de yaw em relação ao eixo longitudinal de Modelo, a análise deste esforço foi desconsiderada nesta etapa do trabalho, uma vez que estas grandezas tendem a ser muito próximas de zero.

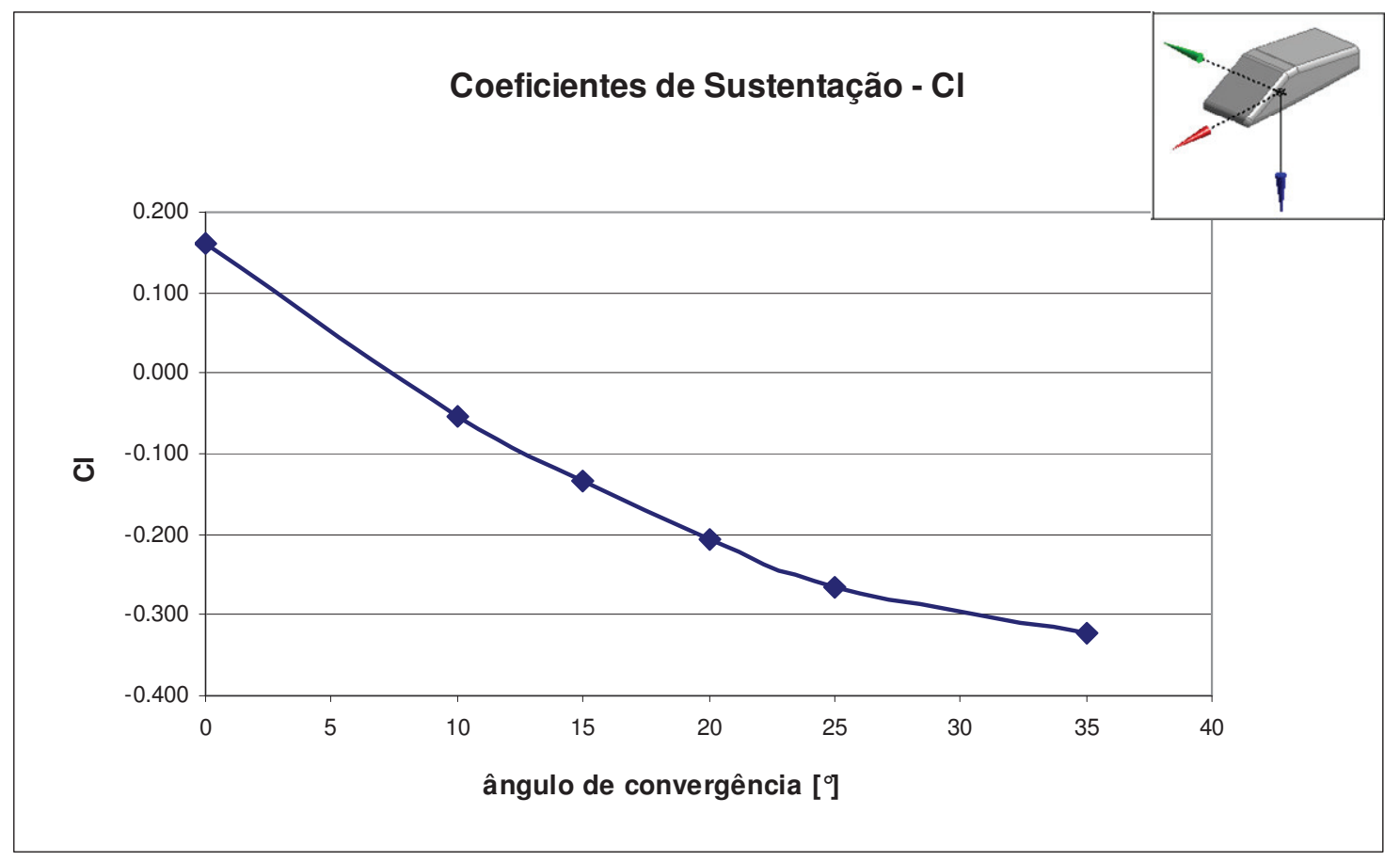

FIGURA 26: Coeficiente de Sustentação apresentado pelo Modelo SAE, para diferentes ângulos de convergência de sua superfície superior. O sinal positivo está direcionado para valores negativos do eixo $\mathrm{z}$.

Na Figura 26, constata-se que a sustentação total do modelo aumenta, à medida que ângulos mais inclinados são adotados. Novamente ressalta-se que o valor negativo corresponde ao valor de maior sustentação, uma vez que o eixo z está direcionado para baixo. Observa-se uma variação em torno de $95 \%$ no coeficiente de sustentação ao se adotar uma convergência de $35^{\circ}$.

Para ângulos maiores que $10^{\circ}$, observa-se um aumento na sustentação e no coeficiente de arrasto. Em virtude disso, pode-se concluir que tais valores de convergência, 
não se configuram como uma ferramenta, a qual impõe melhorias aerodinâmicas nos modelos rodoviários.

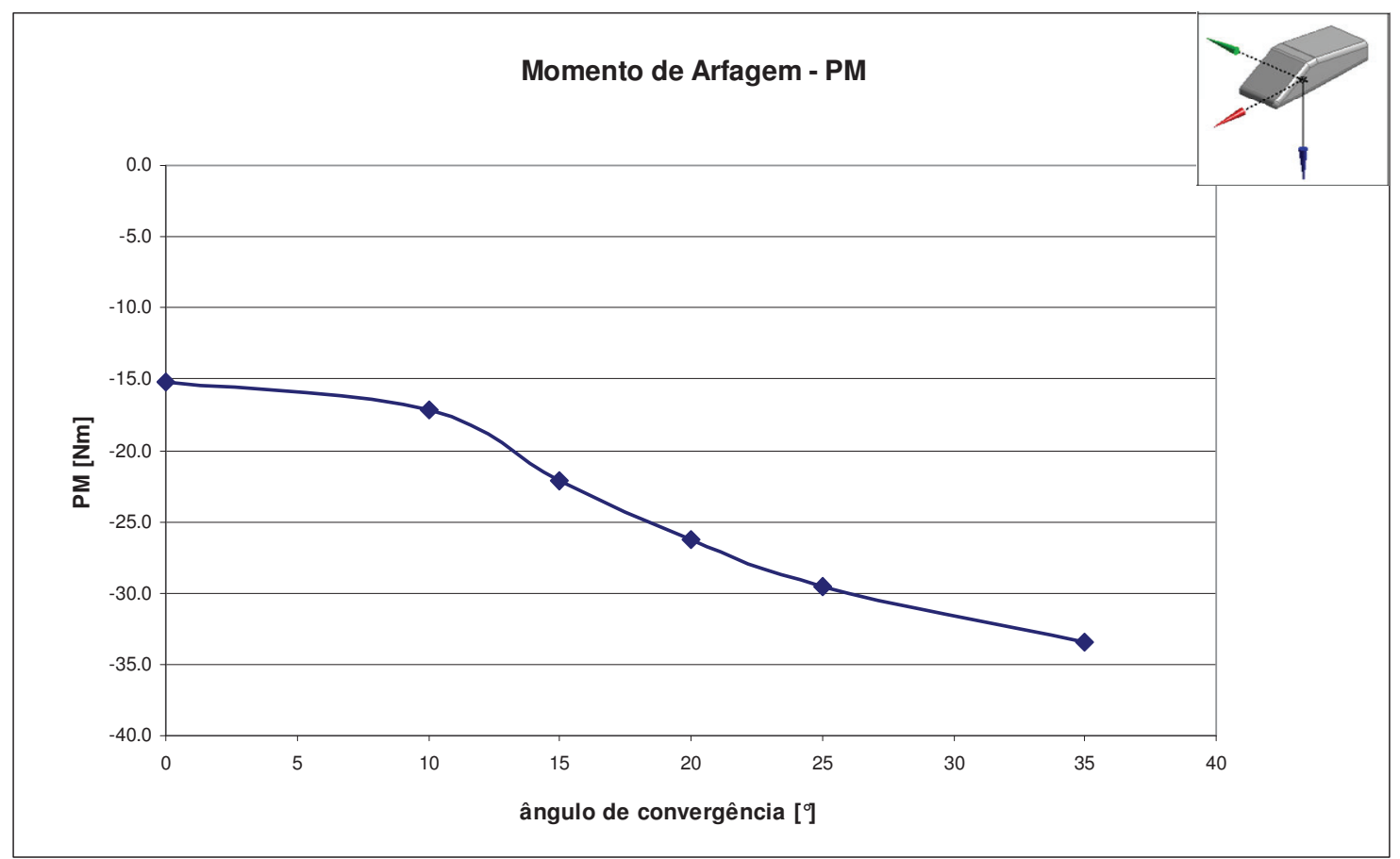

FIGURA 27: Momento de Arfagem apresentado pelo Modelo SAE, com diferentes ângulos de convergência para sua superfície superior.

Nota-se na Figura 27, a variação do Momento de Arfagem em função do ângulo de convergência. Tomando como positivo, segundo SAJ1594, o momento no sentido de suspender a região dianteira do modelo, conclui-se que com o aumento do ângulo de convergência, promove uma elevação na sustentação traseira, no sentido inverso ao eixo z, de forma considerável e superior a variação de sustentação na região dianteira, o que explica o aumento do momento de arfagem no sentido contrário ao convencionado.

O translado das zonas de baixa pressão para a região traseira do modelo fica evidente na Figura 28, gráfico que representa a distribuição de pressão ao longo de um plano longitudinal, no centro do túnel virtual, para os ângulos de $10^{\circ}$ e $35^{\circ}$ de convergência. Em tons de verde mais escuro e azul verificam-se as regiões de menor pressão. 


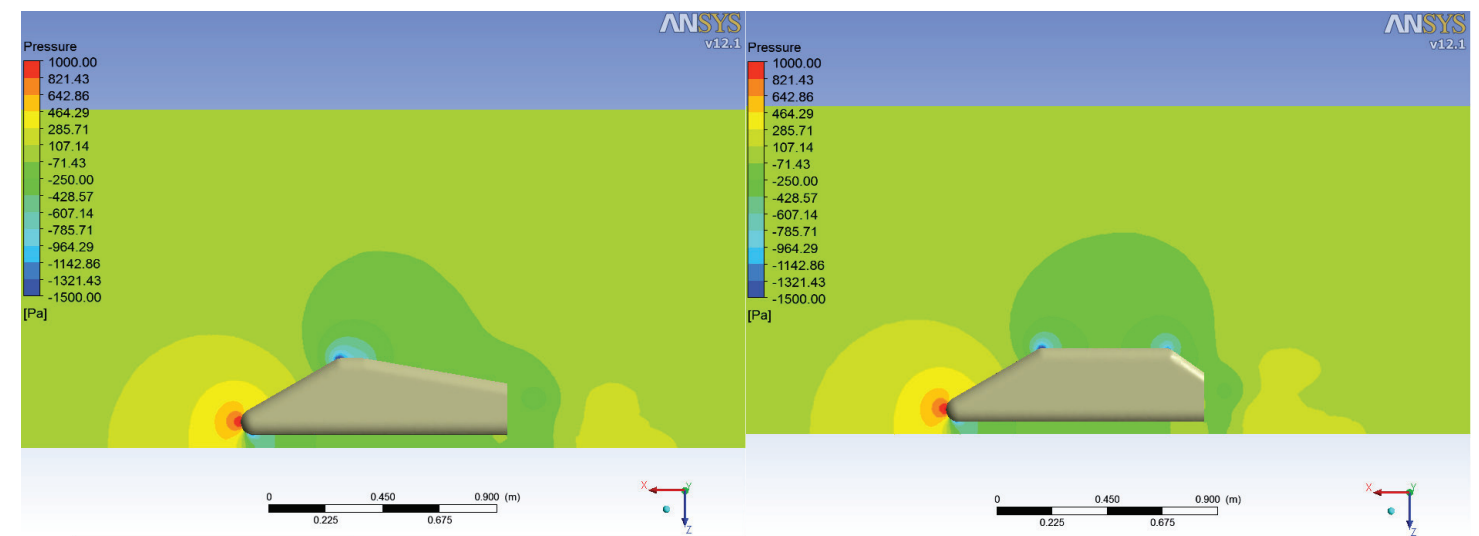

FIGURA 28: Distribuição de pressão no plano longitudinal central do túnel de vento virtual. À esquerda se situa a geometria com $10^{\circ}$ de convergência e à direita àquela com $35^{\circ}$.

O aumento da sustentação total, assim como a variação da sustentação entre os eixos onde são posicionadas as rodas do veículo, a qual é responsável por um momento de arfagem mais negativo, de fato tende a torna o modelo mais instável. Conclui-se que a adoção de geometrias convergentes, apesar de promover redução de arrasto, compromete sua estabilidade direcional. É, portanto necessário impor outras modificações geométricas, a fim de evitar que este efeito indesejável ocorra. Este assunto será abordado adiante neste trabalho.

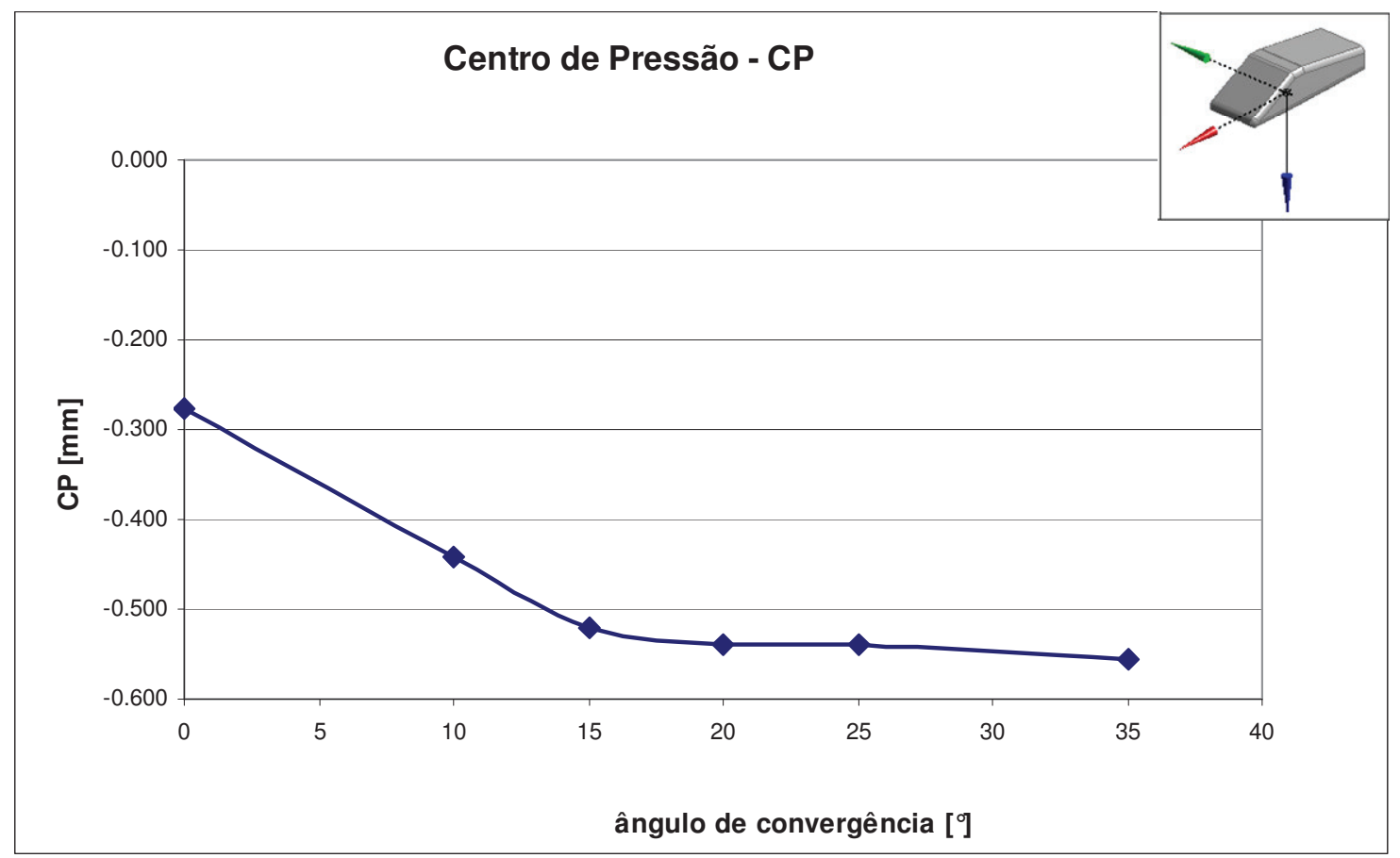

FIGURA 29: Centro de Pressão apresentado pelo Modelo SAE, para diferentes ângulos de convergência de sua superfície superior, quando submetido a um escoamento simétrico. $\mathrm{O}$ sinal negativo é referente aos valores negativos no eixo $\mathrm{x}$. 
A Figura 29, acima, demonstra a variação da posição do centro de pressão em função dos ângulos de convergência adotados. Nota-se que o aumento desse ângulo promove um deslocamento do ponto em direção à extremidade traseira do modelo. Tal comportamento evidencia, mais uma vez, a maior contribuição da região traseira do modelo para variação da sustentação e momento de arfagem, ao se impor as geometrias convergentes. Considerando a diminuição da Força Normal aplicada sobre a região de posterior do protótipo analisado, verifica-se que neste caso a translação do centro de pressão está relacionada a uma diminuição na estabilidade direcional.

Para terminar a análise dos casos, a respeito da adoção de ângulos de convergência, para um escoamento simétrico em torno do Modelo, é preciso investigar o porquê do aumento gradativo do ângulo de convergência gerar um arrasto mínimo, quando o valor desse ângulo está próximo de $10^{\circ}$, e ao continuar os incrementos neste ângulo, o valor do arrasto é deteriorado.

Ahmed (1979) observou que o arrasto de pressão era oriundo da perda de quantidade de movimento, proveniente do descolamento do escoamento na região traseira do veículo. Ele observou que neste local desprendiam-se dois pares de vórtices contra-rotativos: um longitudinal e outro transversal próximo à superfície vertical traseira. Ao ensaiar o Modelo SAE puderam-se constatar estes mesmos pares de vórtices, evidentes nas Figuras 30, 31 e 32 .

Vetores de velocidade no plano longitudinal central são utilizados, na Figura 30, para ilustrar as regiões onde a quantidade de movimento é menor. Verifica-se que a geometria sem convergência apresenta uma esteira com região de baixo momento linear maior que a geometria que apresenta $10^{\circ}$ de convergência. Esta é de fato uma evidência para o menor arrasto apresentado por esta última.

Focalizando nestes locais de baixo momento linear, Figura 31, se torna clara a ocorrência de dois vórtices contra-rotativos na região de recirculação. Vê-se que a geometria sem convergência apresenta vórtices de maior intensidade e com dimensões maiores. 


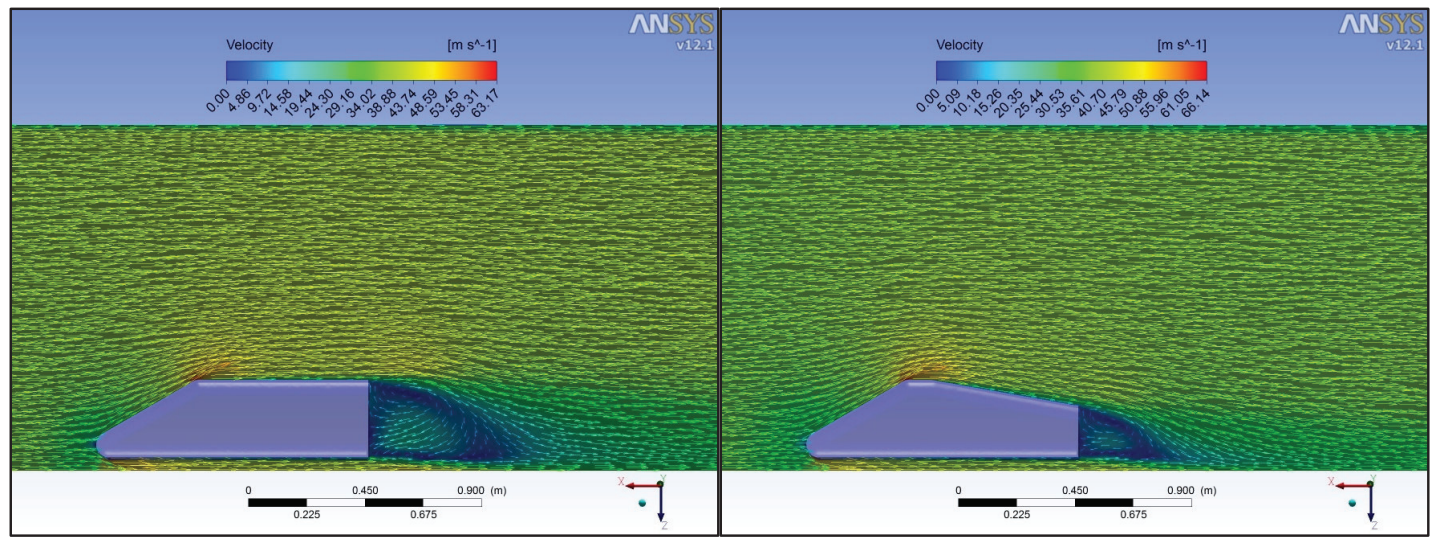

FIGURA 30: Vetores velocidade do escoamento aferido no plano de simetria longitudinal, sobre o eixo $\mathrm{x}$, a fim de avaliar qualitativamente a quantidade de movimento na esteira do modelo.

FONTE: ANSYS Fluent v12.1

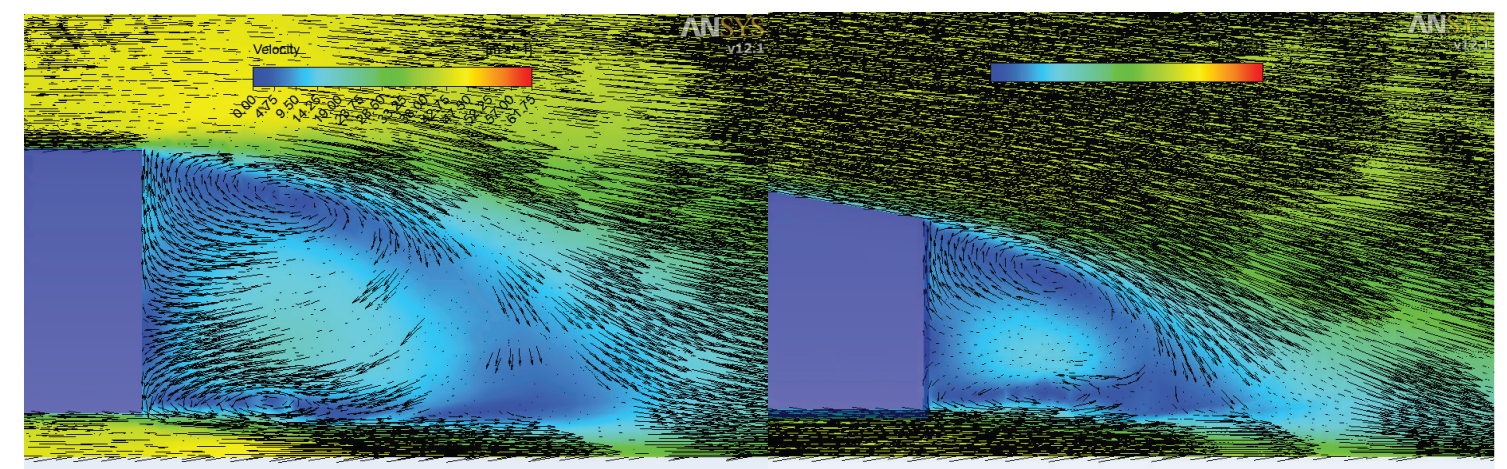

FIGURA 31: Vetores velocidade do escoamento aferido no plano de simetria longitudinal, tomados em detalhe para a visualização do par de vórtices contra-rotativos na superfície vertical traseira do modelo.

FONTE: ANSYS Fluent v12.1

Na Figura 32, estão ilustradas linhas de corrente que passam pela superfície frontal do modelo e o circulam até transcorrer sua esteira. Neste caso o ângulo de convergência adotado igual a $35^{\circ}$. Como Ahmed (1979), foi possível concluir que à medida que ângulos de convergência maiores foram adotados, a diferença entre as velocidades do fluxo que escoava nesta superfície e o que escoava na lateral do modelo, se tornou cada vez maior, de maneira a intensificar os vórtices longitudinais. Esta é uma justificativa para o aumento do arrasto ao se utilizar ângulos maiores que $10^{\circ}$ de convergência. 


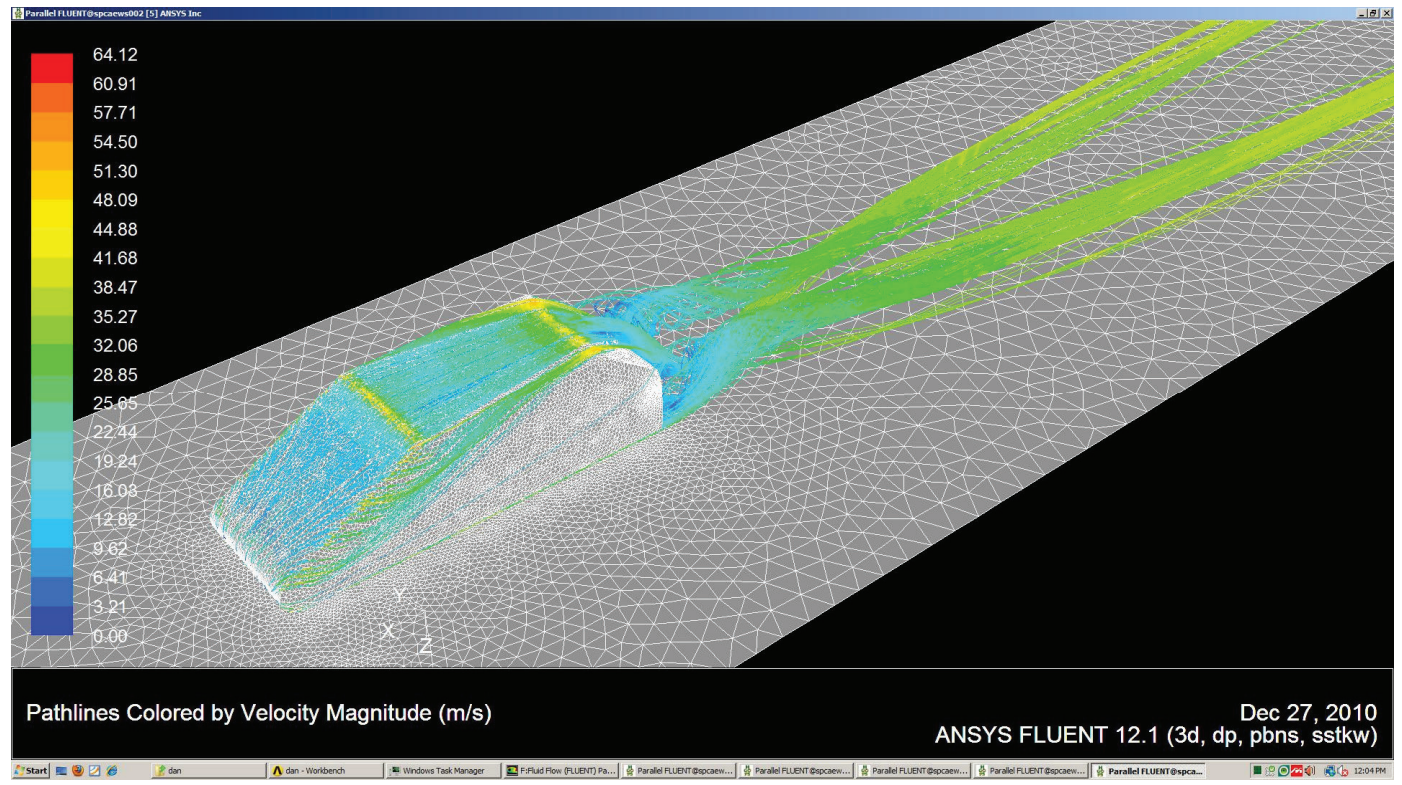

FIGURA 32: Linhas de corrente aplicadas ao caso em que o ângulo de convergência da superfície superior do Modelo tem valor igual a $35^{\circ}$. É possível constatar a ocorrência do descolamento da camada limite na seção convergente.

FONTE: ANSYS Fluent v12.1

Nota-se ainda na Figura 32 que no centro da superfície convergente, são apresentados valores mais baixos para a velocidade, em tom de azul escuro, se comparada às linhas de corrente ao seu redor. A perda da quantidade de movimento decorre da separação da camada limite, também responsável pelo aumento no arrasto de pressão.

\subsection{Manutenção da Estabilidade Veicular}

No parágrafo anterior foi visto que a adoção de geometrias convergentes é benéfica ao arrasto, se utilizados ângulos apropriados, porém promove um aumento na sustentação e no momento de arfagem, assim comprometendo a estabilidade do Modelo SAE.

Para contrapor a sustentação na região traseira deste modelo, são apresentados neste item do trabalho dois casos, em que são utilizados diferentes ângulos de divergência: o primeiro com valor de $6^{\circ}$, e segundo com $10^{\circ}$, conforme a Tabela 6 . 
TABELA 6: Características Aerodinâmicas resultantes das simulações para o ângulo de convergência da superfície superior igual a $10^{\circ}$, conjugado com ângulos de divergência da superfície inferior nos valores de $0^{\circ}, 6^{\circ}$ e $10^{\circ}$.

\begin{tabular}{|c|r|r|r|r|c|c|}
\hline \multicolumn{7}{|c|}{ Modelo SAE - Ângulo de Convergência: $\mathbf{1 0}^{\circ}$} \\
\hline Ângulo de Divergência: & Sustentação & \multicolumn{1}{c|}{ Cl } & Arrasto & Cd & Momento de Arfagem & CP \\
\hline 0 & -6.1 & -0.052 & -38.3 & -0.330 & -17.2 & -0.443 \\
\hline 6 & 16.8 & 0.144 & -35.9 & -0.309 & -11.1 & -0.281 \\
\hline 10 & 29.4 & 0.254 & -36.5 & -0.315 & -7.7 & -0.165 \\
\hline
\end{tabular}

A utilização destes ângulos difusores se baseia no Efeito Venturi, citado em capítulos anteriores. Conforme abordado no Parágrafo 3.3.2 deste trabalho, esta ferramenta se baseia na expansão gradativa da superfície inferior do modelo, por um balanço de velocidade e pressão em função da área transversal, promove uma aceleração nas linhas de corrente que se encontram confinadas sob o modelo e, por consequiência, uma menor pressão estática. A maior eficiência do ângulo de difusão, se comparada à região convergente, deve-se a sua proximidade ao solo, decorrendo o fato de que um menor ângulo de difusão é suficiente para contrapor a sustentação provida pelo ângulo convergente.

$\mathrm{O}$ uso do difusor se mostra de fato como uma ferramenta eficiente na medida em que promove uma redução na pressão não somente na região traseira, mas em uma área ampla da superfície inferior do modelo. O gráfico a seguir, Figura 33, demonstra a pressão observada nesta superfície.

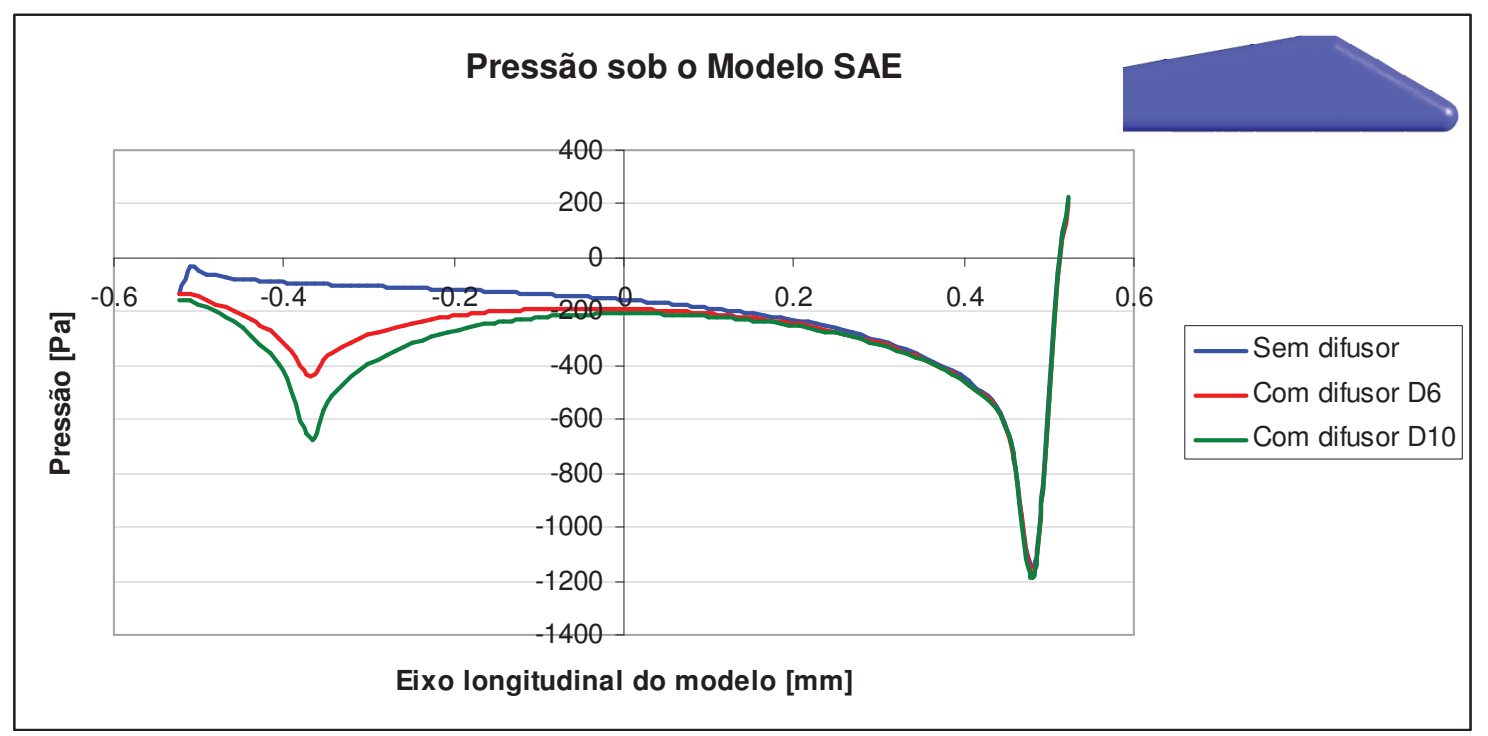

FIGURA 33: Pressão ao longo de um eixo longitudinal localizado na superfície inferior do Modelo SAE. Observa-se a área afetada pelo uso dos difusores. 
Tomando o valor de 0,162 para o coeficiente de sustentação da geometria inicial, sem convergência e divergência (Tabela 5, primeira linha), tem-se que o ângulo de convergência de $10^{\circ}$ aliado ao de divergência de $6^{\circ}$ gera $\mathrm{Cl}$ igual a $89 \%$ do valor inicial. Para uma divergência de $10^{\circ}$ esta porcentagem aumenta para $156 \%$. Fica evidente, portanto que o ângulo de difusão de $6^{\circ}$ é suficiente para gerar um coeficiente de sustentação comparável à geometria inicial, na qual suas superfícies inferior e superior são paralelas.

A geometria com divergência de $10^{\circ}$ é a que fornece menor sustentação como pode ser visto na Figura 34. Este ângulo foi citado por Katz (2006), como sendo o melhor ângulo de difusão para se adotar em geometrias automobilísticas. A indicação deste valor para veículos de corrida considera a elevada sustentação gerada e a não separação da camada limite.

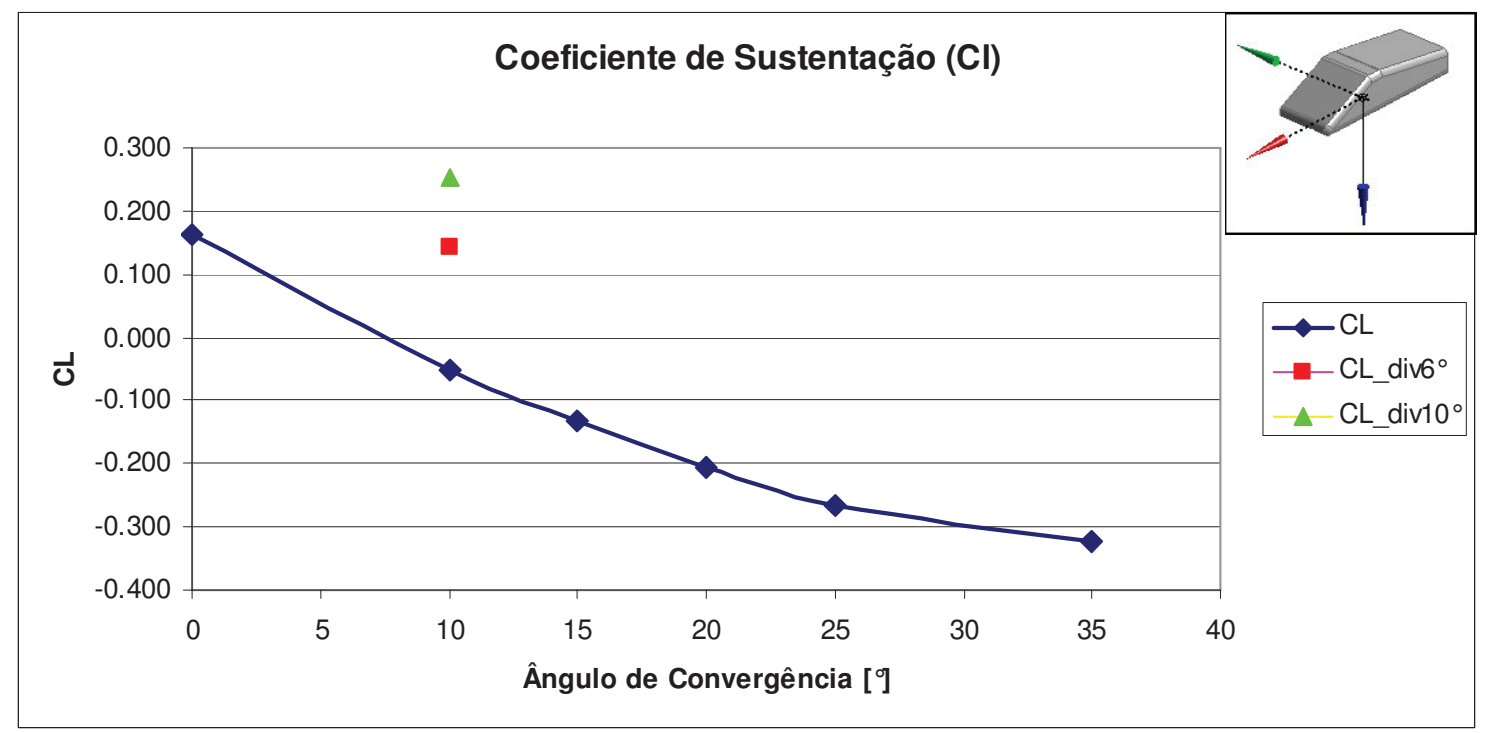

FIGURA 34: Coeficientes de Sustentação apresentados pelo Modelo SAE, para diferentes ângulos de convergência de sua superfície superior. E ainda os valores destes coeficientes na presença de um ângulo de difusão

O gráfico de momento de arfagem encontra-se disposto abaixo, Figura 35. Mais uma vez, é possível ver que a adoção do difusor trouxe uma melhoria para os parâmetros que caracterizam a estabilidade veicular. Apresentando valores melhores do que a geometria inicial. A adoção deste dispositivo de geração de downforce, em uma análise quantitativa, promoveu um decréscimo de cerca de $35 \%$ no momento de arfagem, para um ângulo de $6^{\circ}$ de divergência e $55 \%$ para o de $10^{\circ}$. Destaca-se que este decréscimo ocorre em cima de valores negativos de momentos de arfagem, o que significa uma maior sustentação no eixo traseiro 
em relação ao dianteiro. Isto nos permite dizer que o uso dos difusores produz uma distribuição mais igualitária da sustentação entre os eixos do modelo convergente.

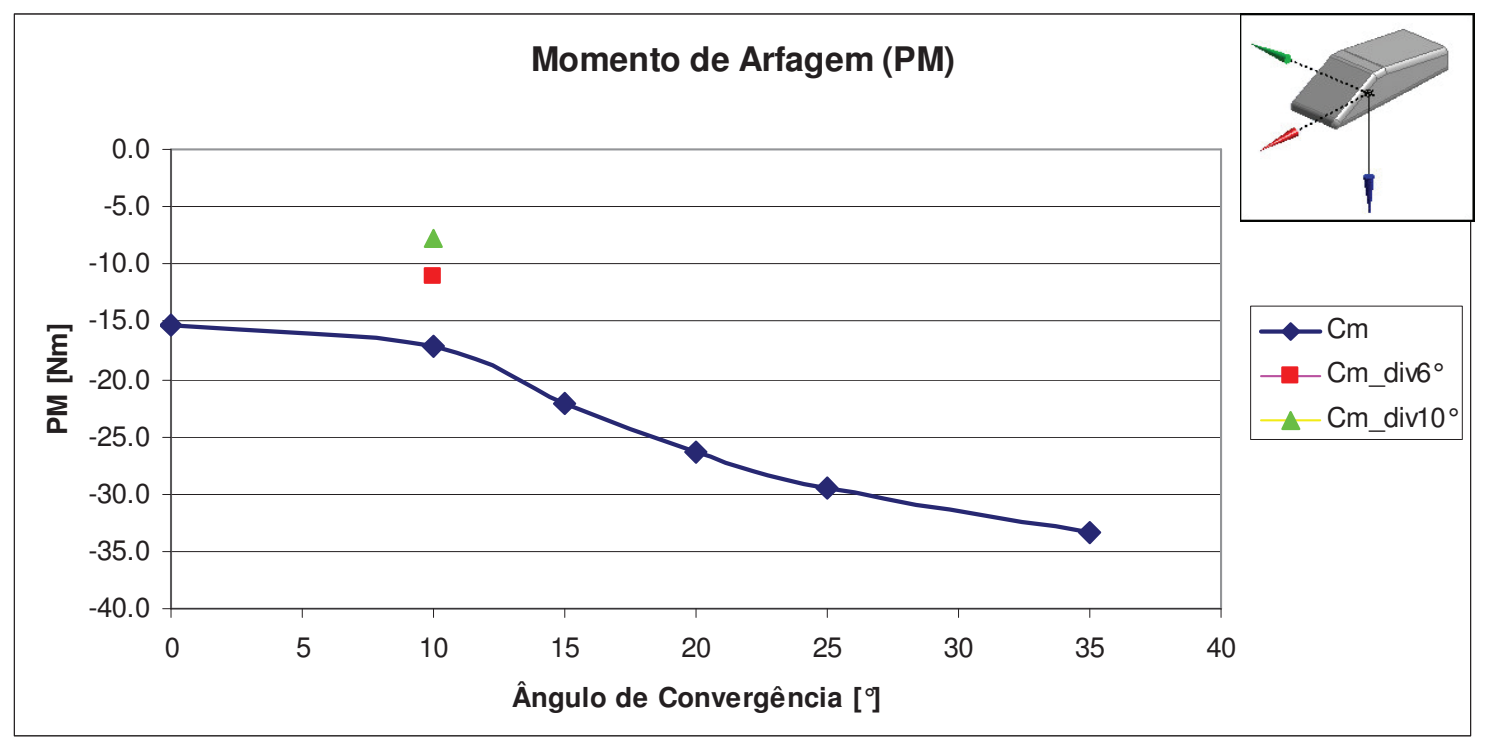

FIGURA 35: Momentos de Arfagem apresentados pelo Modelo SAE, para diferentes ângulos de convergência de sua superfície superior. E ainda os valores destes coeficientes na presença de um ângulo de difusão. O sinal positivo está direcionado para movimentos no sentido de suspender a região dianteira do Modelo.

Na Figura 36, observa-se que a adoção de uma superfície difusora não promove aumento significativo no arrasto. Neste caso, está promovendo até mesmo uma redução do arrasto total do Modelo SAE, comparando-se à geometria inicial. Este é o principal argumento em defesa do uso dessa ferramenta em veículos de corrida, uma vez que produz alto downforce sem penalizar com um arrasto maior. 


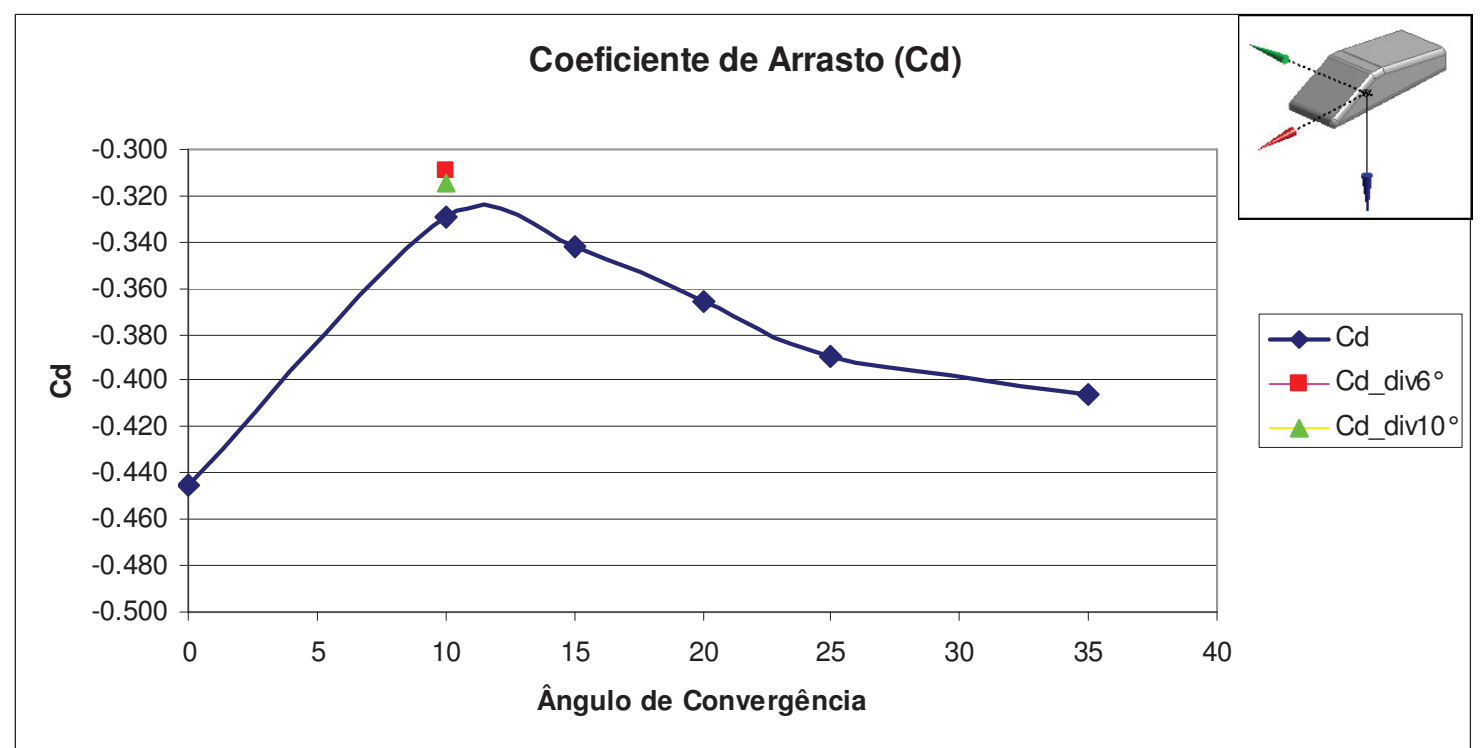

FIGURA 36: Coeficientes de Arrasto Total apresentados pelo Modelo SAE, para diferentes ângulos de convergência de sua superfície superior. E ainda os valores destes coeficientes na presença de um ângulo de difusão. O sinal negativo atribui-se ao sentido contrário da grandeza em relação àquele convencionado para $\mathrm{x}$.

Fazendo uso dos vetores velocidade, novamente, fica claro pela Figura 37, que a região, a qual apresenta menor quantidade de momento linear é significativamente menor se comparada com a geometria inicial. Comparando as geometrias as quais apresentam o difusor àquela que apresenta somente a região convergente, constata-se uma diminuição da zona de baixo momento linear devido à aceleração promovida pelo difusor às linhas de corrente que passam sob o Modelo, gerando dessa forma um menor arrasto de pressão.

Visualizando com mais detalhe os vetores nesta região para a geometria dotada de $6^{\circ}$ de divergência, ilustrados na Figura 38, conclui-se que o uso desta ferramenta proveu uma maior simetria entre os vórtices contra-rotativos transversais. O que justificaria a diminuição no coeficiente de arrasto, em relação à geometria que apresentava somente o ângulo de convergência. Esta variação ficou em torno de $4.5 \%$ para o difusor de $10^{\circ}$ e $6.5 \%$ para o de $6^{\circ}$. 


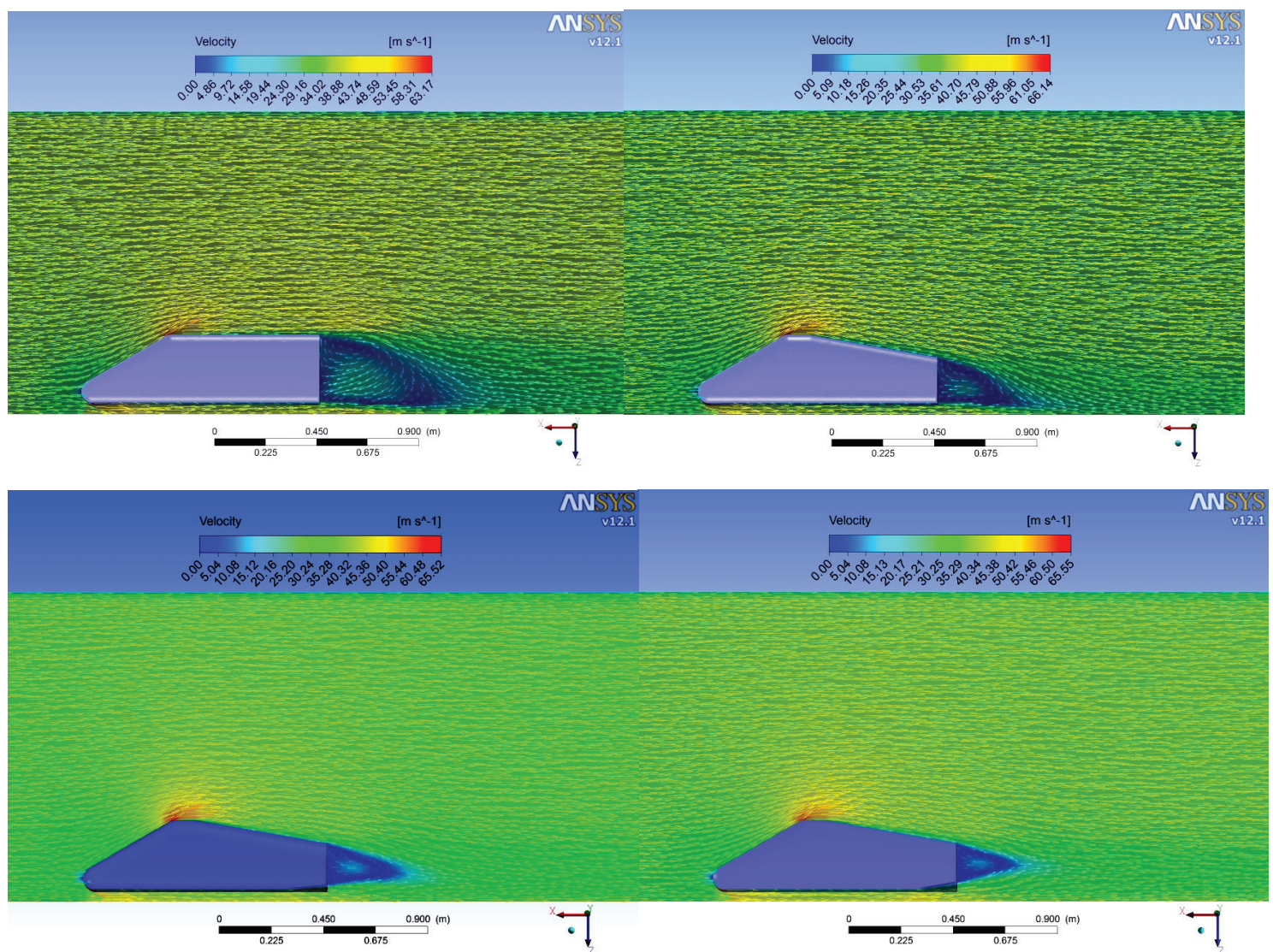

FIGURA 37: Vetor velocidade do escoamento aferido no plano de simetria longitudinal, sobre o eixo x, a fim de avaliar qualitativamente a quantidade de movimento na esteira do modelo. Note que os dois modelos na região inferior da figura apresentam o difusor. FONTE: ANSYS Fluent v12.1

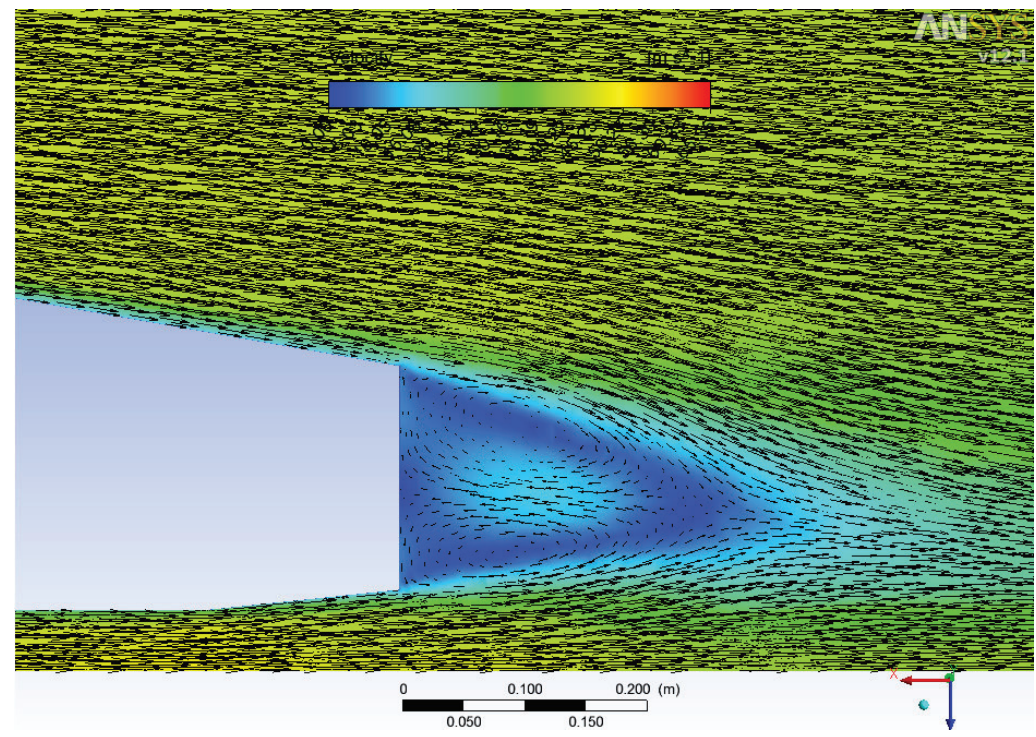

FIGURA 38: Detalhe dos vetores velocidade na esteira da geometria dotada de $6^{\circ}$ de divergência. É possível constatar uma maior simetria nos vórtices contra-rotativos.

FONTE: ANSYS Fluent v12.1 


\subsection{Influência do Ângulo de Guinada sobre o Carregamento aplicado no Modelo SAE}

Uma vez concluída a análise sobre o escoamento simétrico, é preciso avaliar os coeficientes aerodinâmicos diante um carregamento assimétrico proveniente, nas situações reais, de ventos laterais. Uma justificativa para a análise destes casos pode ser vista em Sovran (1984), ao concluir em seu estudo que nem sempre a melhor geometria perante um escoamento simétrico, é aquela que demonstra os menores coeficientes aerodinâmicos quando submetida a escoamentos assimétricos.

Ao impor um escoamento assimétrico ao Modelo SAE, a distribuição de pressão em torno de sua superfície se alterou e conseqüentemente os carregamentos aerodinâmicos. Na Figura 39 podemos ver um comparativo da distribuição de pressão sobre a superfície superior do modelo perante um escoamento simétrico e assimétrico.
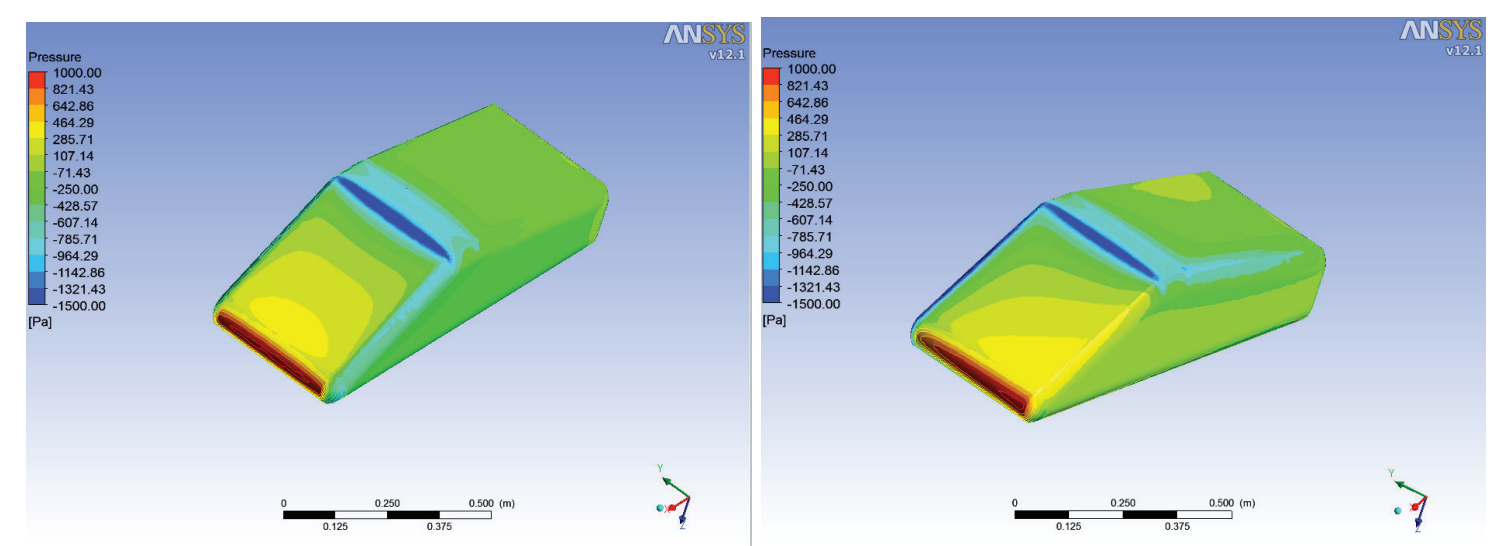

FIGURA 39: Distribuição de pressão sobre a superfície do Modelo SAE, perante a uma escoamento simétrico, a esquerda, e assimétrico a direita.

Utilizando um plano horizontal ao redor da superfície do modelo fica evidente o surgimento de uma zona de baixa pressão no entorno da superfície contrária àquela onde o escoamento incide. Sendo este o principal fator responsável pelo surgimento da força lateral e momento de yaw. Isto fica claro na ilustração a seguir: 


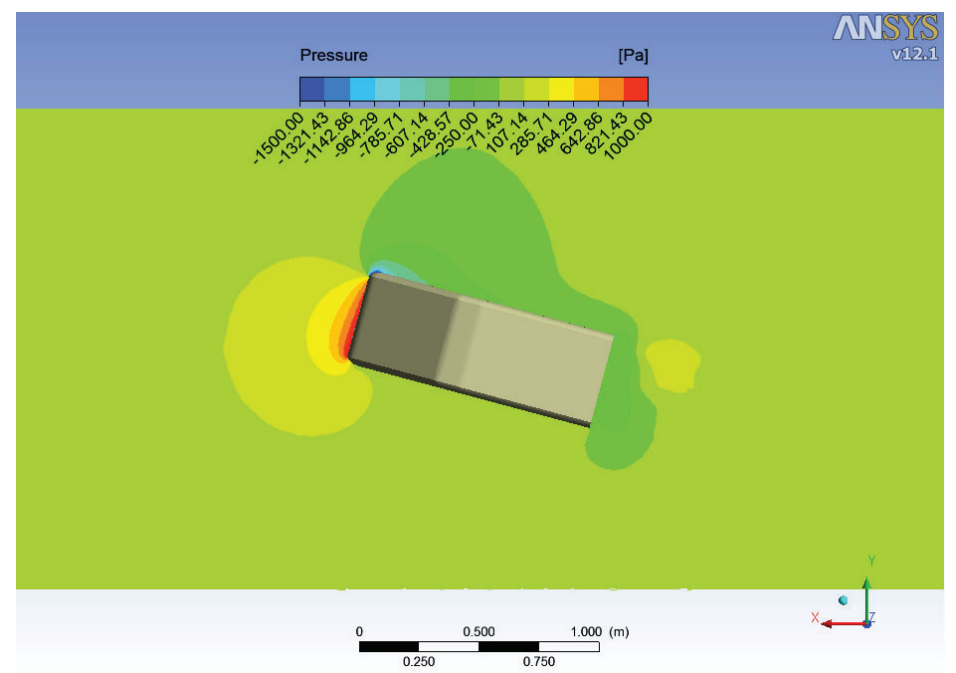

FIGURA 40: Distribuição de pressão sobre um plano horizontal localizado $50 \mathrm{~mm}$ acima da superfície inferior sendo paralelo a esta. É evidente o surgimento de uma zona de baixa pressão no lado oposto à incidência do escoamento.

A Tabela 7, abaixo, apresenta as características aerodinâmicas do Modelo SAE dotado de um ângulo de convergência de $10^{\circ}$, conjugado aos ângulos de divergência de $6^{\circ} \mathrm{e}$ $10^{\circ}$, para diferentes ângulos de yaw. Como justificado no Parágrafo 4.3.1, adotou-se para estes ângulos valores que variam entre $0^{\circ}$ e $21^{\circ}$, com passo de três graus.

TABELA 7: Características Aerodinâmicas resultantes de diferentes configurações geométricas. Legenda: $\mathrm{C} 10=$ Ângulo de convergência de $10^{\circ} ; \mathrm{D} 10=$ Ângulo de Divergência de $10^{\circ} ;$ D6 = Ângulo de Divergência de $6^{\circ} ;$ Y $\underline{\mathbf{x}}=$ Ângulo de Guinada (Yaw).

\begin{tabular}{|c|c|c|c|c|c|c|c|c|c|c|c|}
\hline \begin{tabular}{|l|} 
Configuração: \\
\end{tabular} & Sustentação & $\overline{C L}$ & Arrasto & $\mathbf{C d}$ & Momento de Rolagem & Momento de Arfagem & \begin{tabular}{|l|} 
Momento de Guinada \\
\end{tabular} & \begin{tabular}{|l|} 
Força Lateral \\
\end{tabular} & $\mathbf{C m}$ & Cn & $\mathbf{C P}$ \\
\hline & $\mathbf{N}$ & n.a. & $\mathbf{N}$ & n.a. & $\mathrm{Nm}$ & $\mathrm{Nm}$ & $\mathrm{Nm}$ & $\mathbf{N}$ & n.a. & n.a. & n.a. \\
\hline C10 D6 & 16.8 & 0.144 & -35.9 & -0.309 & 0.04 & -11.1 & -0.1 & 0.3 & -0.091 & 0.000 & -0.281 \\
\hline C10 D6 Y3 & 21.5 & 0.185 & -34.9 & -0.300 & 0.67 & 11.5 & 3.3 & 12.5 & 0.094 & 0.027 & 0.280 \\
\hline C10 D6 Y6 & 24.0 & 0.207 & -37.9 & \begin{tabular}{|l|}
-0.326 \\
\end{tabular} & 1.10 & 12.5 & 6.7 & 23.8 & 0.103 & 0.055 & 0.280 \\
\hline C10 D6 Y9 & 27.9 & 0.240 & -42.2 & -0.364 & 1.73 & 13.9 & 10.2 & 35.0 & 0.114 & 0.083 & 0.275 \\
\hline C10 D6 Y12 & 32.4 & 0.279 & -49.2 & \begin{tabular}{|l|}
-0.424 \\
\end{tabular} & 1.98 & 15.9 & 13.1 & 46.9 & 0.130 & 0.107 & 0.262 \\
\hline C10 D6 Y15 & 39.3 & 0.338 & -54.7 & \begin{tabular}{|l|}
-0.471 \\
\end{tabular} & 2.16 & 18.0 & 16.4 & 57.4 & 0.148 & 0.135 & 0.268 \\
\hline C10 D6 Y18 & 44.8 & 0.386 & -62.0 & -0.534 & 2.50 & 21.4 & 19.3 & 69.2 & 0.175 & 0.158 & 0.279 \\
\hline C10 D6 Y21 & 52.7 & 0.454 & -70.7 & \begin{tabular}{|l|}
-0.609 \\
\end{tabular} & 2.54 & 23.5 & 21.9 & 82.0 & 0.193 & \begin{tabular}{l|l|}
0.179 \\
\end{tabular} & 0.267 \\
\hline & & & & & & & & & & & \\
\hline C10 D10 & 29.4 & 0.254 & -36.5 & \begin{tabular}{|l|}
-0.315 \\
\end{tabular} & 0.00 & -7.7 & 0.0 & 0.0 & -0.063 & 0.000 & -0.165 \\
\hline \begin{tabular}{|l|} 
C10 D10 Y3 \\
\end{tabular} & 35.5 & 0.306 & -35.2 & \begin{tabular}{|l|}
-0.303 \\
\end{tabular} & 0.77 & 11.3 & 3.3 & 12.0 & 0.093 & 0.027 & 0.226 \\
\hline \begin{tabular}{|l} 
C10 D10 Y6 \\
\end{tabular} & 39.3 & 0.338 & -37.4 & -0.322 & 1.13 & 12.6 & 6.8 & 23.0 & 0.103 & 0.055 & 0.232 \\
\hline C10 D10 Y9 & 41.8 & 0.360 & -41.5 & \begin{tabular}{|l|}
-0.358 \\
\end{tabular} & 1.57 & 13.4 & 10.1 & 34.8 & 0.110 & 0.083 & 0.227 \\
\hline \begin{tabular}{|l|} 
C10 D10 Y12 \\
\end{tabular} & 46.1 & 0.397 & -46.9 & \begin{tabular}{|l|}
-0.404 \\
\end{tabular} & 2.17 & 14.4 & 13.3 & 45.8 & 0.118 & 0.109 & 0.220 \\
\hline \begin{tabular}{|l|} 
C10 D10 Y15 \\
\end{tabular} & 53.9 & 0.464 & -53.4 & \begin{tabular}{|l|}
-0.460 \\
\end{tabular} & 2.55 & 16.7 & 16.4 & 57.2 & 0.137 & 0.134 & 0.220 \\
\hline \begin{tabular}{|l|} 
C10 D10 Y18 \\
\end{tabular} & 58.4 & 0.503 & -60.9 & -0.525 & 2.76 & 19.0 & 19.1 & 69.8 & 0.156 & 0.156 & 0.226 \\
\hline \begin{tabular}{|l|}
$\mathrm{C} 10 \mathrm{D} 10 \mathrm{Y} 21$ \\
\end{tabular} & 65.4 & 0.563 & -69.5 & -0.599 & 3.49 & 21.2 & 21.8 & 82.2 & 0.174 & 0.179 & 0.222 \\
\hline
\end{tabular}

Primeiramente é avaliado o comportamento do coeficiente de arrasto, o qual constitui um dos principais tópicos deste trabalho. Sabendo que o arrasto está orientado de forma contrária ao eixo $\mathrm{x}$, temos que este aumenta com o acréscimo do ângulo de guinada, exceto para o caso $\mathrm{Y}=3^{\circ}$ em que o Cd teve um decréscimo de 0,01 . 
Este acréscimo no coeficiente de arrasto é explicado devido ao surgimento de zonas de recirculação nas extremidades da face contrária àquela onde o escoamento incide. Estas zonas se caracterizam por uma perda de quantidade de movimento, levando a um aumento no arrasto, na direção do eixo longitudinal, do modelo. Chama-se atenção para o fato, do acréscimo neste coeficiente, permitir uma aproximação por uma curva com perfil exponencial, como está explícito na Figura 41.

$\mathrm{Na}$ prática esta variação na força de arrasto exige do grupo moto-propulsor uma potência maior. Seguindo a aproximação proposta por Hucho (1998, Capítulo 3), na qual 40\% da variação no arrasto é convertida em uma diferença no consumo do veículo, temos que cerca de $90 \%$ de aumento do arrasto para o modelo com $10^{\circ}$ de divergência e $96 \%$ para aquele com $6^{\circ}$ de divergência, promove um aumento no consumo de 36\% e 38\%, respectivamente.

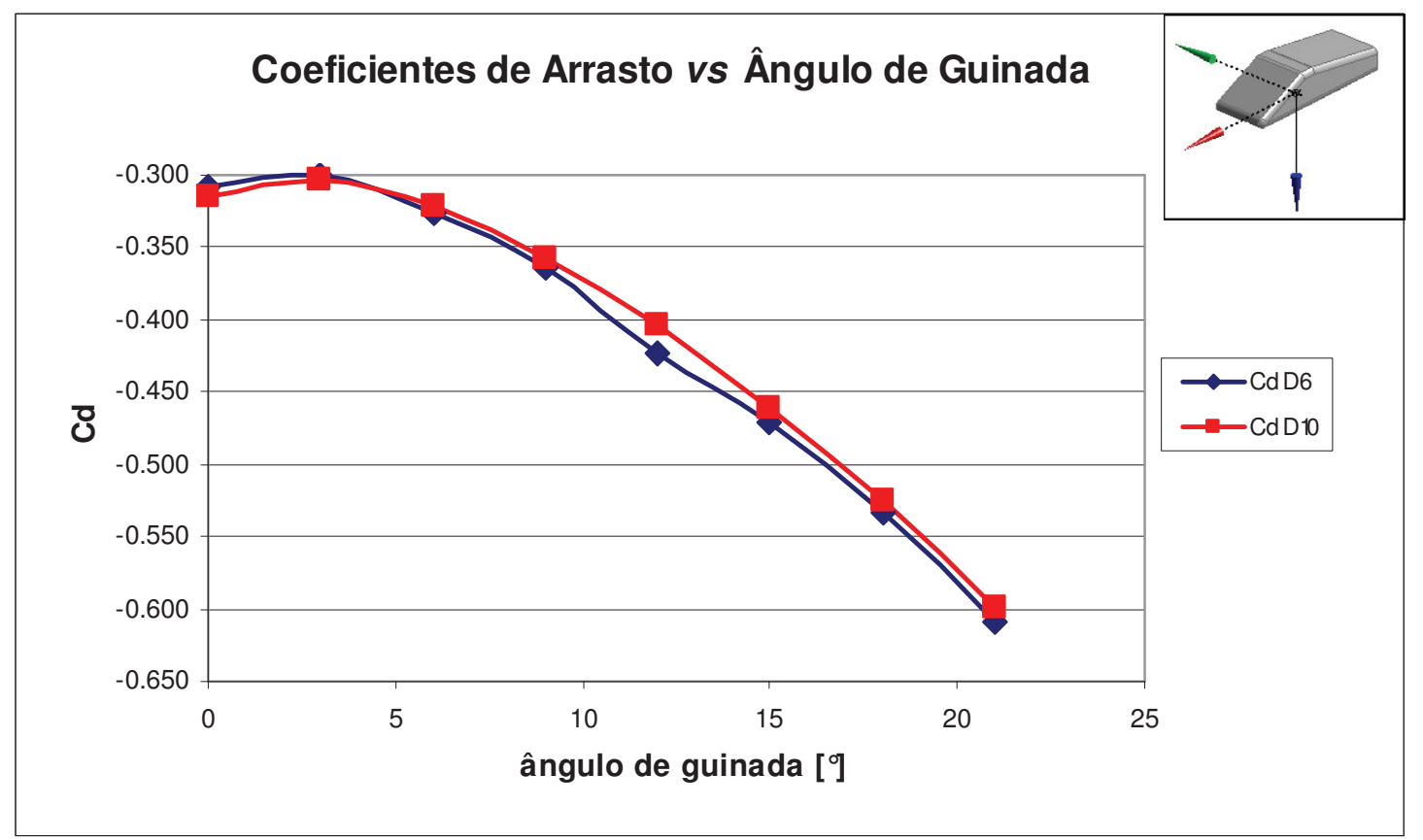

FIGURA 41: A variação do coeficiente de Arrasto em função do ângulo de guinada. Cd D6 refere-se à divergência $6^{\circ}$ e Cd D10 a divergência $10^{\circ}$.

O segundo aspecto a ser analisado é a variação na sustentação em função do ângulo de yaw, ou guinada. A Figura 42 evidencia uma diferença entre os coeficientes de sustentação apresentados com diferentes ângulos de divergência. Nota-se que a disparidade de aproximadamente 0.11 é conservada, ao submeter o modelo a um escoamento simétrico e a escoamentos assimétricos, com diversos ângulos de yaw. Isto, pois a geometria possui uma mesma área exposta, sendo diferente somente a distribuição na superfície inferior do modelo, 
devido ao difusor. A eficiência desta ferramenta permanece, portanto inalterada com a variação do ângulo de guinada ou yaw.

Com base nos dados obtidos nas simulações, é possível estabelecer uma expressão que relacione o coeficiente de sustentação ao ângulo de guinada. As curvas, presentes na Figura 42, permitem concluir que uma aproximação por uma função de primeiro grau traduz de forma satisfatória a relação existente entre esses parâmetros. A constante desta é determinada pelo coeficiente de sustentação obtido no escoamento simétrico, sua inclinação, coincidente para os dois casos analisados, é dada pelo valor 0,0142. Neste caso é preciso ressaltar que a sustentação está diminuindo, uma vez que os valores positivos correspondem ao sentido para baixo do eixo z.

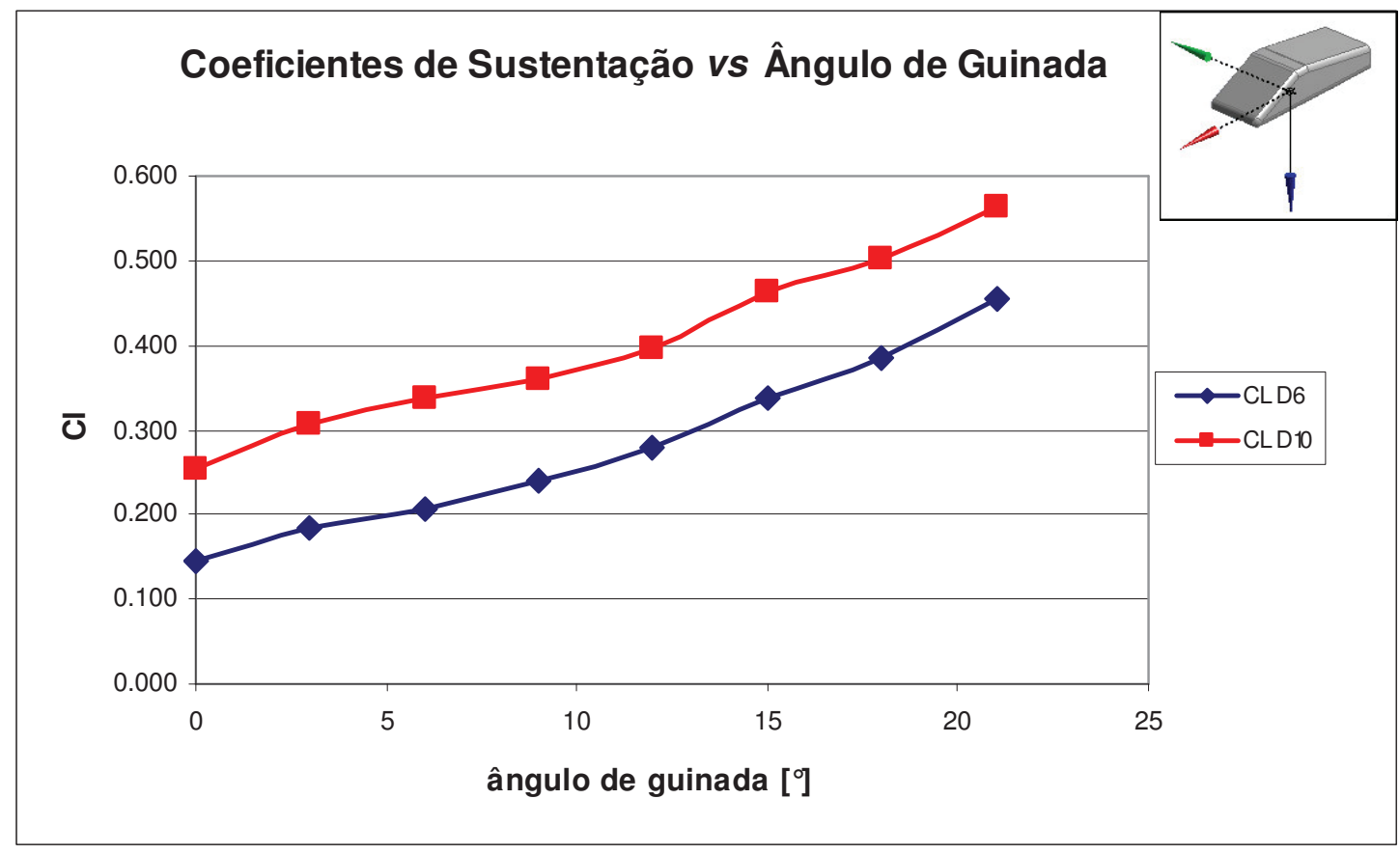

FIGURA 42: A variação do coeficiente de sustentação em função do ângulo de guinada. CL D6 refere-se à divergência $6^{\circ}$ e CL D10 a divergência $10^{\circ}$.

O gráfico do Momento de Arfagem é apresentado na Figura 43. Uma interessante constatação que se tem ao visualizar a curva abaixo é devido a grande variação neste esforço ao mudar a condição do escoamento de simétrico para assimétrico. Poucos graus para o ângulo de yaw são suficientes para inverter o sentido desse momento. Aproximadamente $1.5^{\circ}$ para este ângulo corresponde a um Momento de Arfagem nulo. Mais uma vez, vale ressaltar que o momento positivo é convencionado no sentido de erguer a região dianteira do modelo. 
Considerando a diminuição de sustentação e a inversão de sentido do momento de arfagem, apresentados nos gráficos das Figuras 42 e 43, pode-se inferir que o surgimento de uma zona de recirculação, ou separação, na região dianteira da face lateral oposta àquela onde o escoamento incide, é responsável pela pelo aumento da pressão na superfície superior do modelo, Figura 39, verificado em colorações amareladas e avermelhadas. O fato da sustentação dianteira se tornar a parte predominante na composição da sustentação, fato relacionado a variação do momento de arfagem, favorece a característica understeer do Modelo SAE, ou seja, uma aderência maior dos pneumáticos traseiros.

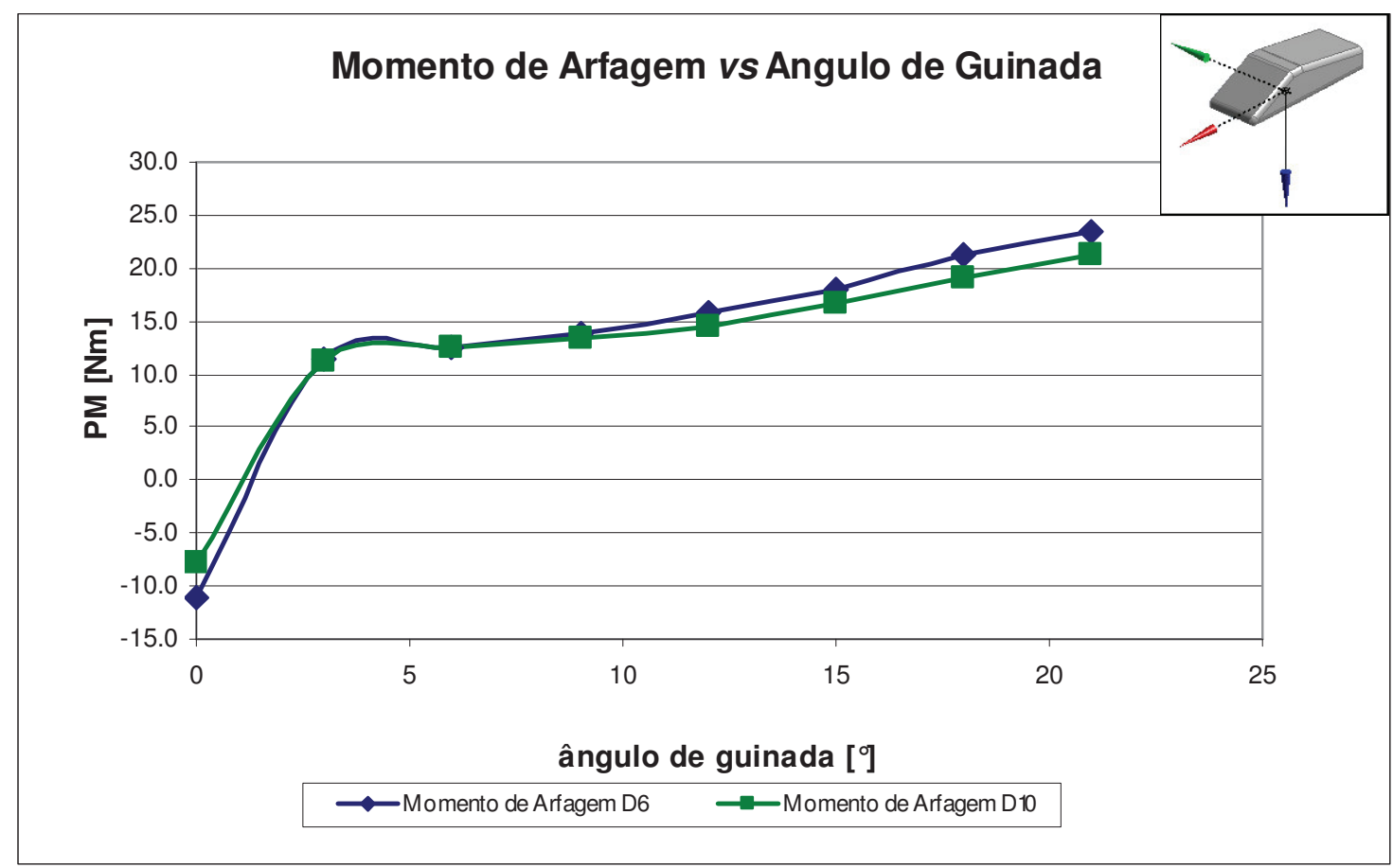

FIGURA 43: Variação do coeficiente de Momento de Arfagem em função do ângulo de guinada. D6 refere-se à divergência $6^{\circ}$ e D10 a divergência $10^{\circ}$.

A assimetria do escoamento torna o Momento de Rolagem um esforço notório se comparado com os casos simétricos testados. Este esforço, demonstrado em função do ângulo de guinada no gráfico da Figura 44, de forma semelhante aos demais, é crescente na medida em que ângulos maiores são adotados.

Estes valores crescentes para o momento de rolagem podem também ser aproximados por uma função de primeira ordem. Esta, dotada somente da inclinação da curva, uma vez que a constante é igual à zero, recebe um valor médio para as duas geometrias ensaiadas, correspondente a 0,1545 . 
Observa-se que mesmo o aumento no Momento de Rolagem, se comparado aos demais momentos desenvolvidos em escoamentos assimétricos, possui grandeza demasiadamente menor. Tem-se que, para $21^{\circ}$ de yaw, o Momento de Arfagem possui uma grandeza cerca de seis vezes maior que o Momento de Rolagem. Por esta razão este parâmetro não é considerado crítico, como o momento de arfagem e yaw, por exemplo, na análise da estabilidade direcional de um veículo.

Na Figura 17, parágrafo 3.6 deste trabalho, se encontra ilustrado um método de redução do momento de rolagem, o qual consiste na adoção de uma superfície lateral inclinada. Neste mesmo parágrafo sugere-se também a utilização de vértices arredondados para estas faces.

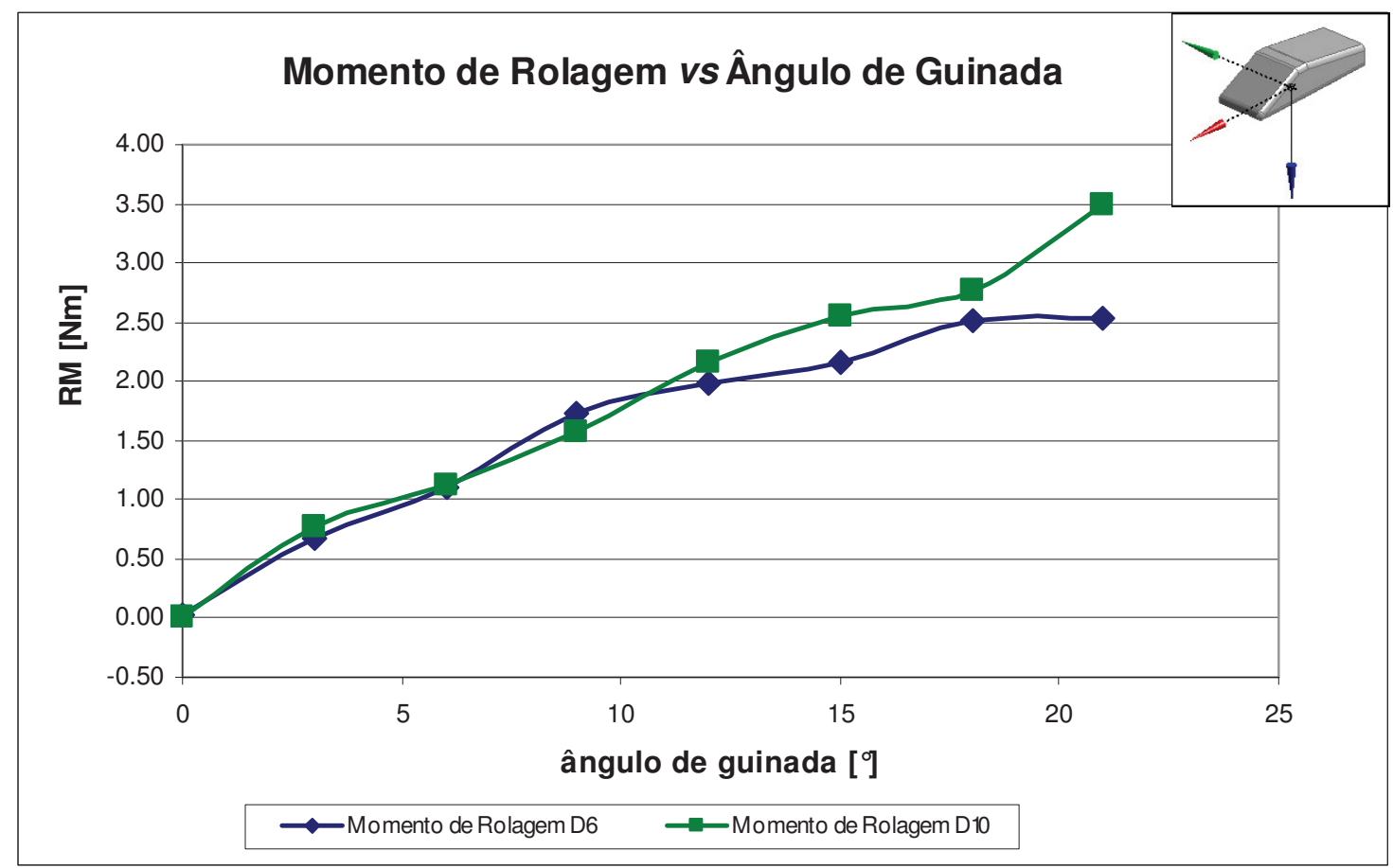

FIGURA 44: Variação do coeficiente de Momento de Rolagem em função do ângulo de guinada. D6 refere-se à divergência $6^{\circ}$ e D10 a divergência $10^{\circ}$.

Nas Figuras 45 e 46 demonstra-se os dois principais objetos de análise do caso assimétrico, que visa pesquisar os impactos deste escoamento sobre os coeficientes aerodinâmicos. Estes parâmetros são denominados Momento de Yaw e Força Lateral.

Ressalta-se que o Momento de Yaw varia de forma crescente, à medida que o ângulo de guinada é acrescido. Este esforço, que para um escoamento simétrico possui valores muito próximos à zero, segue um perfil de curva linear até alcançar seus valores máximos, dentre os casos estudados para o ângulo de $21^{\circ}$. Observa-se pela Tabela 7, que a grandeza dos 
Momentos de Yaw para as geometrias com ângulos de divergência de $6^{\circ}$ e $10^{\circ}$, é praticamente a mesma, apresentando valores de $21,9 \mathrm{Nm}$, para a primeira, e 21,8 $\mathrm{Nm}$, para a segunda geometria citada.

No gráfico abaixo comprova-se esta similaridade da variação do momento de yaw em função do ângulo de guinada. Este comportamento era esperado, pois, novamente, a área da superfície exposta ao escoamento, em particular a área lateral, é praticamente a mesma, o que leva a uma distribuição de coeficiente de pressão similar entre os casos estudados. Segundo Hucho (1998, Capítulo 5), a distribuição dos esforços laterais está ligada à área lateral e aos arredondamentos feitos em seus vértices.

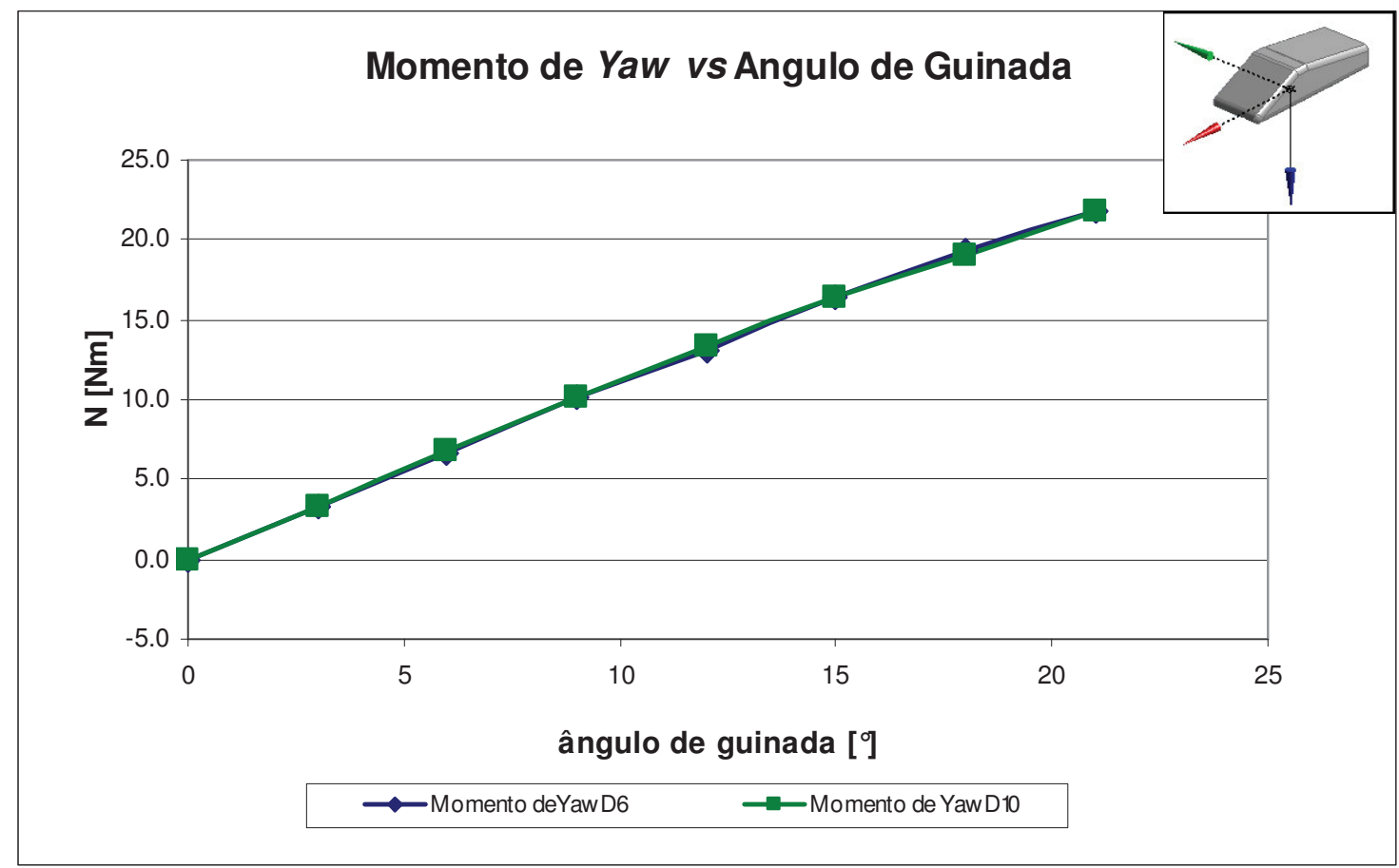

FIGURA 45: Momento de Yaw em função do ângulo de guinada. D6 refere-se à divergência $6^{\circ}$ e D10 a divergência $10^{\circ}$.

Em Hucho (1998, Capítulo 5) é estabelecido que: se a variação do momento de yaw é positiva em função do ângulo de yaw, então o modelo é considerado instável. Com base nesta afirmação, tem-se que as duas geometrias ensaiadas tendem a apresentar um detrimento em sua estabilidade direcional, quando submetidas a ventos laterais.

A Figura 46 nos revela que as grandezas de Força Lateral aplicadas sobre as geometrias analisadas, de forma análoga ao momento de yaw, são demasiadamente próximas 
e possuem um crescimento linear. Tomando como base os valores obtidos nas simulações, temos uma inclinação para esta função de primeira ordem igual a 0,033 .

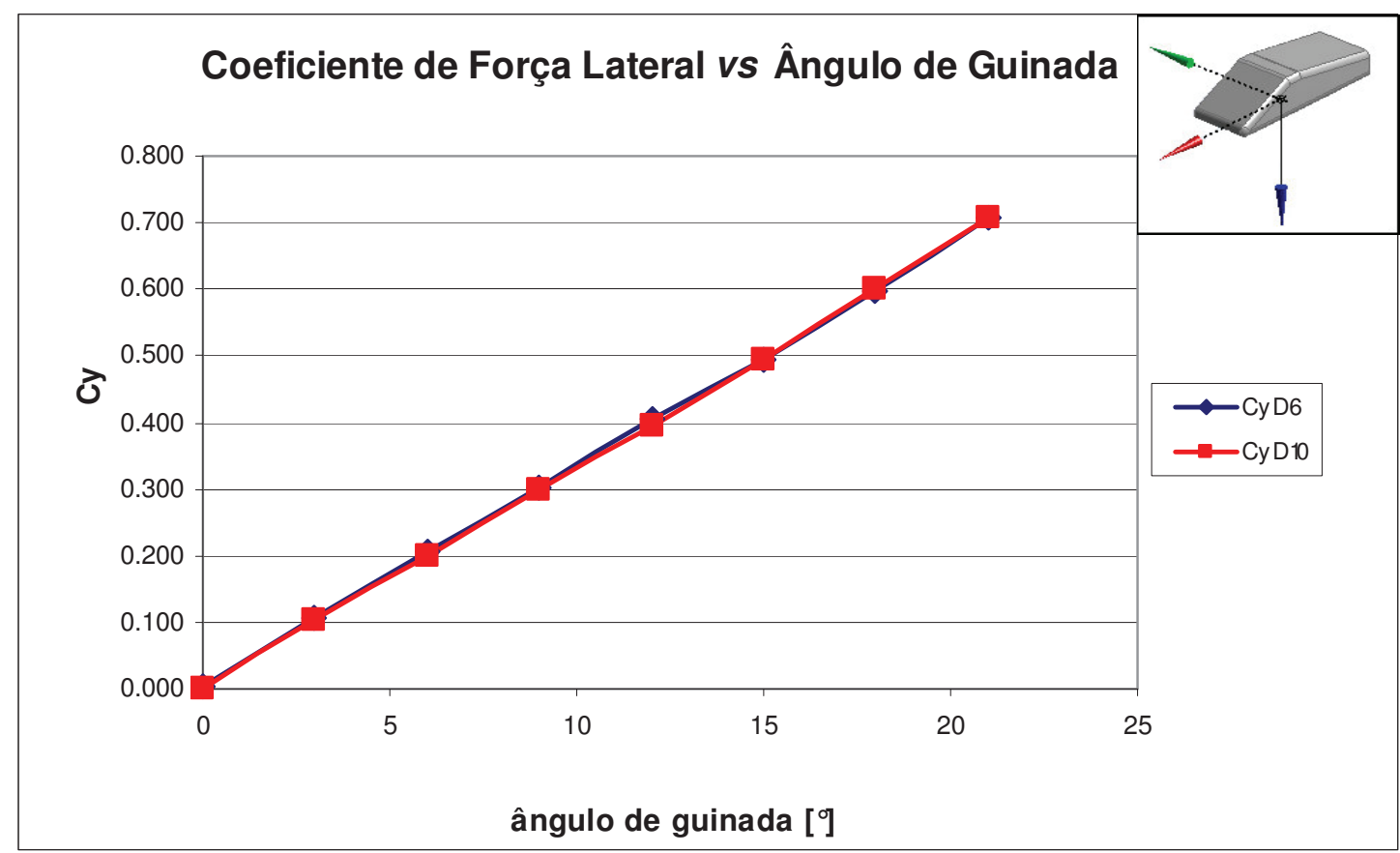

FIGURA 46: Coeficientes de Força Lateral experimentados pelo Modelo SAE, dotado de geometrias divergentes de $6^{\circ}$ e $10^{\circ}$ (D6 e D10, respectivamente), em função do ângulo de guinada.

Neste momento é importante fazer uma observação a respeito da linearidade dos esforços aerodinâmicos, como: sustentação, momento de rolagem, momento de guinada e força lateral. Hucho (1998, Capítulo 5) enunciou esta linearidade para ângulos de yaw com valores até $20^{\circ}$, nesta obra são levantados os gráficos para geometrias hatchback, notchback e fastback, onde fica constatado que esta linearidade independe da geometria simulada. Esta afirmação foi trabalhada no Parágrafo 3.7 e a adequação às condições reais de tráfego justificada na metodologia deste trabalho.

A Figura 47 traz de forma sucinta a variação dos principais parâmetros afetados pela variação do ângulo de guinada, são eles: momento de arfagem, arrasto, força lateral e momento de yaw. Por este gráfico temos a possibilidade de verificar o aumento gradual de tais esforços. Este comportamento, assim como a grande semelhança observada entre as geometrias com divergência de $6^{\circ}$ e $10^{\circ}$ nos permite generalizar os impactos devido ao aumento do ângulo de guinada. Nota-se um incremento no arrasto veicular, como também nos parâmetros que determinam a estabilidade. Estes últimos variam de forma a diminuir esta última, exceto o momento de arfagem, como foi trabalhado nos parágrafos acima. Na análise feita por Hucho (1998, Capítulo 5) ao ensaiar geometrias hatchback, fastback e notchback, 
demonstrou-se uma inversão no comportamento das curvas em função da geometria traseira, de forma a nos levar a crer que o momento de arfagem pode apresentar características relativas à perda de estabilidade, para casos em que não seja utilizado o difusor.

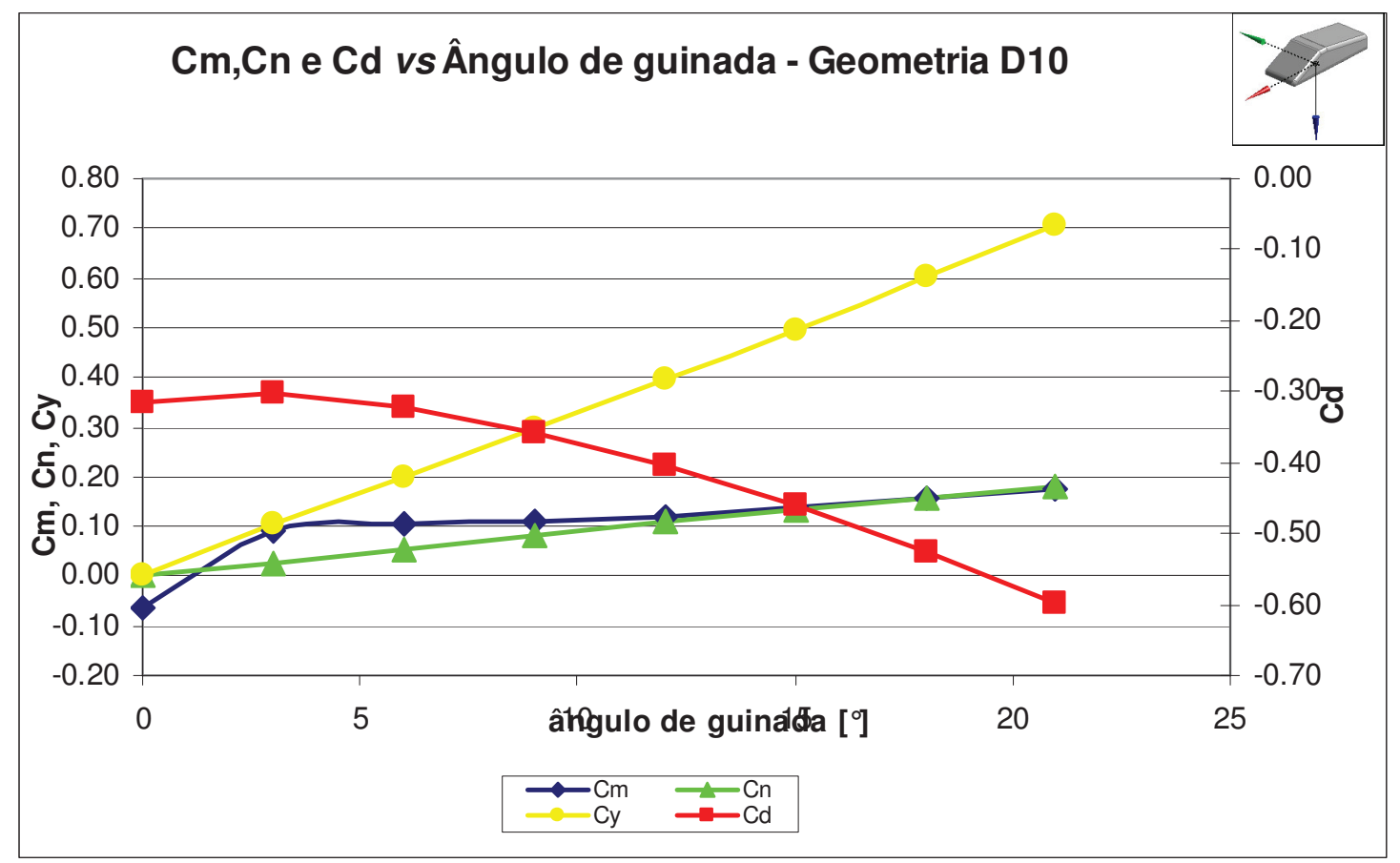

FIGURA 47: Variação dos coeficientes de Arrasto, Momento de Arfagem, Momento de Guinada e Força Lateral em função do ângulo de guinada. D10 refere-se à divergência $10^{\circ}$.

Com isso, conclui-se a análise da manutenção da estabilidade em virtude da incidência de um escoamento assimétrico. Com base nas informações fornecidas acima é possível estabelecer as condições necessárias para operação de um veículo referenciando-se na geometria do Modelo SAE, e ainda, se basear nestes dados para impor melhorias ao mesmo. Isto, com objetivo de tornar a variação do momento de yaw em função do ângulo de guinada negativa, critério utilizado por Hucho (1998, Capítulo 5) para classificar um modelo em relação a sua estabilidade. Acredita-se que modificações na geometria frontal sejam suficientes para este propósito. 


\section{Capítulo 6}

\section{CONCLUSÕES E SUGESTÕES}

A ciência aerodinâmica veicular é relativamente nova e neste período tem recebido grande destaque, devido aos fatores ambientais já citados e ao custo do petróleo. Por isso mais e mais pessoas estão interessadas em descobrir os fenômenos que estão por trás do escoamento que envolve os veículos automotores.

A complexidade desse escoamento tri-dimensional e a necessidade de se criar uma banco de dados maior a respeito dessa área de conhecimento são os principais aspectos que motivam pesquisadores a continuar seus estudos.

O primeiro objetivo deste trabalho era justamente contribuir para que pessoas que estão começando os seus estudos tenham acesso a uma contextualização histórica do desenvolvimento da aerodinâmica veicular. Ao tratar ao longo de 52 páginas sobre conceitos históricos da indústria automotiva e automobilística, ferramentas utilizadas para a análise do escoamento, tais como os túneis de vento e computadores, ainda ao abordar aspectos teóricos relacionados à geração do arrasto e a manutenção da estabilidade, acredita-se que este objetivo tenha sido alcançado.

Descrevendo-se detalhadamente cada ferramenta de análise da aerodinâmica veicular pôde-se direcionar a utilização destas, sua importância e o momento para seu uso durante a fase de projeto. Como exemplo, toma-se o uso da analise fluidodinâmica computacional como uma ferramenta importantíssima na visualização dos efeitos que estão ocorrendo no escoamento. Ela permite observar zonas de separação da camada limite e

quantificar os carregamentos aerodinâmicos de forma satisfatória. É uma ferramenta que deve ser voltada para as primeiras fases do projeto e com ela devem ser realizados ensaios, que antes eram conduzidos em túneis de escalas menores.

A análise final da eficiência aerodinâmica continua vinculada à utilização do túnel de vento, em escala real, devido ao grande esforço computacional para se impor acuracidade a solução. Devido sua precisão e praticidade na realização de pequenas modificações, esta ferramenta é utilizada para consolidar a geometria final do veículo, além de validar via comparação de resultados, as simulações feitas anteriormente. 
Os conceitos acerca do arrasto e da estabilidade veicular foram bem trabalhados. Enfatizando-se que o arrasto veicular é proveniente das regiões de separação, que este corpo rombudo impõe sobre o modelo. Por sua vez, a estabilidade está ligada aos conceitos de força lateral e momento de yaw (ou guinada). Logo, através de modificações geometrias é possível obter melhorias para ambos.

Esta idéia é comprovada com as simulações realizadas no Fluent v12.1, as quais foram divididas em três fases: obtenção de uma geometria que fornecesse menor arrasto; adoção de modificações que mantivessem a sustentação e o momento de arfagem no mesmo patamar dos esforços apresentados pela geometria inicial; e por fim a análise dos parâmetros aerodinâmicos em diferentes ângulos de guinada para avaliação de seus impactos.

Pelos resultados discutidos, tornou-se claro a não existência de um antagonismo entre o arrasto e a estabilidade direcional, e que a adoção de um difusor, apenas, é suficiente para anular qualquer impacto negativo ocasionado pela adoção de geometrias convergentes. A análise sobre a variação do ângulo de guinada nos ofereceu a possibilidade de ver sua influência sobre os demais parâmetros. De uma forma geral todos os coeficientes aerodinâmicos sofrem acréscimos quando submetido a escoamentos assimétricos. Esta parte do trabalho gerou resultados semelhantes aos observados durante a Revisão Bibliográfica, de onde se conclui que se obteve êxito nesta etapa. A geometria utilizada para esta análise, Modelo SAE, foi de grande importância para este fato.

É claro que uma análise aerodinâmica deve ser bem mais explorada durante o desenvolvimento de um novo modelo. Por esta razão o autor sugere para estudos futuros a simulação deste modelo perante diferentes ângulos de arfagem e a adoção de mais ângulos de convergência a fim de se verificar a ocorrência da descontinuidade observada no Modelo Ahmed. O autor sugere ainda a análise dos casos estudados em túneis de vento a título de comparação. 


\section{REFERÊNCIAS BIBLIOGRÁFICAS ${ }^{1}$}

AHMED, S.R., BAUMERT, W., The Structure of Wake Flow Behind Road Vehicles, Aerodynamics of Transportation, ASME-CSME Conference, pp 93-103, Niagara Falls, 1979.

AMODEO, JOE, ALAJBEGOVIC, ALES, JANSEN, WILKO, Thermal Management Simulation for Passenger Cars - Towards Total Vehicle Analysis.

ANDERSON JR., JOHN D., Computational Fluid Dynamics - The Basics with Applications, $2^{\text {nd }}$ Edition, McGraw-Hill,Inc., USA, 1995.

ANSYS FLUENT 12.0/12.1 Documentation Files, Theory Guide, parágrafos $1,2,3,4,15,18,19,20$.

ANSYS FLUENT 12.0/12.1 Documentation Files, User's Guide, parágrafos 1,6 e 12.

BERndTSSON, A., ECKERT, W.T., MERCKER, E., The Effect of Ground plane

Boundary Layer Control on Automotive Testing in a Wind Tunnel, SAE Paper No 880248, Society of Automotive Engineers, Warrendale, Pa., 1988.

BROADLEY, IAN and GARRY, KEVIN, Improving the Aerodynamic Stability of a Practical, Low Drag, Aero-Stable Vehicle, SAE Paper No. 2000-01-1577, Society of Automotive Engineers, Warrendale, Pa., 2000.

BUCHHEIN, R., DEUTENBACH, K.-R., LUCKOFF, H.-J., Necessity and Premises for Reducing the Aerodynamic Drag of Future Passenger Cars, SAE Paper No. 810185, Society of Automotive Engineers, Warrendale, Pa., 1981.

CASTEJON, DANILO, COLLI, GUSTAVO, VOLPATO, ORLANDO e SALVETTI, ALVARO, Heated Injector Cold Start System for Flex-Fuel Motorcycles. SAE Paper No. 2010-36-0156, Society of Automotive Engineers, Warrendale, Pa., 2010.

COGOTTI, ANTONELLO, Aerodynamic Characteristics for Cars Wheels, International Journal of Vehicle Design, SP3, pp 173-196, 1983.

COGOTTI, ANTONELlO, Generation of a Controlled Level of Turbulence in the

Pininfarina Wind Tunnel for the Measurement of Unsteady Aerodynamics and Aeroacoustics, SAE Paper No. 2003-01-0430, Society of Automotive Engineers, Warrendale, Pa., 2003.

${ }^{1}$ De acordo com a Associação Brasileira de Normas Técnicas. NBR 6023. 
DOMINY, R.D., A, RYAN and D.B., SIMS-WILLIANS, The Aerodynamic Stability of a Le Mans Prototype Race Car under Off-Design Pitch Conditions, SAE Paper No. 2000-01-0872, Society of Automotive Engineers, Warrendale, 2000.

FACKRELL, J. E., and HARVEY, J. K., The Aerodynamics of an Isolated Road Wheel, May 11, Los Angeles, California, Proceedings of the Second AIAA Symposium of Aerodynamics of Sports and Competition Automobiles, B. Pershing _ed._, Western Periodicals Co., ISBN 0879380284, 1975.

FOUX, AMMON, FANGER V., SHIMON e KATZ, JOSEPH, Full-Scale, On-Road Study of the Effect of Automobile Shape on its Aerodynamic Characteristics, and Comparison with Small-Scale Wind Tunnel Results, SAE Paper No. 850287v001, Society of Automotive Engineers, Warrendale, Pa., 1985.

GAYLARD, A.P., The Appropriate Use of CFD in the Automotive Design Process. SAE Paper No. 2009-01-1162, Society of Automotive Engineers, Warrendale, Pa., 2009.

GILHAUS, M. ALFONS e RENN, E., VOLKER, Drag and Driving Stability Related Aerodynamic Forces and Their Interdependence- Results of Measurements on 3/8 scale Basic Car Shapes. SAE Paper No. 860211v001, Society of Automotive Engineers, Warrendale, Pa., 1986.

GUilmineuAU, E., CHOMETON, F., Numerical and Experimental Analysis of Unsteady Separated Flow behind an Oscillating Car Model. SAE Paper No. 200801-0738, Society of Automotive Engineers, Warrendale, Pa., 2008.

HOLLOWAY, SCOTT, H. LEYLEK, JAMES, D. YORK, WILLIAM, KHALIGHI, BAHRAM. Aerodynamics of a Pick Truck: Combined CFD and Experimental Study. SAE Paper No. 2009-01-1167, Society of Automotive Engineers, Warrendale, Pa., 2009.

HOUGHTON, E.L. e CARPENTER, P.W., Aerodynamics for Engineering Students, $5^{\text {th }}$ Edition, Butterworth Heinemann, Burlington, M.A., 2003.

HOWELL, JEFF e LE GOOD, GEOFF, Vortex Drag for a Simple Bluff Body at incidence in Ground Proximity. SAE Paper No.2005-01-0869, Society of Automotive Engineers, Warrendale, Pa., 2005.

HUCHO, W-H., SOVRAN, GINO, Aerodynamics of Road Vehicles, Annual Review of Fluid Mechanics, 1993, cap 25, pgs. 485-537.

HUCHO, W-H., Aerodynamics of Road Vehicles, $4^{\text {th }}$ Edition, Society of Automotive Engineers, Warrendale, Pa., 1998, Cap.: 1,3,4,5,13,15. 
HUCHO, W-H., JANSEN,L.J., EMMELMANN, H-J, The Optimization of Body Details A Method for Reducing the Aerodynamic Drag of Road Vehicles, SAE Paper No 760185, Society of Automotive Engineers, Warrendale, Pa., 1976.

HUMINIC, ANGEL and HUMINIC, GABRIELA, On Aerodynamics of Racing Cars, SAE Paper No. 2008-01-0099, Society of Automotive Engineers, Warrendale, Pa., 2008. JOHANSSON, MAGNUS O. and KATZ, JOSEPH, Lateral Aerodynamics of a Generic Sprint Car Configuration, SAE Paper No. 2002-01-3312, Society of Automotive Engineers, Warrendale, Pa., 2002.

KATAOKA, T., CHINA, H., NAKAGAWA, K., YANAGIMOTO,K., YOSHIDA,M., Numerical Simulation of Road Vehicle Aerodynamics and Effect of Aerodynamic Devices, SAE Paper No. 910597, Society of Automotive Engineers, Warrendale, Pa., 1991.

KATZ, JOSEPH, GARCIA, DARVIN, SLUDER, ROBIN, Aerodynamics of Race Car Liftoff, SAE Paper No. 2004-01-3506, Society of Automotive Engineers, Warrendale, Pa., 2004.

KATZ,J., Race Car Aerodynamics - Design for Speed, 2nd Edition, Bentley Publisher, Cambridge, USA, 1995.

KATZ,J., Aerodynamics of Race Cars, Annual Review of Fluid Mechanics, 2006.38: 27-63.

LE GOOD, GEOFFREY M. and GARRY, KEVIN P., On the Use of Reference Models

in Automotive Aerodynamics, SAE Paper No. 2004-01-1308, Society of Automotive Engineers, Warrendale, Pa., 2004.

Milliken, Willian F. e Milliken, DOUGlaS L., Race Car Vehicle Dynamics, Society of Automotive Engineers, Warrendale, Pa., 1995.

MORELli, ALBERTO, A new Aerodynamic Approach to Advanced Automobile Basic Shapes, SAE Paper No. 2000-01-0491, Society of Automotive Engineers, Warrendale, Pa., 2000.

ONO, K., HIMERO, R., FUJITANI, K., UEMATSU, Y., Simultaneous Computational of External Flow around a Car Body and the Internal Flow through its Engine Compartment, SAE Paper No. 920342, Society of Automotive Engineers, Warrendale, Pa., 1992.

REGERT, TAMAS e LARROS, TAMAS, Description of flow field in the wheelhouses of cars, International Journal of Heat and Fluid Flow 28 (2007), pgs. 616-629. 
SCHLICHTING, Dr. HERMANN, Boundary-Layer Theory, $4^{\text {th }}$ Edition, McGraw-Hill, USA., 1979.

SOVRAN, GINO, The Effect of Ambient Wind on a Road Vehicle's Aerodynamic Work Requirement and Fuel Consumption, SAE Paper No. 840298v001, Society of Automotive Engineers, Warrendale, Pa., 1984.

Surface Vehicle Information Report - Aerodynamic Testing of Road Vehicles- Open Throat Wind Tunnel Adjustment, SAEJ2071v001, Society of Automotive Engineers, Warrendale, Pa., 1990.

Surface Vehicle Information Report - Aerodynamic Testing of Road Vehicles- Testing methods and Procedures, SAEJ2084v001, Society of Automotive Engineers, Warrendale, Pa., 1993.

Surface Vehicle Recommended Practice - Vehicle Aerodynamics Terminology, SAEJ1594v001, Society of Automotive Engineers, Warrendale, Pa., 1987

WRIGHT, P. G., The Influence of Aerodynamics on the Design of a Formula One Racing Cars, Impact of Aerodynamics on Vehicle Design, International Journal of Vehicle Design, SP3, 1983, pp 158-172.

ZHANG, X., TOET, W., ZERIHAN, J., Ground Effect Aerodynamics of Race Cars, Applied Mechanics Reviews, Volume 59, pgs. 33-49, Janeiro de 2006.

ZIELINSKI, KURT and ECCLES, JONATHAN Application of Emergent Aerodynamic Calculation Tools, SAE Paper No. 2008-01-0096, Society of Automotive Engineers, Warrendale, Pa., 2008. 


\section{APÊNDICE A -}

\section{Definição das variáveis presentes no modelo de turbulência SST k- $\omega$}

As equações apresentadas no tópico 3.9 descrevem o modelo de turbulência SST k- $\omega$ o qual foi utilizado no presente trabalho. Estas são oriundas das equações de Navier-Stokes submetidas ao método de solução de RANS, considerando-se as flutuações das grandezas físicas do escoamento.

As variáveis que compõem as equações apresentadas no tópico 3.9 foram avaliadas da seguinte forma:

A difusividade é equacionada da seguinte forma:

$$
\begin{aligned}
& \Gamma_{k}=\mu+\frac{\mu_{t}}{\sigma_{k}} ; \\
& \Gamma_{\omega}=\mu+\frac{\mu_{t}}{\sigma_{\omega}} ;
\end{aligned}
$$

Onde $\sigma_{\mathrm{k}}$ e $\sigma_{\omega}$ são chamados números de turbulência de Prandtl para $\mathrm{k}$ e $\omega$, respectivamente. A viscosidade turbulenta é expressa como:

$$
\mu_{t}=\frac{\rho k}{\omega} \frac{1}{\max \left[\frac{1}{\alpha^{*}}, \frac{S F_{2}}{a_{1} \omega}\right]} ;
$$

Com $\mathrm{S}$ representando a magnitude da variação da pressão e

$$
\begin{aligned}
& \sigma_{k}=\frac{1}{F_{1} / \sigma_{k, 1}+\left(1-F_{1}\right) / \sigma_{k, 2}} ; \\
& \sigma_{\omega}=\frac{1}{F_{1} / \sigma_{\omega, 1}+\left(1-F_{1}\right) / \sigma_{\omega, 2}} ; \\
& \alpha^{*}=\alpha_{\infty}^{*}\left(\frac{\alpha_{\infty}^{*}+\operatorname{Re}_{t} / R_{k}}{1+\operatorname{Re}_{t} / R_{k}}\right) ; \operatorname{com}: \operatorname{Re}_{t}=\frac{\rho k}{\mu \omega} ; R_{k}=6 ; \alpha_{0}^{*}=\frac{\beta_{i}}{3} ; \beta_{i}=0.072 ;
\end{aligned}
$$

$\mathrm{O}$ vetor de interpolação é representado pelas funções $\mathrm{F}_{1}$ e $\mathrm{F}_{2}$ :

$F_{1}=\tanh \left(\Phi_{1}^{4}\right)$;

$\Phi_{1}=\min \left[\max \left(\frac{\sqrt{k}}{0.09 \omega y}, \frac{500 \mu}{\rho y^{2} \omega}\right), \frac{4 \rho k}{\sigma_{w, 2} D_{\omega}^{+} y^{2}}\right] ;$

$D_{\omega}^{+}=\max \left[2 \rho \frac{1}{\sigma_{\omega, 2}} \frac{1}{\omega} \frac{\partial k}{\partial x_{j}} \frac{\partial \omega}{\partial x_{j}}, 10^{-10}\right] ;$

$F_{2}=\tanh \left(\Phi_{2}^{2}\right)$;

$\Phi_{2}=\max \left[2 \frac{\sqrt{k}}{0,09 \omega y}, \frac{500 \mu}{\rho y^{2} \omega}\right]$; 
Onde y é a distância até a superfície mais próxima, $D_{\omega}^{+}$é a parte positiva do termo de difusão.

$\tilde{G}_{k}=\min \left(G_{k}, 10 \rho \beta^{*} k \omega\right) ; G_{k}=-\rho \overline{u_{i}^{\prime} u_{j}^{\prime}} \frac{\partial u_{j}}{\partial x_{i}} ; G_{\omega}=\frac{\alpha}{v_{t}} \tilde{G_{k}} ;$

$G_{k}$ tem sua consistência avaliada pela hipótese de Boussinesq: $G_{k}=\mu_{t} S^{2}$

Admitindo $\mathrm{S}$ como o valor médio do tensor que mede a variação de tensão: $S=\sqrt{2 S_{i j} S_{i j}}$;

$$
\begin{aligned}
& \alpha=\frac{\alpha_{\infty}}{\alpha}\left(\frac{\alpha_{0}+\operatorname{Re}_{t} / R_{\omega}}{1+\operatorname{Re}_{t} / R_{\omega}}\right) ; \alpha_{\infty}=F_{1} \alpha_{\infty, 1}+\left(1-F_{1}\right) \alpha_{\infty, 2} ; \\
& \alpha_{\infty, 1}=\frac{\beta_{i, 1}}{\beta_{\infty}^{*}}-\frac{k^{2}}{\sigma_{\omega, 1} \sqrt{\beta_{\infty}^{*}}} ; \alpha_{\infty, 2}=\frac{\beta_{i, 2}}{\beta_{\infty}^{*}}-\frac{k^{2}}{\sigma_{\omega, 2} \sqrt{\beta_{\infty}^{*}}} ; k=0.41 ;
\end{aligned}
$$

Dissipação de k e $\omega$ :

$$
Y_{k}=\rho \beta^{*} k \omega ; Y_{\omega}=\rho \beta \omega^{2} ; \beta_{i}=F_{1} \beta_{i, 1}+\left(1-F_{1}\right) \beta_{i, 2} ;
$$

Difusão:

$$
D_{\omega}=2\left(1-F_{1}\right) \rho \sigma_{\omega, 2} \frac{1}{\omega} \frac{\partial k}{\partial x_{j}} \frac{\partial \omega}{\partial x_{j}}
$$

Constantes do Modelo:

$\sigma_{k, 1}=1.176 ; \sigma_{\omega, 1}=2.0 ; \sigma_{k, 2}=1.0 ;$

$$
\sigma_{\omega, 2}=1.168
$$

$a_{1}=0.31 ; \beta_{i, 1}=0.075 ; \beta_{i, 2}=0.0828$

Para regiões próximas a parede, vale a função de parede:

$\omega_{\omega}=\frac{\rho\left(u^{*}\right)^{2}}{\mu} \omega^{+}$

$\mathrm{O}$ valor de $\omega^{+}$dentro da subcamada laminar, dentro da camada limite, é dado por:

$\omega^{+}=\min \left(\omega_{\omega}^{+}, \frac{6}{\beta_{i}\left(y^{+}\right)^{2}}\right)$;

Onde: $\omega_{\omega}^{+}=\left\{\begin{array}{l}\left(\frac{50}{k_{S}^{+}}\right)^{2}, k_{S}^{+}\langle 25 \\ \frac{100}{k_{S}^{+}}, k_{S}^{+} \geq 25\end{array}\right.$

$k_{S}^{+}=\max \left(1, \frac{\rho k_{s} u^{*}}{\mu}\right) ; \mathrm{k}_{\mathrm{s}}$ é a altura da rugosidade.

Na região turbulenta, ainda dentro da camada limite:

$$
\begin{aligned}
& \omega^{+}=\frac{1}{\sqrt{\beta_{\infty}^{*}}} \frac{d u_{\text {turb }}^{+}}{d y^{+}} ; \\
& \omega^{+}=\frac{u^{*}}{\sqrt{\beta_{\infty}^{*} k y}} ;
\end{aligned}
$$


Estas variáveis são importantes para caracterização dos dimensionais (comprimento, volume) das células que compõe a malha nas camadas limites ou em regiões estreitas onde ocorre o escoamento. São valores que auxiliam no refino da malha, ou seja, promove uma melhor discretização do problema. 


\section{APÊNDICE B -}

\section{Características da malha construída para a geometria padrão (sem convergência e divergência)}

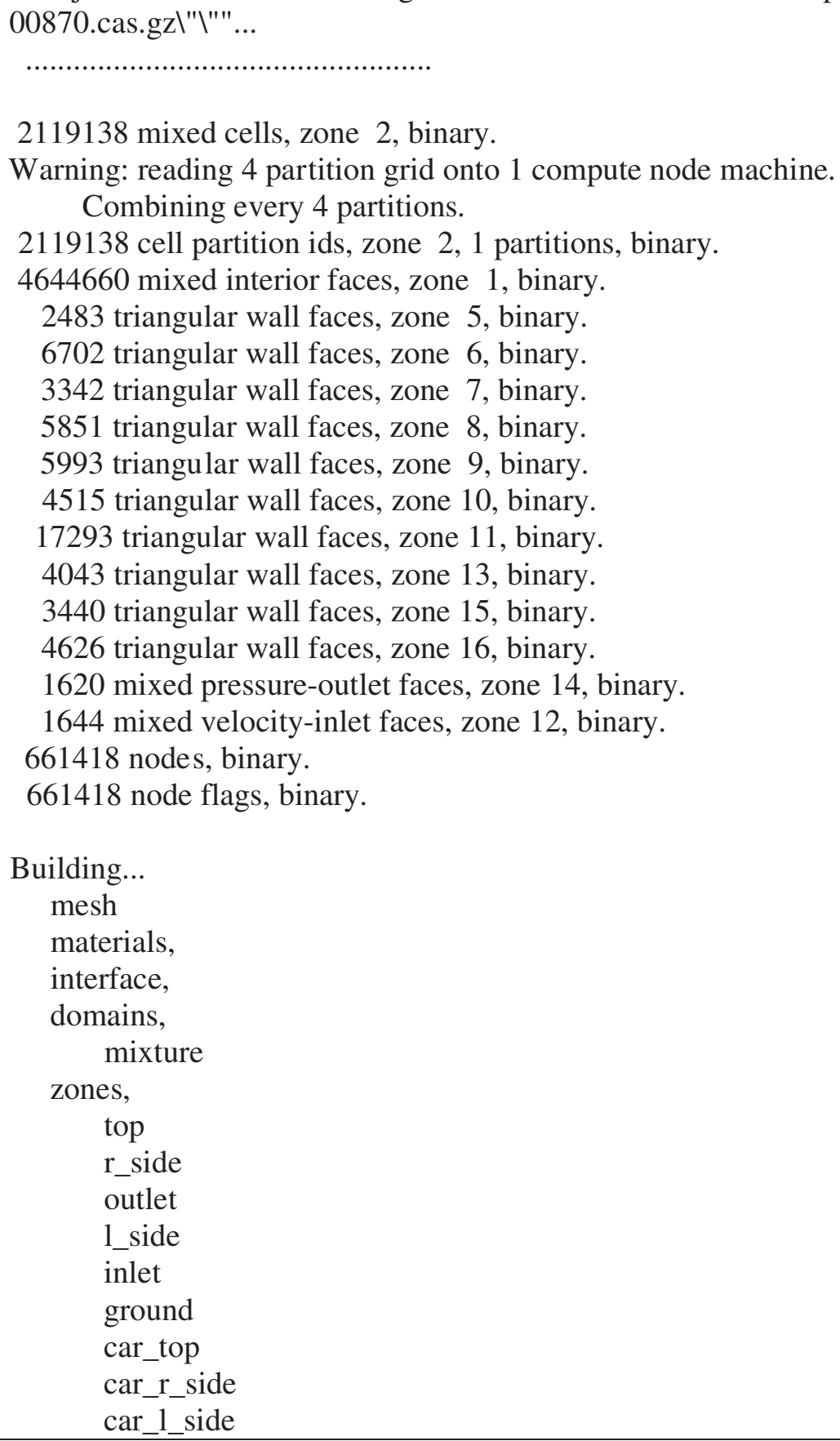

2119138 mixed cells, zone 2, binary.

Warning: reading 4 partition grid onto 1 compute node machine.

Combining every 4 partitions.

2119138 cell partition ids, zone 2, 1 partitions, binary.

4644660 mixed interior faces, zone 1 , binary.

2483 triangular wall faces, zone 5, binary.

6702 triangular wall faces, zone 6 , binary.

3342 triangular wall faces, zone 7, binary.

5851 triangular wall faces, zone 8, binary.

5993 triangular wall faces, zone 9, binary.

4515 triangular wall faces, zone 10, binary.

17293 triangular wall faces, zone 11, binary.

4043 triangular wall faces, zone 13, binary.

3440 triangular wall faces, zone 15 , binary.

4626 triangular wall faces, zone 16, binary.

1620 mixed pressure-outlet faces, zone 14, binary.

1644 mixed velocity-inlet faces, zone 12, binary.

661418 nodes, binary.

661418 node flags, binary.

Building...

mesh

materials,

interface,

domains,

mixture

zones,

top

r_side

outlet

1_side

inlet

ground

car_top

car_r_side

car_l_side 


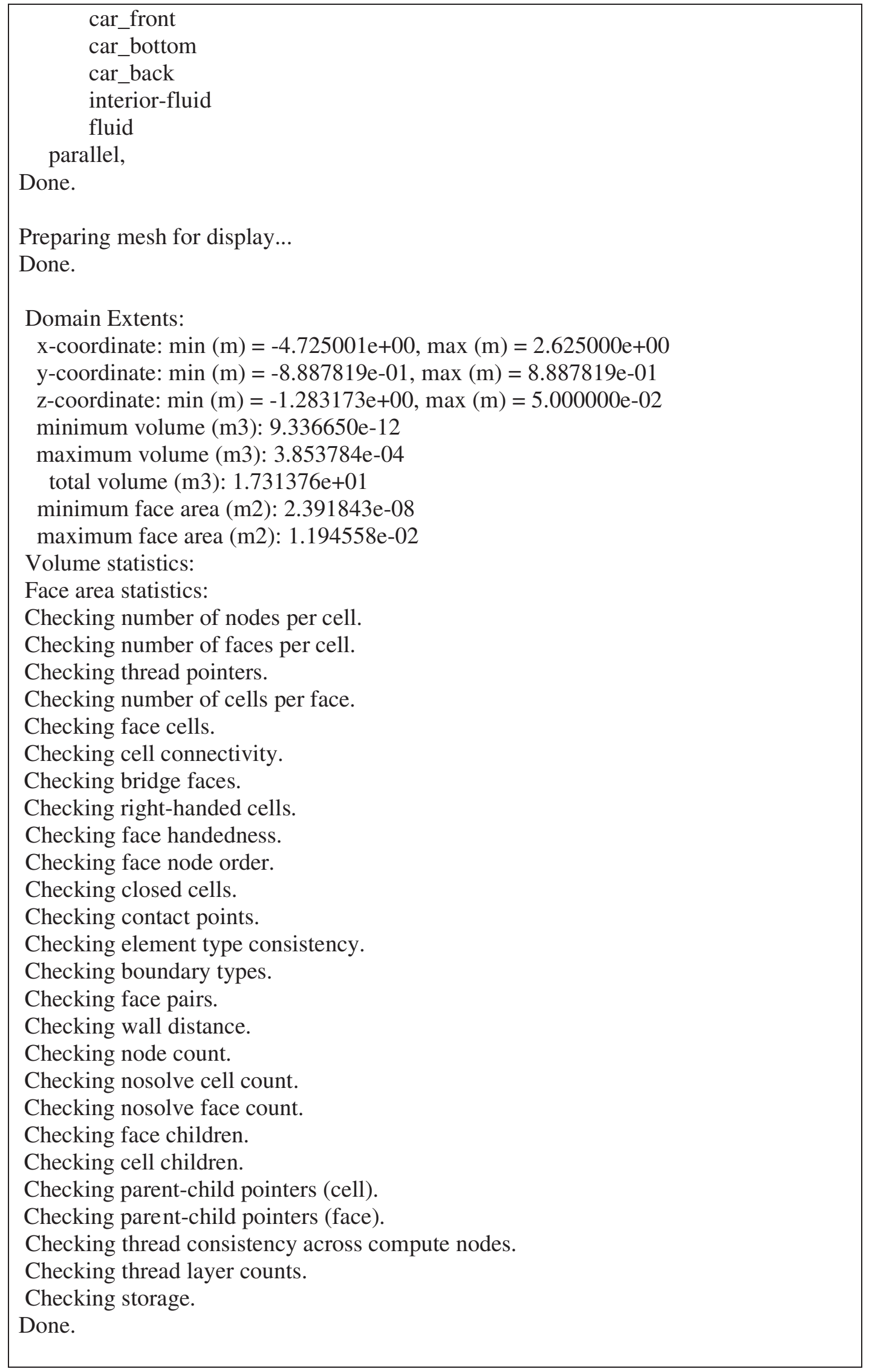


Mesh Quality:

Applying quality criteria for tetrahedra/mixed cells.

Maximum cell squish $=7.65643 \mathrm{e}-01$

Maximum cell skewness $=7.99881 \mathrm{e}-01$

Maximum aspect ratio $=1.86181 \mathrm{e}+02$

Mesh Size

Level Cells Faces Nodes Partitions

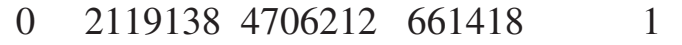

Interrupting...

Done. 